Review

\title{
Review of Supported Pd-Based Membranes Preparation by Electroless Plating for Ultra-Pure Hydrogen Production
}

\author{
David Alique, David Martinez-Diaz, Raul Sanz and Jose A. Calles * (1) \\ Department of Chemical and Energy Technology, Rey Juan Carlos University, C/Tulipán s/n, Móstoles, \\ 28933 Madrid, Spain; david.alique@urjc.es (D.A.); david.martinez.diaz@urjc.es (D.M.-D.); \\ raul.sanz@urjc.es (R.S.) \\ * Correspondence: joseantonio.calles@urjc.es; Tel.: +34-91-488-7378; Fax: +34-91-488-7068
}

Received: 11 December 2017; Accepted: 15 January 2018; Published: 23 January 2018

\begin{abstract}
In the last years, hydrogen has been considered as a promising energy vector for the oncoming modification of the current energy sector, mainly based on fossil fuels. Hydrogen can be produced from water with no significant pollutant emissions but in the nearest future its production from different hydrocarbon raw materials by thermochemical processes seems to be more feasible. In any case, a mixture of gaseous compounds containing hydrogen is produced, so a further purification step is needed to purify the hydrogen up to required levels accordingly to the final application, i.e., PEM fuel cells. In this mean, membrane technology is one of the available separation options, providing an efficient solution at reasonable cost. Particularly, dense palladium-based membranes have been proposed as an ideal chance in hydrogen purification due to the nearly complete hydrogen selectivity (ideally 100\%), high thermal stability and mechanical resistance. Moreover, these membranes can be used in a membrane reactor, offering the possibility to combine both the chemical reaction for hydrogen production and the purification step in a unique device. There are many papers in the literature regarding the preparation of Pd-based membranes, trying to improve the properties of these materials in terms of permeability, thermal and mechanical resistance, poisoning and cost-efficiency. In this review, the most relevant advances in the preparation of supported Pd-based membranes for hydrogen production in recent years are presented. The work is mainly focused in the incorporation of the hydrogen selective layer (palladium or palladium-based alloy) by the electroless plating, since it is one of the most promising alternatives for a real industrial application of these membranes. The information is organized in different sections including: (i) a general introduction; (ii) raw commercial and modified membrane supports; (iii) metal deposition insights by electroless-plating; (iv) trends in preparation of Pd-based alloys, and, finally; (v) some essential concluding remarks in addition to futures perspectives.
\end{abstract}

Keywords: review; palladium; membrane; Pd alloy; electroless plating; membrane reactor; hydrogen separation; hydrogen production

\section{Introduction}

The continuous population growth and economy intensification imply an increase of global energy demand. Up to date, this increasing demand has been usually covered by massive use of fossil fuels, causing global warming due to the large emission of anthropogenic greenhouse gases, as well as other combustion pollutants [1]. This situation is even more problematic because the fossil resources worldwide depletion and thus, it represents a clearly unsustainable scenario for the future. In the last years, it has been suggested a wide set of alternatives for the progressive replacement of fossil fuels as 
primary energy resource [2,3]. In this situation, the implementation of the so-called hydrogen-based economy is considered as a real choice and it is receiving great attention in the last years [4-8].

Hydrogen is advised as a very promising energy carrier due to its long-term viability, high energy density $\left(14 \mathrm{~J} \cdot \mathrm{kg}^{-1} \cdot{ }^{\circ} \mathrm{C}^{-1}\right)$, environmentally welcoming combustion emissions and high resources to be produced from. Indeed, hydrogen is the most abundant element in the Earth, although it is usually found combined with other elements, mainly in water and hydrocarbon molecules. The idea is to transfer the energy obtained for different primary energy sources, preferentially renewables (i.e., wind, solar or biomass, among others), to hydrogen, which can be stored, transported and eventually used in different energy applications. Ideally, hydrogen will be obtained from water by using these renewable energies, thus minimizing the environmental impact while the energy demand is covered $[9,10]$. However, the hydrogen generation by thermochemical processes seems to be a more realistic option in the near future for cost-cutting [11-14]. Hence, hydrogen can be generated from a wide variety of raw materials containing hydrocarbons for both centralized and distributed production systems by using relatively mature technologies [14], being the use of biomass and waste materials especially attractive [15-19]. In these cases, a mixture of gaseous compounds is frequently produced, being necessary to purify the hydrogen up to required levels accordingly to the final application, i.e., PEM fuel cells, turbines or combustion engines [20]. Indeed, the hydrogen purification step is a crucial process in the successful implementation of the hydrogen energy system from both technical and economical point of view.

Among readily available alternatives for hydrogen purification, the use of membranes for hydrogen separation/production applications has been proposed and used in practice. This technology shows relevant advantages such as low energy consumption, environmentally good properties and also additional potential to be combined with a reaction unit in a multifunctional membrane reactor [21,22]. The combination of simultaneous chemical reaction and hydrogen separation in one unique step results in additional benefits in terms of conversion increase by shifting the reaction equilibrium as one of the products, hydrogen, is selectively separated from the reaction media [23,24]. Particularly, dense metallic based membranes have been proposed for years due to their potential to transport hydrogen in a dissociative form with a theoretically complete perm-selectivity $[25,26]$. Thus, the structure of metals belonged groups III-V, such as $\mathrm{Pd}, \mathrm{Ni}$ and $\mathrm{Pt}$ (in pure form and alloyed), has the ability to allow the hydrogen diffusion through the metal lattice, while avoiding the permeation of other molecules [27,28]. In this way, the solution-diffusion mechanism, depicted in Figure 1, is used to describe the hydrogen permeation process in these $\mathrm{H}_{2}$-selective membranes.

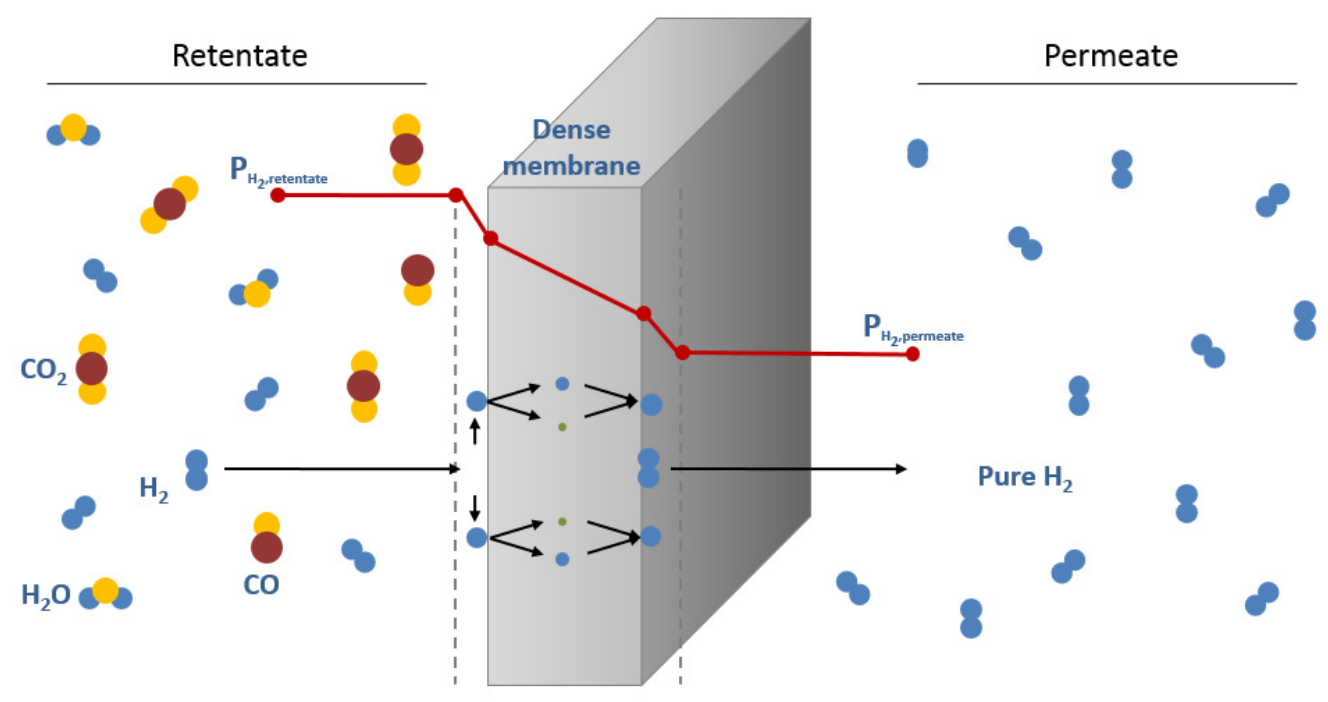

Figure 1. Solution-diffusion mechanism for hydrogen permeation through the metal lattice of a dense membrane. 
Up to date, palladium is the most studied metal for preparing these $\mathrm{H}_{2}$-selective membranes. The earliest studies date from the XIX century, when Deville and Troost discovered the capability of hydrogen to penetrate into bulk palladium [29,30] and Graham determined that this metal was able to absorb hundred times its own volume in hydrogen [31]. However, the use of palladium membranes for hydrogen separation/production applications does not appear until the fifties years. From this decade, as the related research publications evidence, these membranes have been gaining increasing interest. This trend can be observed in Figure 2, where it is shown the number of scientific documents published by year and region considering hydrogen, palladium and membrane or membrane reactor as keywords. It has to be pointed out the increase of related publications during the most recent years, mainly due to a greater awareness on environmental protection and renewable energies development, where hydrogen emerges as a very promising clean energy vector that, as mentioned before, requires to be purified $[20,25]$.

a) 175

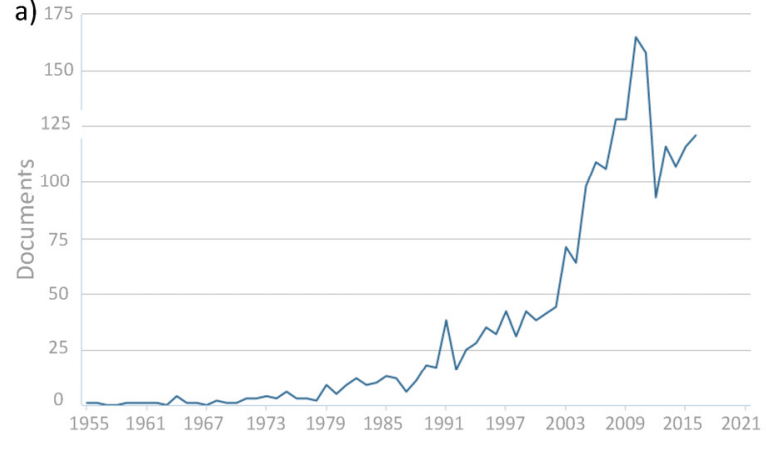

c) 7

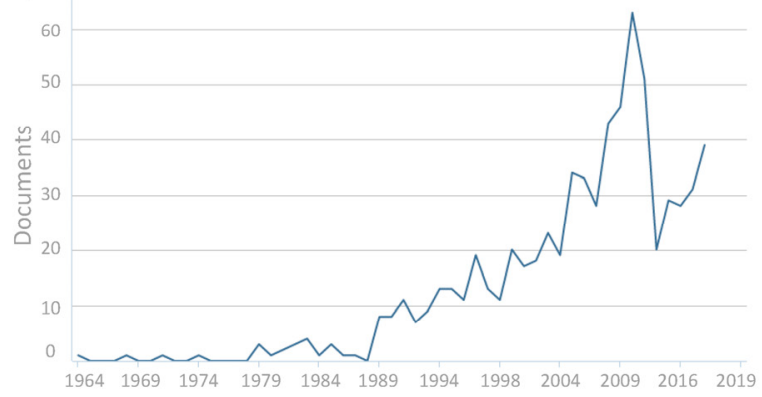

b)

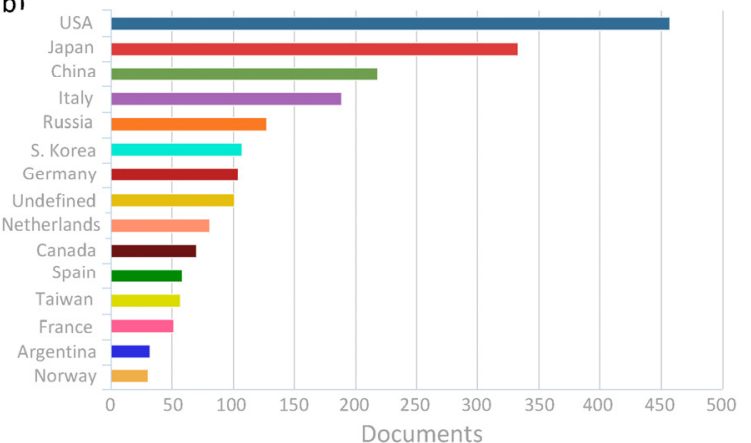

d)

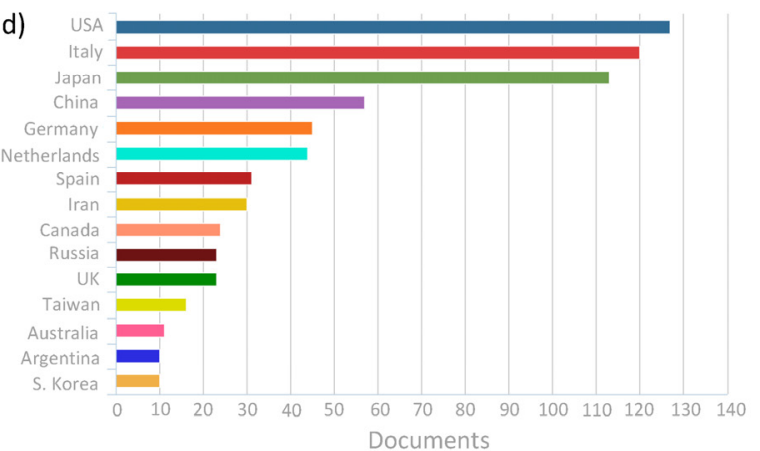

Figure 2. Citation analysis report by Scopus for keywords: palladium + membrane + hydrogen $(\mathbf{a}, \mathbf{b})$ and palladium + membrane reactor + hydrogen $(\mathbf{c}, \mathbf{d})$.

Analysing the number of publications by region, it is evident that this topic is investigated widely around the word, topping the list the United States of America with very ambitious policies but closely followed by different countries of Asia (Japan and China) and Europe (mainly Italy, Germany and The Netherlands).

Currently, main efforts are focused to reduce the cost of these membranes and to increase its mechanical resistance, lifespan and fabrication reproducibility [32,33]. Palladium is expensive and scarce and the growing demand for its use in large-scale applications is expected to keep driving up its price [34]. Two of the most studied strategies to reduce the cost of the membranes are: (a) minimizing the amount of palladium required to achieve a fully dense layer [35-38] and (b) increasing the use life-span since these membranes can suffer deactivation by poisoning and cracking by thermal or mechanical stress [39-43]. Taking into account the typical equation used to describe the hydrogen permeation flux $\left(J_{\mathrm{H}_{2}}\right)$ through a Pd-based membrane (Richardson equation, Equation (1)) as function 
of hydrogen permeability $(k)$, metal thickness $(t)$ and pressure driving force $\left(P_{H_{2}, \text { ret }}^{n}-P_{H_{2}, \text { per }}^{n}\right)$, it is obvious that a decrease in the metal thickness provokes an increase of the permeation capability $[28,44]$.

$$
J_{H_{2}}=\frac{k}{t}\left(P_{H_{2}, r e t}^{n}-P_{H_{2}, p e r}^{n}\right)
$$

In case of the Pd-based membrane is totally free of defects, the hydrogen permeation is determined by the solution-diffusion in the bulk metal and the exponential factor takes the value $n=0.5$, denoting the equation as Sieverts' law.

However, the preparation of ultrathin palladium layers entails two main problems: (i) limitation of membrane mechanical resistance and (ii) difficulty to obtain films free of defects. The use of porous supports tries to overcome these problems and thus, to maintain adequate mechanical properties saving palladium [45-49].

On the other hand, many authors focus their efforts in developing new fabrication processes for ensuring a better reproducibility and reducing the number of rejected membranes [49-51] or modifying the selective layer (Pd-based alloys) in order to improve some particular properties, such as resistance to hydrogen embrittlement or deactivation by sulphur compounds [52-56].

Several technologies can be used to incorporate a thin film of the hydrogen selective metal, preferentially Pd or Pd-based alloy, onto a porous support. Cold-rolling [57-59], physical vapour deposition [60-63], chemical vapour deposition [64-66], electrochemical plating [67-69] and electroless plating can be mentioned [33,62,70,71]. The last option (electroless plating, or its acronym ELP) provides important advantages in terms of adherence and uniformity of deposits on both conducting and non-conducting surfaces with complex geometries. Additionally, it has manufacturing low cost, becoming very popular for most of the studies carried out in the literature [72-75].

Considering all these facts, this review expects to provide a general overview of the most recent and relevant advances for preparation of dense Pd-based membranes for hydrogen production in membrane reactors, particularly focused on supported membranes obtained by electroless plating technology onto inorganic porous supports. The manuscript is divided into different sections focused on: (i) materials, pre-treatments and surface modifications of raw membrane supports, (ii) palladium deposition by electroless plating and (iii) development of new metal Pd-based alloys. Finally, some essential concluding remarks and brief comments about trendy futures perspectives have been also included.

\section{Membrane Supports}

Dense Pd-based membranes can be classified in two main groups, unsupported and supported ones, in which a thin selective film is deposited onto a porous substrate. The first type is usually prepared from relatively thick palladium (or Pd-based alloys) foils that, as Tosti et al. indicate in case of requiring tubular geometry, are cold-rolled and welded $[17,76]$. Typical thicknesses are ranged from 50 to $150 \mu \mathrm{m}$. However, as previously mentioned, a thick Pd layer strongly hinders both hydrogen permeate rate and membrane cost. Thus, development of new ultrathin membranes without jeopardizing mechanical resistance and presence of defects is the main objective of many researchers in this field $[59,60,77]$. This goal is usually achieved by incorporating a thin Pd layer on the surface of a porous material that provides the required mechanical resistance to the supported membrane [71,78-80]. This complex task is subject of numerous studies since many factors must be considered, i.e., the compatibility between support and selective layer, which strongly determines the mechanical resistance of the membrane due to cracks can be formed at high temperatures because of different expansion coefficients, as it will be discussed in detail later.

Numerous porous materials, such as Vycor glass [81,82], sintered metals [71,78,83], a wide variety of ceramics [53,71,84,85] and even polymers [86-88], can be used as supporting materials for the $\mathrm{H}_{2}$-selective layer. The most relevant attributes of supports to be selected include porosity properties (mainly average porosity and pore sizes distribution), surface roughness and mechanical, chemical 
and thermal stabilities [89]. In this context, it is expected great porosity with a narrow distribution of small pore sizes, high mechanical strength and chemical resistance and similar thermal expansion coefficient to that of $\mathrm{Pd}$ [90]. In regards of textural properties, the support porosity needs to be open and interconnected enough to ensure a non-limiting gas transport through the support, besides the critical sizes of pore-mouth and of pore-throat [91]. It is accepted that usually both pore size and roughness strongly determine morphology and continuity of the selective layer. In this mean, Mardilovich et al. [92] indicated that the minimum thickness necessary to prepare an electroless plated Pd film onto a porous support is around three times the average size of the greatest pores. Despite Vycor glass was one of the first porous supports used to incorporate Pd by electroless plating [81,82], currently is more frequent the use of sintered porous metals $[71,78,93,94]$ or ceramic materials $[53,71,84,95]$, making a clean sweep on the majority of scientific publications in this field.

The use of porous polymers as substrates for membranes reactors, which usually operates a high temperature, is currently scarce due to the low thermal resistance of these materials [96]. For this particular application, the metallic supports are the preferred ones, such as stainless-steel 316L [71,83], Hastelloy [97,98], Inconel [94], nickel [99] or, in some particular cases, Ti-based alloys such as Ti-Al [100] or Ni-Ti [101]. They usually ensure good mechanical properties, hardness and adequate thermal expansion coefficient, similar to that of palladium, in the range of $10.5-12.5 \times 10^{-6}{ }^{\circ} \mathrm{C}^{-1}$. Moreover, these materials are easily sealed and coupled to membrane reactor modules, conventionally made of stainless-steel [96]. However, these supports present relatively large pores with a wide pore sizes distribution that makes the generation of a thin and free-defect Pd layer difficult. In fact, it is usual that manufactures do not provide the concrete value of pore sizes in these supports, giving an average related value, known as media grade, that represents the particle size that is rejected in a $95 \%$ for a filtration process with this support [62]. Moreover, it is also possible that metal inter-diffusion between support and Pd-based selective layer takes place after operating the membrane at high temperatures for long times. This phenomenon causes a marked decrease in the permeation capacity [89]. To overcome both drawbacks, the original support has to be modified prior to the incorporation of the $\mathrm{H}_{2}$ selective layer, as we detail in following sections [89,93,99].

On the other hand, ceramic supports provide a smoother surface with accurate control on porosity and narrow pore sizes distributions up to a few nanometres [38]. These properties facilitate the deposition of defect-free palladium layers with really low thickness and many researchers choose to use them as support for membranes [41,53,84]. Among some possibilities, the use of alumina, $\mathrm{Al}_{2} \mathrm{O}_{3}$ [102,103], is predominant, usually combining both $\alpha-\mathrm{Al}_{2} \mathrm{O}_{3}$ and $\gamma-\mathrm{Al}_{2} \mathrm{O}_{3}$ particles in order to prepare asymmetric supports with big pores in the core to ensure greater permeabilities and smaller ones on the top layer to facilitate the palladium incorporation [71]. However, this material presents a thermal expansion coefficient noticeable different to that of palladium, besides a weak mechanical resistance, jeopardizing the integrity of the supported membrane, which is quite important on membrane reactors [91]. Other alternative less frequent is the use of yttria-stabilized zirconia $\left(\mathrm{ZrO}_{2}-\mathrm{YSZ}\right)$, with closer thermal expansion coefficient to that of palladium $\left(10.0 \times 10^{-6}{ }^{\circ} \mathrm{C}^{-1}\right)$, to prepare ceramic supports $[85,96]$. Anyway, different metallic or ceramic supports can be used to prepare totally dense supported Pd-based membranes, although a prevalent solution is still not reached. The advantages provided for ceramic ones are problems when using metal supports and vice versa, so different trends can be observed in literature. Some authors lean towards ceramic supports, mainly formed by alumina, in order to ensure the incorporation of an ultrathin Pd-based layer without defects, focusing on the membrane preparation, while other ones prefer to use the metallic supports thinking on real application of membranes in stainless-steel industrial devices.

Independently of constituent material of supports, the geometry is also important and quite a few configurations can be found in the literature, distinguishing mainly planar [100,101], tubular [71,78] and hollow fibre geometries [104,105]. In general, tubular geometries of both ceramics and metallic materials are prevalent in case of considering the use in a membrane reactor, while porous metals with planar geometry are most frequent in case of studying the membrane preparation with only 
purification purposes [106-108]. However, this situation has changed in the last years with the appearing of plate-type geometries and hollow fibres in design of trending reactor systems with micro-channels [109].

Table 1 summarizes the most frequent inorganic supports present in the literature for Pd-based membrane preparation, indicating important parameters such as material, geometry, average porosity and illustrative pore sizes. Several relevant manufacturers around the world have been considered, such as Mott Metallurgical Corp. (USA), Pall Corp. (USA), GKN Sinter Metal (UK), Inopor GmbH (Germany), TAMI industries (France) or NGK Insulators Ltd. (Japan). Currently, lower prices can be achieved for ceramic supports, despite they present smaller pore sizes than metallic ones, although their reutilization is not easy due to the frequent breaking during operation.

Table 1. Usual inorganic commercial supports for Pd-based membrane preparation.

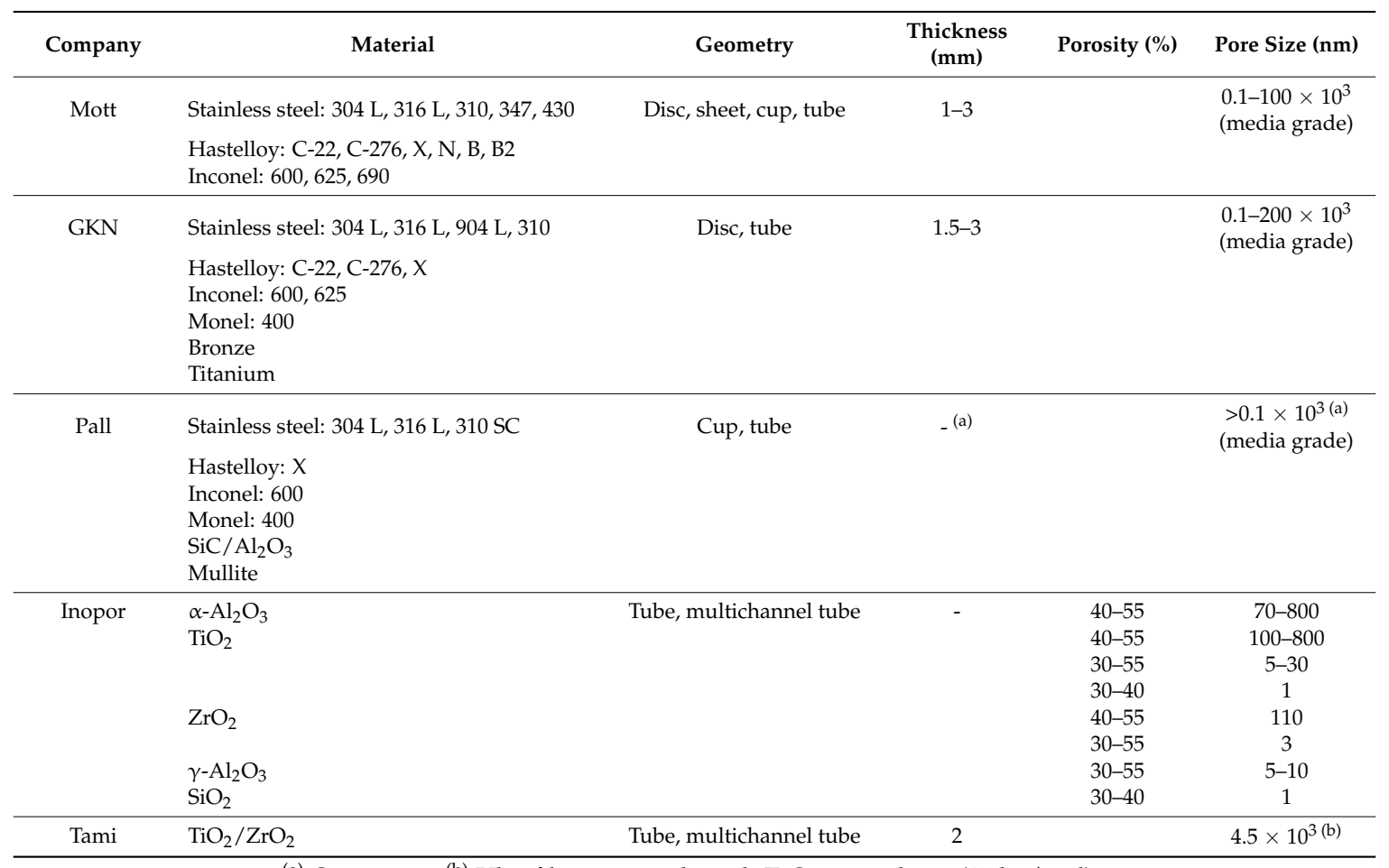

(a) On request, (b) Ultrafiltration grade with $\mathrm{ZrO}_{2}$ active layer $(15 \mathrm{~kg} / \mathrm{mol})$.

As previously mentioned, it is not common the direct use of commercial supports to prepare supported membranes, especially in case of metallic substrates. On the opposite, it is usual to carry out some pre-treatments and surface modifications of the support to improve the final quality of the membrane. In addition to conventional initial cleaning procedures, most of these modifications are focused on the improvement of layers adherence and/or the reduction of average pore sizes and roughness in the support surface to achieve thinner hydrogen selective layers. These treatments can be classified in three general categories: (i) chemical treatment, (ii) physical treatment and (iii) incorporation of an intermediate layer. Considering the great importance of these steps on the final properties of the membrane and its costs, some of the most relevant advances and extended practices are summarized in the next paragraphs. We have focused on metallic supports since, as mentioned above, they are the most suitable to use in membrane reactors to hydrogen production, which is the aim of the review. Moreover, it should be noted that the external surface of ceramic supports is not usually modified prior to deposit the selective layer due to the good original properties in terms of average pore diameter and surface roughness. 


\subsection{Chemical Treatment}

The use of chemicals to modify the surface of supports is known as etching. It is commonly applied for polymers but it can also be used to modify some original properties of inorganic materials. These treatments consist of dipping the support in a corrosive solution, traditionally a strong acid and maintaining it at controlled temperature for a short period of time. The main effect of these treatments is to dissolve oxides thin films formed on the top of the supports, being also possible to remove part of the support bulk material. This action is primary determined by support composition, acid concentration, temperature and time of the treatment. Mardilovich et al. [110] used a solution of hydrochloric acid to treat a commercial stainless-steel support, achieving a noticeably increase of roughness on the surface of stainless-steel particles that form the support after only $5 \mathrm{~min}$. of immersion. Moreover, the new treated surface evidenced better properties for the subsequent palladium incorporation as a pre-activated surface, increasing the plating rate and improving the adherence. A similar treatment was reported by Li et al. [111] but mixing the hydrochloric acid with some amount of nitric acid and Kim et al. [101] for preparing a supported Pd membrane over a porous nickel support. In this way, the etching pre-treatment of an inorganic support can provide benefits for the pre-activation of support surface and adherence of the selective layer at a relatively low cost, independently of using any other additional treatment such as mechanical modification or the incorporation of an additional layer.

\subsection{Mechanical Treatment}

A different alternative to modify original supports, mainly the metallic ones, can be carried out by the polishing of the external surface. The plasticity of the metal particles that form the support is used to reduce both external pore size and roughness through a mechanical treatment with an abrasive material. One of the first references about the use of this alternative to prepare Pd supported membranes, published by Jayaraman et al. in the nineties, utilized commercial sandpapers with different grit numbers to smooth the original surface of the support [112]. Particularly, they used commercial sandpapers with grades \#320, \#500 and \#800. Later, Mardilovich et al. [110] used a similar polishing process with commercial sandpapers to modify the surface of porous stainless-steel supports. They indicated that it was possible to reduce both external average pore size and roughness, although most porosity was lost, decreasing the permeation capacity of the modified support up to $20 \%$ of the untreated one. Most recently, a similar technique based on the use of an abrasive sandpaper has been reported in the literature, as evidence the works published by Li et al. [111], Ryi et al. [113] or Pinacci et al. [114]. This polishing technique has not been only proposed for modifying the surface properties of supports, being also possible the reparation of defects in palladium thin films of supported membranes by mechanical treatments [115]. Despite this type of mechanical treatment is the predominant one, it is also possible to find some work in which high velocity shot peening with ion particles is used to achieve the plastic deformation of the metal particles of the support. However, the high cost of this alternative makes the traditional abrasive ones prevalent [116].

However, some researchers have critical opinions about these mechanical treatments due to the reduction of the permeation capability and adhesion properties of the thin selective layer, which in turn constrain the performance of the supported membrane. In this context, it is accepted that the adhesion between a support and a thin selective layer depends on the mechanical binding and anchoring effects. Consequently, it is necessary a minimal support roughness for ensuring a good adhesion of the top coatings [117,118]. This is clearly indicated in works published by Collins [119] and Huang [120], where larger pores and a certain external roughness in supports improve the adhesion of the thin coating layer. In this manner, it can be stated that it is necessary to achieve a compromise solution between the original surface modification and maintaining certain anchoring points to guarantee a suitable adherence of the Pd selective layer. 


\subsection{Incorporation of Intermediate Layers}

In spite of using chemical and/or mechanical treatments, the incorporation of an intermediate layer between the commercial support and the top selective layer is the most preferred alternative to improve the external surface of the support. This option can be used simultaneously for different objectives such as modification of the original morphology, metal inter-diffusion mitigation, adhesion improvement of the Pd selective layer, corrosion prevention of support or even incorporation of first metal nuclei as pre-activated surface. The last one is usually the main reason to incorporate intermediate layers on ceramic supports due to these materials usually present a very smooth surface with very narrow pore sizes distribution, up to $3 \mathrm{~nm}[71,121]$ without need of additional modifications. However, metallic supports display a typical rough surface and wide pore sizes [62,71], being the incorporation of an intermediate layer a critical issue to achieve a really thin palladium layer. Considering the final target of the intermediate layer, its composition and thickness need to be adjusted at a reasonable cost and, up to now, a unique solution is not reached.

Anyway, one of the most important factor to be considered is the compatibility between the different components of the supported membrane. Figure 3 shows the thermal expansion coefficient for some of the materials most frequently used as intermediate layer, besides common metal support raw materials (316L stainless-steel or Hastelloy X) and selective layer constituents (mainly palladium, silver, copper and gold).

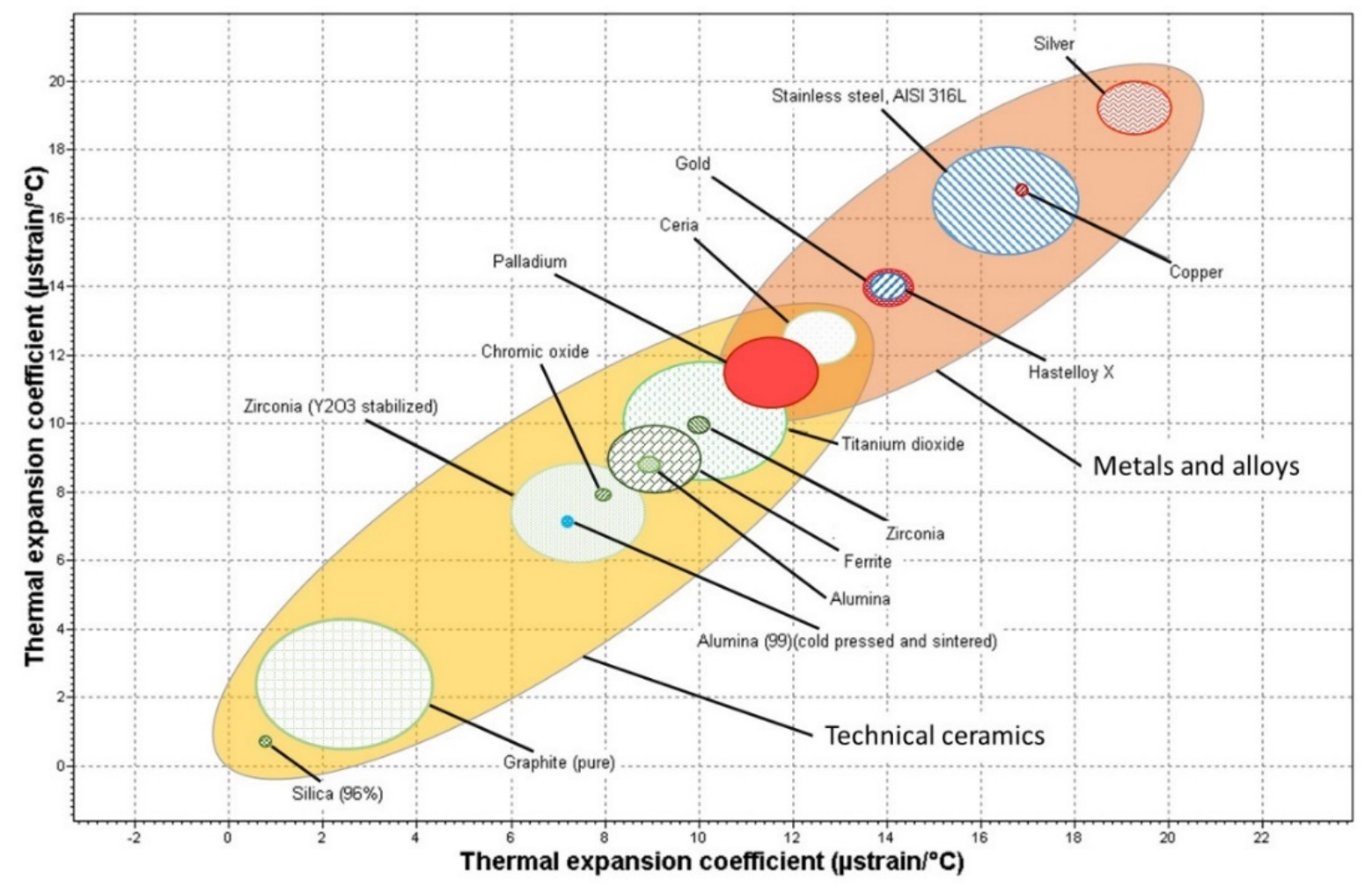

Figure 3. Thermal expansion coefficients for typical constituents of supported membranes for hydrogen separation.

At large, small differences between the thermal expansion coefficients of the supported membrane elements are recommended to ensure enough mechanical resistance at operating conditions, usually at moderate or high temperatures. According to the data shown in Figure 3, cerium oxide appears as a very attractive alternative, with a thermal expansion coefficient between of palladium and common metallic supports (i.e., AISI 316L stainless-steel or Hastelloy X). This material was employed by Tong et al. [122] to modify a macro porous stainless-steel tubular support to prepare a supported Pd 
membrane with a selective layer of around $13 \mu \mathrm{m}$ thickness. They evidenced a really good stability of the supported system after long-term experiments, obtaining almost equal hydrogen permeability to the theoretical value for a pure Pd membrane. A similar intermediate layer of $\mathrm{CeO}_{2}$ was prepared by Qiao et al. [123] to prevent intermetallic diffusion between a PSS support and a PdCu alloy selective layer. This intermediate layer was prepared through a sol-gel method and the modification of the original support also improved the adherence between the metallic support and the selective layer.

In addition to $\mathrm{CeO}_{2}$, many other materials have been also successfully incorporated as an effective intermediate layer, even though they present different thermal expansion coefficient to that of the selective layer or the support. A first relevant group is formed by zirconium oxide and related materials. Some authors, such as Wang et al. [124] or Gao et al. [125], modify commercial PSS supports by the incorporation of $\mathrm{ZrO}_{2}$ particles to reduce the thickness of the hydrogen selective layer up to around $10 \mu \mathrm{m}$. A similar thickness was achieved by Tarditi et al. [93] by the incorporation of the $\mathrm{ZrO}_{2}$ particles through a vacuum-assisted method, while Lee at al. [126] reduced this thickness up to $3.5 \mu \mathrm{m}$ for a better permeability. Other researchers added small amounts of yttria to the based-zirconia material in order to increase the structure stability of the material, obtaining an yttria-stabilized zirconia (YSZ) [50,117]. References in literature present the use of YSZ as an effective intermediate layer with the double aim of reducing the palladium thickness and preventing the intermetallic diffusion between support and selective layer, indicating sol-gel methods or atmospheric plasma spraying as successful techniques for the material incorporation [70,78,127].

Considering the relatively good surface properties of alumina as support, the use of this material as intermediate layer to modify the metallic supports has been also proposed by different authors. In this way, Yepes et al. [128] and Li et al. [129] decreased the original pore size of the metallic support by incorporating an alumina top layer that prevents possible inter-diffusion processes between the original support and the selective layer. Broglia et al. [130] reported the incorporation process of $\gamma-\mathrm{Al}_{2} \mathrm{O}_{3}$ particles by dip-coating onto a PSS support to achieve a totally defect-free Pd layer of around $11 \mu \mathrm{m}$. Chi et al. [131] detailed the use of different graded alumina particles for a better modification of commercial PSS tubes. They used particles with a size close to $10 \mu \mathrm{m}$ to fill the widest pores and smaller particles (size around $1 \mu \mathrm{m}$ ) for a final smooth of the surface. Thus, they eventually achieved a thin free-defects Pd layer with less than $5 \mu \mathrm{m}$ in thick and good thermal stability. Lee et al. [126] compared the effect of using $\mathrm{Al}_{2} \mathrm{O}_{3}$ and $\mathrm{ZrO}_{2}$ technical ceramics with similar thickness as support modifiers and they indicated that both materials act effectively as diffusion barrier, although the use alumina yield a lower membrane permeability.

Other conventional material used as intermediate layer is the $\mathrm{SiO}_{2}$, being possible to accomplish different functions such as surface support modifier, intermetallic diffusion limiter, perm-selectivity booster or even catalyst for some chemical processes. For instance, Nam et al. [132] modify a commercial 316L stainless-steel substrate by the incorporation of amorphous silica. In this way, they reduced the selective layer, constituted by a $\mathrm{PdCu}$ alloy, up to $2 \mu \mathrm{m}$ but maintaining an excellent separation behaviour with hydrogen permeance of $8.37 \times 10^{-7} \mathrm{~mol} \cdot \mathrm{m}^{-2} \cdot \mathrm{s}^{-1} \cdot \mathrm{Pa}^{-1}$ and $\mathrm{H}_{2} / \mathrm{N}_{2}$ selectivity of around 70,000 at $450{ }^{\circ} \mathrm{C}$. Calles et al. [62] published the use of three different siliceous materials as intermediate layer for preparing supported Pd-PSS membranes: amorphous disordered silica, amorphous ordered silica (HMS) and crystalline silica (silicalite-1). In all cases, both roughness and pore size of the original supports were reduced and, consequently, the minimum Pd thickness required to obtain a defect-free selective membrane. The best results were obtained for the silicalite- 1 material, reducing the Pd thickness up to $5 \mu \mathrm{m}$ and yielding a hydrogen permeance of $1.423 \times 10^{-4} \mathrm{~mol} \cdot \mathrm{m}^{-2} \cdot \mathrm{s}^{-1} \cdot \mathrm{Pa}^{-0.5}$ with a complete hydrogen selectivity at $400^{\circ} \mathrm{C}$. Similar modifications of metallic supports with microporous silica layers can be found for increasing the $\mathrm{H}_{2}$ perm-selectivity of the composite without any other additional layer [133] or even combined with palladium in a mixed-matrix structures [134]. Recently, these materials have been also applied on the top of finished supported Pd membranes in order to repair small defects and pinholes, significantly increasing the $\mathrm{H}_{2}$ selectivity with a very low cost [135]. 
Materials that combine silica and alumina are the well-known zeolites, crystalline materials with controlled pore sizes distribution and additional catalytic properties. Among the wide variety of possible structures, the use of zeolites NaA [136], NaX [137], Z-21 [138], FAU-type [139] and TS-1 [140,141] as effective intermediate or protective layers in membrane preparation can be found in the literature. On the whole, the higher cost of these materials limits their use to very specific processes, mainly for membrane reactors in which undesirable products are presented and the zeolite plays the role of both support modifier and catalyst.

Other method quite simple to modify the support, with high reproducibility and reasonable cost, is the direct oxidation of 316L PSS supports in air atmosphere at high temperatures. This process yields a top coating of mixed $\mathrm{Fe}_{2} \mathrm{O}_{3}-\mathrm{Cr}_{2} \mathrm{O}_{3}$, which is able to prevent the inter-diffusion process [78]. Ma et al. [142] patented a controlled in-situ oxidation method to prepare Pd composite membranes over porous stainless-steel supports and thus, they achieve effective inter-diffusion barriers with thermal treatments upper than $600{ }^{\circ} \mathrm{C}$. Following this pioneering work, other researchers such as Guazzone et al. [143] or Mateos-Pedrero et al. [144] modified PSS supports by the incorporation of metal oxides derived from an oxidation process at temperatures higher than $400^{\circ} \mathrm{C}$. Mostly, only slight modifications on the support surface can be observed after the thermal treatments due to the very limited thickness of the new oxide layer and, consequently, the Pd thickness is not reduced as much as when other alternatives are used. In case of using really high temperatures for the treatment $\left(>700{ }^{\circ} \mathrm{C}\right)$, more oxides are generated, although in that cases the original porosity of the support drastically drops.

In the last years, some other materials have been investigated to develop more efficient intermediate layers and achieve better supported membranes. Some of these new materials are thin TiN thin layers obtained by sputtering [145], a combination of silver as diffusion barrier and aluminium hydroxide gel for filling in the biggest pores of the support [146], bi-metal multi-layers formed by staked layers of Pd and Ag [147], nickel [148] or even tungsten powders [47]. However, despite these promising results, a definitive solution has not yet been found.

One original alternative consists of using a temporary material to make the incorporation of the selective Pd layer easier. For instance, Tong et al. reported this methodology for the first time, employing an aluminium hydroxide gel or a polymer to modify the top surface of a PSS support. Then, they deposited the Pd layer over the modified surface and, finally, the temporary intermediate layer was removed in order to recover the original pores of the support $[149,150]$. Figure 4 collects the main steps carried out during this attractive method. Following this procedure, the authors prepare membranes with around $5 \mu \mathrm{m}$ of palladium thickness that exhibited a maximum hydrogen permeation flux of $0.82 \mathrm{~mol} \cdot \mathrm{m}^{-2} \cdot \mathrm{s}^{-1}$ with infinite hydrogen selectivity at $600{ }^{\circ} \mathrm{C}$ and $\Delta \mathrm{P} 200 \mathrm{kPa}$.

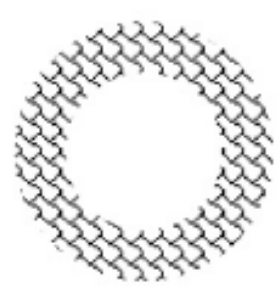

(a)

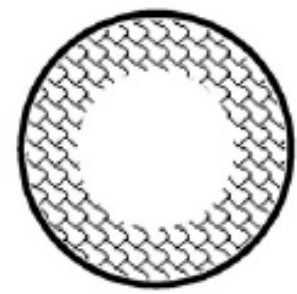

(b)

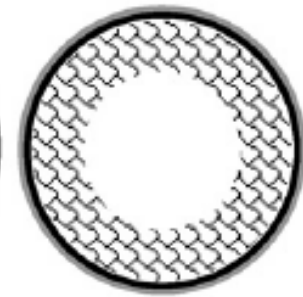

(c)

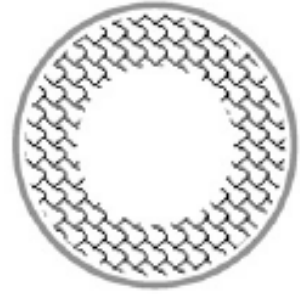

(d)

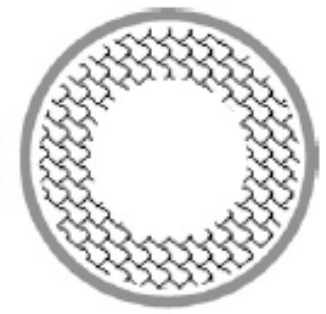

(e)

Figure 4. Use of a temporary intermediate layer for the preparation of a Pd-composite membrane: (a) original support; (b) polymer + support; (c) Pd layer + polymer + support; (d) Pd layer + small gap + support; and (e) defect-free Pd layer + small gap + support [150], with permission from (C) Elsevier.

Finally, despite the presence of an intermediate layer in ceramic substrates is less common, some examples can also be found in the literature. For instance, the work published by $\mathrm{Hu}$ et al. [151], in which a low-cost macroporous $\mathrm{Al}_{2} \mathrm{O}_{3}$ support is modified with graphite and clay from a conventional 
2B-pencil. With this method, they achieved a totally defect-free supported membrane with a palladium thickness of $5 \mu \mathrm{m}$. In spite of the incorporation of intermediate layers onto the ceramic supports prior to incorporate the final selective coating is scarce, is possible to found some works that use this alternative to improve the surface activation, as published by Zhao et al. [152]. They used a Pd(II)-modified boehmite sol for modifying the original surface and achieved a thickness of the selective layer of only $1 \mu \mathrm{m}$. A very particular application of this methodology is the synthesis of pore-filled membranes, in which YSZ particles are used to modify the original surface of ceramic supports in a double layer. The aim is to get a good adhesion and uniform coating of the membrane film onto the support, as well as create a barrier that plays as protection of the Pd-selective layer [50]. More details about this alternative can be found in the next section, talking about recent developments for improving the metal deposition processes via Electroless Plating.

The morphology of the external surface of a typical commercial metal support and its modification after the incorporation of some of the previously described materials as intermediate layer are collected in Figure 5. As it can be seen, the original PSS surface is practically covered after the incorporation of the different materials, obtaining a very homogeneous external surface while surface roughness and original pore sizes are significantly decreased.

The most relevant information about the wide alternatives included in this section to modify commercial raw supports has been also summarized in Table 2. Support nature and modification alternatives are collected, as well as other relevant parameters such as composition and thickness of $\mathrm{H}_{2}$ selective layer and permeation properties of the final supported membrane.
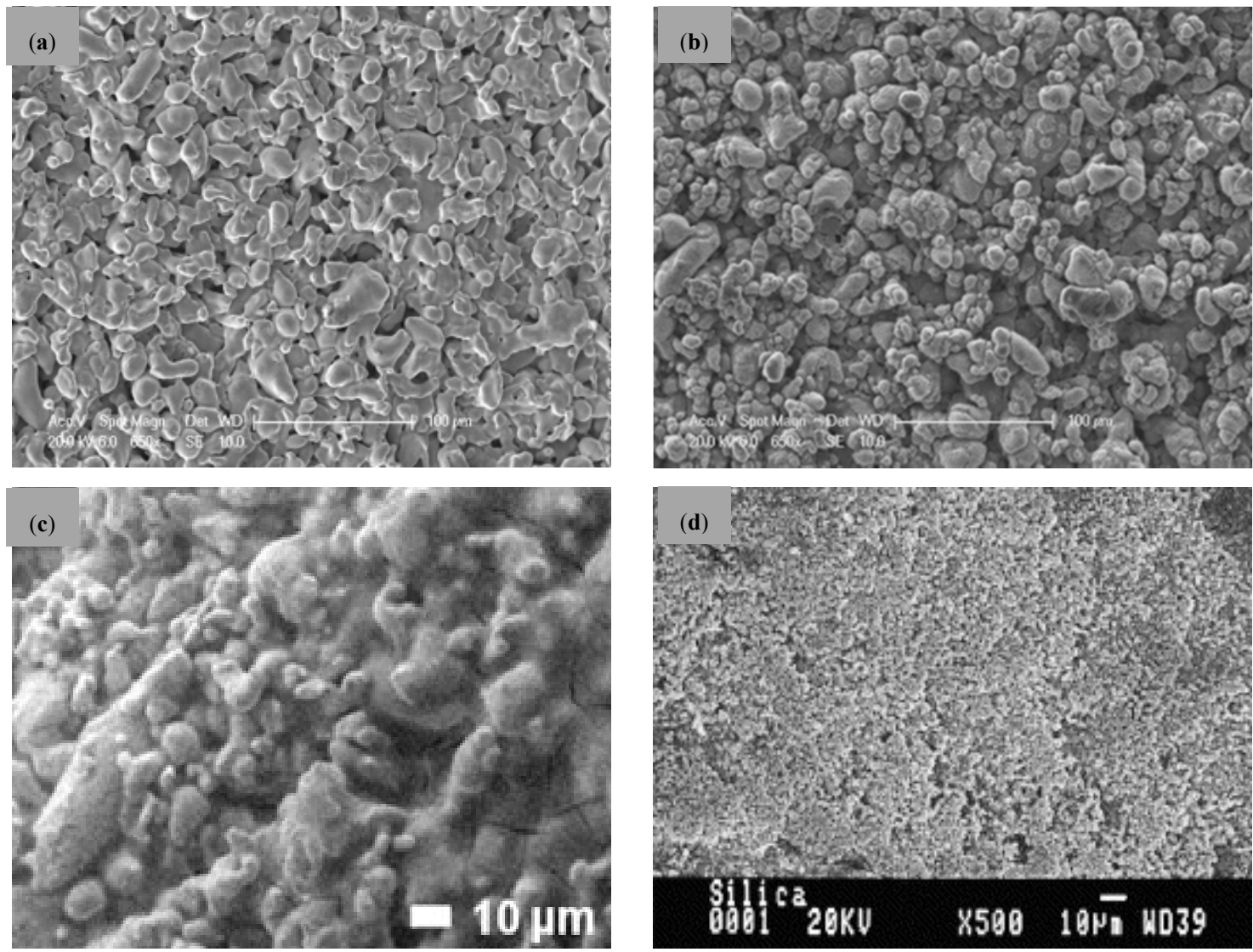

Figure 5. Cont. 

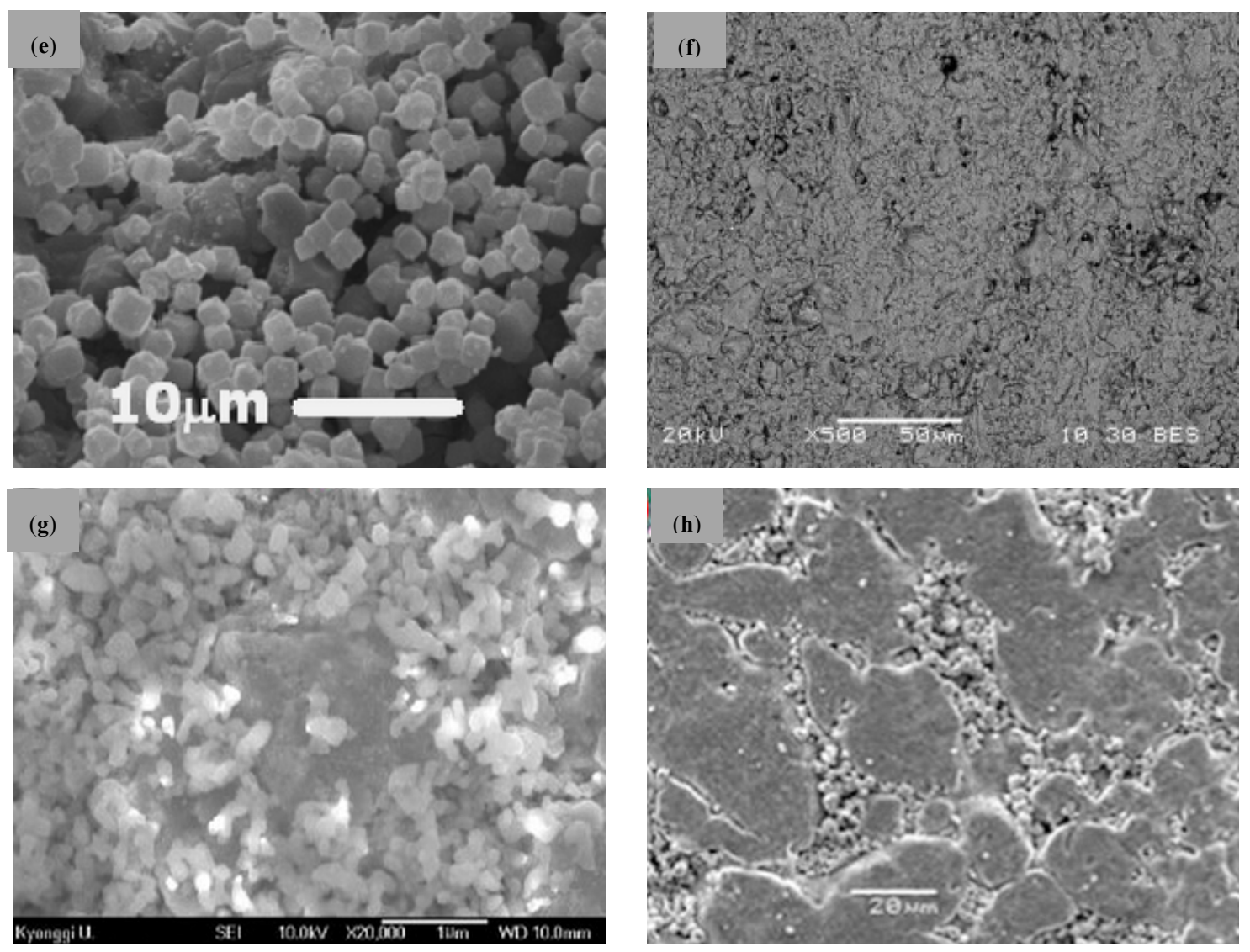

Figure 5. Porous stainless-steel supports before (a); and after the incorporation of different materials as intermediate layer: mixed oxides by calcination in air (b); alumina (c); amorphous silica (d); zeolite (e); zirconia (f); ceria (g); and tungsten (h). Figure adapted from originals published in [47,51,78,99,132,136,153], with permission from (C) Elsevier. 
Table 2. Inorganic commercial supports for supported Pd-based membrane preparation.

\begin{tabular}{|c|c|c|c|c|c|c|c|c|c|}
\hline \multirow{2}{*}{ Support } & \multirow{2}{*}{ Modification Alternative } & \multirow{2}{*}{ Particular Details } & \multirow{2}{*}{$\begin{array}{l}\text { Selective } \\
\text { Layer }\end{array}$} & \multirow{2}{*}{$\begin{array}{l}\text { Tselective } \\
\text { Layer (m) }\end{array}$} & \multicolumn{2}{|c|}{ Permeation Conditions } & \multirow{2}{*}{ Permeation Capacity } & \multirow{2}{*}{$\begin{array}{c}\mathbf{H}_{2} \\
\text { Separation } \\
\text { Factor }\end{array}$} & \multirow{2}{*}{ Ref. } \\
\hline & & & & & $\mathrm{T}\left({ }^{\circ} \mathrm{C}\right)$ & $\mathbf{P}(\mathbf{k P a})$ & & & \\
\hline PSS & Chemical treatment & $\mathrm{HCl}, 5$ min. & $\mathrm{Pd}$ & 20.0 & 350 & 100 & $3.11 \times 10^{-4(\mathrm{a})}$ & 5000 & [110] \\
\hline PSS & Chemical treatment & $\mathrm{HCl}-\mathrm{HNO}_{3}$ mixture & $\mathrm{Pd}$ & 5.0 & $450-550$ & 100 & $3.24 \times 10^{-1}-4.34 \times 10^{-1(\mathrm{c})}$ & n.a. & [111] \\
\hline $\mathrm{Ni}$ & Chemical treatment & $\mathrm{HCl}$ & $\mathrm{Pd}$ & 0.3 & 450 & 100 & $1.44 \times 10^{-1(\mathrm{c})}$ & 1600 & [113] \\
\hline $\mathrm{Al}_{2} \mathrm{O}_{3}$ & Mechanical treatment & Sandpapers: $\# 320, \# 500$ and $\# 800$ & $\mathrm{Pd}$ & 0.5 & n.a. & n.a. & n.a. & n.a. & [112] \\
\hline $\mathrm{Ni}$ & Mechanical treatment & Sandpapers: \#1200 & PdCuNi & 12.0 & $350-500$ & $138-276$ & $1.30 \times 10^{-7}-3.80 \times 10^{-7}(\mathrm{~b})$ & $\infty$ & [113] \\
\hline PSS & Mechanical treatment & Ion shot penning & $\mathrm{Pd}$ & 6.0 & 400 & 100 & $5.80 \times 10^{-2(c)}$ & n.a. & [116] \\
\hline PSS & Permanent Intermediate layer & $\mathrm{CeO}_{2}$ particles & $\mathrm{Pd}$ & 13.0 & 550 & 200 & $2.75 \times 10^{-1(c)}$ & $\infty$ & [122] \\
\hline PSS & Permanent Intermediate layer & $\mathrm{CeO}_{2}$, sol-gel & $\mathrm{PdCu}$ & 8.0 & 450 & 100 & $74.00^{\text {(a) }}$ & 2369 & [123] \\
\hline PSS & Permanent Intermediate layer & $\mathrm{ZrO}_{2}$, sol-gel & & 10.0 & 500 & 100 & $8.30 \times 10^{-2(c)}$ & n.a. & [124] \\
\hline PSS & Permanent Intermediate layer & $\mathrm{ZrO}_{2}$, sol-gel & $\mathrm{PdCu}$ & 10.0 & 480 & 100 & $1.10 \times 10^{-7(b)}$ & $\infty$ & [125] \\
\hline PSS & Permanent Intermediate layer & $\mathrm{ZrO}_{2}$, sol-gel, vacuum assisted method & $\mathrm{PdAu}$ & 10.0 & 400 & 100 & $1.10 \times 10^{-3(\mathrm{a})}$ & $>10,000$ & [93] \\
\hline PSS & Permanent Intermediate layer & YSZ particles & $\mathrm{Pd}$ & 27.7 & $350-450$ & $30-400$ & $4.50 \times 10^{-4(\mathrm{a})}$ & $\infty$ & [70] \\
\hline PSS & Permanent Intermediate layer & YSZ particles & $\mathrm{Pd}$ & 13.8 & $350-450$ & $0-250$ & $4.10 \times 10^{-5}-4.10 \times 10^{-4}$ (a) & $\infty$ & [78] \\
\hline Hast $X$ & Permanent Intermediate layer & $\mathrm{YSZ}-\mathrm{Al}_{2} \mathrm{O}_{3} / \mathrm{YSZ}$ & $\mathrm{PdAg}$ & $4.0-5.0$ & $400-600$ & 100 & $100.00 \times 10^{-8(b)}$ & $>200,000$ & [98] \\
\hline PSS & Permanent Intermediate layer & $\gamma-\mathrm{Al}_{2} \mathrm{O}_{3}$, dip-coating & $\mathrm{Pd}$ & 11.0 & n.a. & n.a. & n.a. & n.a. & [130] \\
\hline PSS & Permanent Intermediate layer & Graded $\mathrm{Al}_{2} \mathrm{O}_{3}$ particles & $\mathrm{Pd}$ & $<5.0$ & 500 & n.a. & $2.94 \times 10^{-3}$ (a) & 1124 & [131] \\
\hline PSS & Permanent Intermediate layer & $\mathrm{SiO}_{2}$ particles & $\mathrm{PdCu}$ & 2.0 & 450 & n.a. & $8.37 \times 10^{-7(\mathrm{~d})}$ & 70,000 & [132] \\
\hline PSS & Permanent Intermediate layer & Silicalite-1, sol-gel and dip-coating & $\mathrm{Pd}$ & 5.0 & $350-450$ & $50-250$ & $1.42 \times 10^{-4(\mathrm{a})}$ & $\infty$ & [62] \\
\hline PSS & Permanent Intermediate layer & Zeolite NaA & $\mathrm{Pd}$ & 19.0 & 450 & 50 & $1.10 \times 10^{-3}$ (a) & 608 & [136] \\
\hline PSS & Permanent Intermediate layer & Zeolite FAU-type & $\mathrm{Pd}$ & 1.0 & 200 & 100 & $1.20 \times 10^{-4(\mathrm{a})}$ & n.a. & [139] \\
\hline $\mathrm{Al}_{2} \mathrm{O}_{3}$ & Permanent Intermediate layer & Zeolite TS-1 & $\mathrm{Pd}$ & 2.0 & $350-450$ & $50-500$ & $1.48 \times 10^{-1(\mathrm{c})}$ & 148 & [141] \\
\hline PSS & Permanent Intermediate layer & $\mathrm{Fe}_{2} \mathrm{O}_{3}-\mathrm{Cr}_{2} \mathrm{O}_{3}$, oxidation in air $\left(\mathrm{T}=600^{\circ} \mathrm{C}\right)$ & $\mathrm{Pd}$ & 33.0 & 300 & n.a. & $2.66 \times 10^{-4(a)}$ & n.a. & [143] \\
\hline PSS & Permanent Intermediate layer & $\mathrm{Fe}_{2} \mathrm{O}_{3}-\mathrm{Cr}_{2} \mathrm{O}_{3}$, oxidation in air $\left(\mathrm{T}=600^{\circ} \mathrm{C}\right)$ & $\mathrm{Pd}$ & 19.0 & n.a. & n.a. & n.a. & n.a. & [144] \\
\hline PSS & Permanent Intermediate layer & Tungsten particles & $\mathrm{PdCu}$ & $5.0-20.0$ & n.a. & n.a. & n.a. & n.a. & [47] \\
\hline PSS & Temporary intermediate layer & Aluminum hydroxide gel/polymer & $\mathrm{Pd}$ & 5.0 & 600 & 200 & $3.50 \times 10^{-3(a)}$ & $\infty$ & [150] \\
\hline $\mathrm{Al}_{2} \mathrm{O}_{3}$ & Permanent Intermediate layer & Graphite-Clay (from 2B pencil) & $\mathrm{Pd}$ & 5.0 & 450 & 100 & $3.10 \times 10^{-1(c)}$ & 3700 & [151] \\
\hline $\mathrm{Al}_{2} \mathrm{O}_{3}$ & Permanent Intermediate layer & Pd(II)-modified bohamite sol & $\mathrm{Pd}$ & 1.0 & 450 & n.a. & $2.23 \times 10^{-2}-1.07^{\text {(c) }}$ & $20-130$ & [152] \\
\hline $\mathrm{Al}_{2} \mathrm{O}_{3}$ & Permanent Intermediate layer & YSZ particles & $\mathrm{Pd}$ & 5.0 & $150-500$ & $150-400$ & $0.10-0.60^{(\mathrm{c})}$ & n.a. & [50] \\
\hline
\end{tabular}

Permeation capacity: ${ }^{(\mathrm{a})}$ Permeance $\left(\mathrm{mol} \cdot \mathrm{m}^{-2} \cdot \mathrm{s}^{-1} \cdot \mathrm{Pa}^{-0.5}\right),{ }^{(\mathrm{b})}$ Permeance $\left(\mathrm{mol} \cdot \mathrm{m}^{-2} \cdot \mathrm{s}^{-1} \cdot \mathrm{Pa}^{-1}\right)$ or ${ }^{(\mathrm{c})}$ Permeation flux $\left(\mathrm{mol} \cdot \mathrm{m}^{-2} \cdot \mathrm{s}^{-1}\right)$, n.a.: non available. 


\section{Palladium Incorporation by Electroless Plating}

\subsection{Electroless Plating Standard Method}

The term Electroless Plating (ELP) was coined for the first time in the middle forties by Brenner and Riddell to define the metal deposition in the absence of an external source of electric current [154]. The application of ELP technology to the palladium incorporation on porous supports has been widely used to prepare hydrogen selective membranes for years. As it is previously mentioned in the introduction, this technique does not require any expensive equipment and neither high operational costs due to the absence of electrodes and external electricity sources. Moreover ELP is able to create homogeneous films on complex geometries and non-conducting materials [111,155-157], being the option usually preferred over other methods. Here, a general description of the method is presented, including the most relevant advances carried out during the last years in case of using both metallic and ceramic supports.

Essentially, the use of ELP for the preparation of $\mathrm{H}_{2}$-selective membranes is based on the palladium deposition (or related alloying materials, as it is discussed later) onto a support target surface from an aqueous solution containing the metal precursor. Usually, this precursor is dissolved and stabilized with some ligand in order to form a complex prior to be reduced through a controlled autocatalytic chemical reaction [158,159]. In recent years, most published manuscripts use ammonium hydroxide and ethylenediaminetetraacetic acid to complex the palladium precursor. On the other hand, hydrazine is preferred as reducing agent due to the generation of nitrogen as unique by-product of the chemical reaction, avoiding other prohibited deposits in the film, i.e., phosphorous $[157,159,160]$. Hydrazine is a powerful reducing agent in both acid and alkaline media. The reduction of higher valent metal ions to lower metal ones or to the zero valent state is possible depending on the reaction conditions [161-163]. Hereunder, the main chemical reactions involved in the process for palladium deposition are:

$$
\begin{aligned}
& 2 \mathrm{Pd}\left(\mathrm{NH}_{3}\right)_{4}^{2+}+4 \mathrm{e}^{-} \rightarrow 2 \mathrm{Pd}^{0}+8 \mathrm{NH}_{3} \mathrm{E}^{0}=0.95 \mathrm{~V} \\
& \mathrm{~N}_{2} \mathrm{H}_{4}+4 \mathrm{OH}^{-} \rightarrow \mathrm{N}_{2}+4 \mathrm{H}_{2} \mathrm{O}+4 \mathrm{e}^{-} \mathrm{E}^{0}=1.12 \mathrm{~V}
\end{aligned}
$$

being the global reaction of the process as follows:

$$
2 \mathrm{Pd}\left(\mathrm{NH}_{3}\right)_{4}^{2+}+\mathrm{N}_{2} \mathrm{H}_{4}+4 \mathrm{OH}^{-} \rightarrow 2 \mathrm{Pd}^{0}+8 \mathrm{NH}_{3}+\mathrm{N}_{2}+4 \mathrm{H}_{2} \mathrm{O} \mathrm{E}^{0}=2.07 \mathrm{~V}
$$

In order to achieve a homogeneous Pd deposition, good adherence and reasonable induction times to spontaneously initiate the chemical reactions, the supports need to be seeded with a first nano-sized Pd nuclei before the main plating step [164]. Conventionally, this step has been carried out by repetitive immersions in acidic tin and palladium solutions, also known as sensitization-activation treatment [165]. However, some studies advise problems in membrane stability at high operating temperatures caused by tin residues, which lead to the formation of defects and pinholes in the Pd film, as Paglieri et al. indicated for the first time in the late nineties [166] and other authors endorsed most recently [167]. A detailed study about the correlation between presence of tin residues and membrane stability has been lately published by Wei et al. [167]. Considering these negative effects of classical sensitization-activation treatments, alternative methods avoiding the use of tin solutions have been proposed. Different approaches have been used, such as, the use of activated particles with Pd nuclei for intermediate layers preparation [125,127,146,168,169]; catalysed anodic alumina surfaces to facilitate the Pd electroless plating [170]; the increase of nuclei deposition rate and rupture of conglomerates by applying ultrasounds [171]; the incorporation, decomposition and reduction of a palladium acetate solution in chloroform onto the surface [172]; or, directly, the generation of nano-sized Pd particles by direct reduction of a highly diluted solution with a mixture of ammonia-hydrazine [51,71]. However, up to date it has not been found a better solution and the classical method remains as the top choice for many researchers $[28,46,161]$. 


\subsection{Recent Developments in Electroless Plating}

In last years, great efforts have been carried out to reduce the overall cost of Pd-based membranes manufacturing, mainly focusing in reducing the palladium layer thickness but ensuring absence of defects in the coating $[35,37,38,173]$. As previously commented, one strategy is based on the preparation of supported membranes, which usually involves the modification of raw supports to facilitate the incorporation of an ultrathin free-defects palladium layer [21,62]. Other strategies are focused to improve the metal deposition process, particularly the electroless plating, to achieve better adherence, homogeneity, greater pores coverage or, in a general way, better stability of the Pd-based $\mathrm{H}_{2}$-selective layer with minimum thickness. Along following lines, the most relevant developments in this context are presented, particularly focusing on the advances published in recent years.

Thereby, Uemiya et al. [174] increased the metal incorporation rate by immersing the porous support in a solution containing hydrazine prior to each electroless plating step. Other authors tried to improve the palladium incorporation in deep areas on the surface, where deposited metal particles effectively close the pore mouths of the support and complete a fully dense and continuous layer by the bridge mechanism [175]. Zhao et al. [152] and Zhang et al. [176] reported the use of vacuum in the inner size of the supports to achieve uniform microstructure of Pd layer with a lower average thickness to that of conventional electroless plating. Similar results were obtained by other researchers, such as Yeung [177], Souleimanova [178] or $\mathrm{Li}$ [179] when osmotic effect is generated between the plating solution and an aqueous sucrose solution.

Pacheco Tanaka et al. $[50,52,180]$ went a step further by preparing supported membranes in which the incorporation of Pd or Pd-based alloys was carried out by vacuum-assisted electroless plating between two zirconia oxide ceramic layers, one of them activated with a previous $\mathrm{Pd}$ seed, deposited onto a tubular alumina support. This particular kind of membranes in which the selective layer is placed into a sandwich-type structure was denoted as pore-filled type membranes. The main advantages outlined by the authors includes the ability to operate the membrane below the critical temperature and to maintain a fully mechanical stability, unlike other supported membranes based on a conventional external coating, where fatal damages usually occur. Moreover, the sandwich structure also provides to the selective layer an additional protection against poisoning. Recently, a clear scheme describing in detail the fundamentals of this alternative has been reported by Arratibel et al. [90], as shown in Figure 6 (with permission).

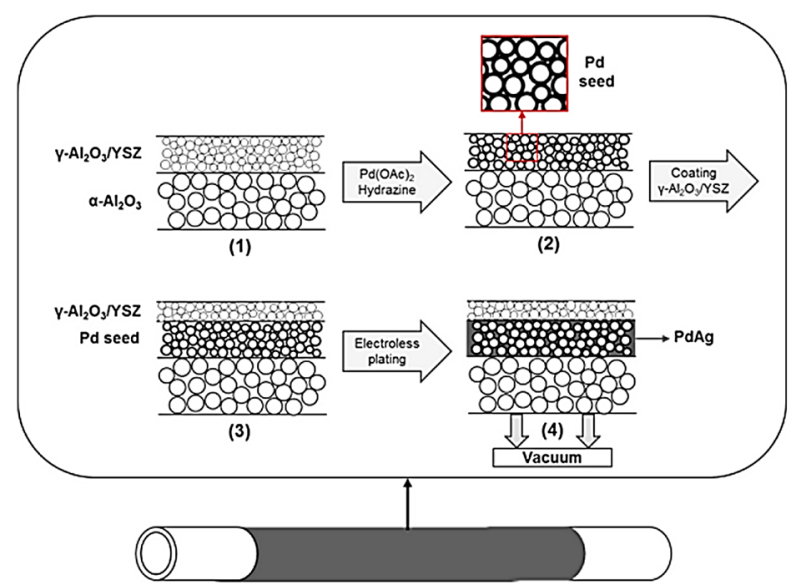

Figure 6. Procedure to prepare pore-filled type membranes [90] with permission from (C) Elsevier.: (1) Incorporation of a first $\gamma-\mathrm{Al}_{2} \mathrm{O}_{3} /$ YSZ layer; (2) Pd seed on smaller ceramic particles; (3) incorporation of a top additional $\gamma-\mathrm{Al}_{2} \mathrm{O}_{3} / \mathrm{YSZ}$ layer and (4) incorporation of a Pd-based layer by vacuum-assisted ELP.

On the other hand, different studies are focused on modifying the plating baths composition to improve the final properties of the palladium film. In this context, it has been demonstrated that conventional electroless plating baths containing ethylenediaminetetraacetic acid (EDTA) present good stability at different temperatures, although it results in limited purity of the palladium layer due to 
the incorporation of carbon deposits from the EDTA complex within the metal particles [97,181,182]. These carbon deposits could diminish the membrane performance by $\mathrm{CO}_{2}$ formation at some operating conditions. Thus preparation of free-EDTA baths has been also investigated, achieving acceptable palladium deposition yields with good stability of plating baths in absence of these stabilizer $[97,181,182]$.

Other authors have studied the influence of fluid dynamics between support and plating bath. Thus, the rotation of the support during the electroless plating has been found to increase the plating rate and the homogeneity of Pd layer, as reported Chi et al. [183]. Compared with static ELP, the use of rotation of the support during the process reached more uniform and smoother surfaces of Pd membranes, which in turns enhances the stability of the supported system. These authors reported a membrane permeance of $3.0 \times 10^{-3} \mathrm{~mol} \cdot \mathrm{m}^{-2} \cdot \mathrm{s}^{-1} \cdot \mathrm{Pa}^{-0.5}$ with ideal hydrogen separation factor upper than 400 for only $5 \mu \mathrm{m}$ thick $\left(\mathrm{T}=400{ }^{\circ} \mathrm{C}, \mathrm{P}=4\right.$ bar).

Despite the effort in the research to improve both quality and cost-efficiency of Pd membranes, other many studies are focused on diminishing the rejected membranes due to the presence of defects or cracking during the fabrication processes. In this mean, novel alternatives to repair possible defects generated on the Pd surface have been recently reported. Thus, Li et al. [179] use the fundamentals of previously reported osmotic effect to incorporate Pd particles preferentially in defect areas for repairing the Pd layer. Following this procedure, they ensure the complete disappearance of defects and a consequent meaningful increase in the ideal hydrogen separation factor without noticeable reduction of the permeation flux nor thickness growth. With similar fundamentals, point plating has been also proposed by Zeng et al. [184] to repair located defects in supported Pd-based membranes. In this case, the method forces the chemical reaction for palladium reduction around defects by feeding both metal source and hydrazine baths from opposite sides of the supported membrane.

Based on these repairing procedures, other researchers have recently reported the separated supply of Pd source and reducing agent bath to prepare Pd-based membranes directly on rough commercial PSS supports [49,51,71,78-80]. This novel procedure, denoted as Electroless Pore-Plating (ELP-PP), uses the wall of the support itself to maintain separated both Pd source and hydrazine solutions. At these conditions, hydrazine preferentially diffuses through the pores of the support and reacts with the amino-palladium complex near the pore area. Ideally, in case of proper activation of the inner pore surface, this reduction initiates from the internal porosity of the support in a similar way to the sealing method previously $[49,51,185]$ asserted that it is possible to save palladium source and to minimize the number of rejected membranes following this methodology, consequently reducing the overall cost of membrane preparation. This is possible because the contact between reactants turns progressively difficult during the Pd incorporation up to the complete block of pores, moment at which the process stops. The comparison of both conventional ELP and ELP-PP alternatives is shown in Figure 7. This method hinders the increasing of palladium incorporation after blocking the pores, in contrast to the behaviour reached by conventional ELP, resulting in a fully dense film with minimum thickness.

In spite of the preferential incorporation of Pd inside the pores of the support, authors revealed the generation of an external film on both commercial and modified PSS supports caused by the wide variety of pore diameters in these supports $[49,51,185]$. The hydrazine cannot pass through the smallest pores because they become fully closed by palladium particles in a relative short time, while the reducing agent can diffuse through the widest ones, partially covered, until the outer surface in contact with the palladium bath, where the external layer is formed. In this manner, it is obvious that several parameters affect the ELP-PP process: (i) pore characteristics of support (average pore diameter and porosity), (ii) reducing and metal plating baths formulation and (iii) ratio between membrane length and volume of solutions. In fact, supports with smaller pores, achieved by direct oxidation of commercial supports in air, provide membranes with an apparent thickness around $10 \mu \mathrm{m}$, a half of the value reached in case of using unmodified supports $(20 \mu \mathrm{m})$. However, this apparent thickness, determined by gravimetric analysis, is 2-6 $\mu \mathrm{m}$ greater than the real value obtained from SEM characterization due to the Pd introduction in the pores of the support is not considered for the estimation. All membranes obtained by this ELP-PP alternative exhibited high stability at different simulated and real operating conditions 
in a WGS membrane reactor with permeances in the range $1-6 \cdot 10^{-4} \mathrm{~mol} \cdot \mathrm{m}^{-2} \cdot \mathrm{s}^{-1} \cdot \mathrm{Pa}^{-0.5}$ and complete $\mathrm{H}_{2}$ selectivity [51]. Within the recent past, this novel method has been also reported for preparation of supported membranes on ceramic supports with noticeable smaller pores respect to typical PSS supports, confirming the great importance of support characteristics on the plating performance (primarily average pore diameter and pore size distribution). In this way, thinner membranes were achieved even though palladium is still present in both internal pores and external surface [71].

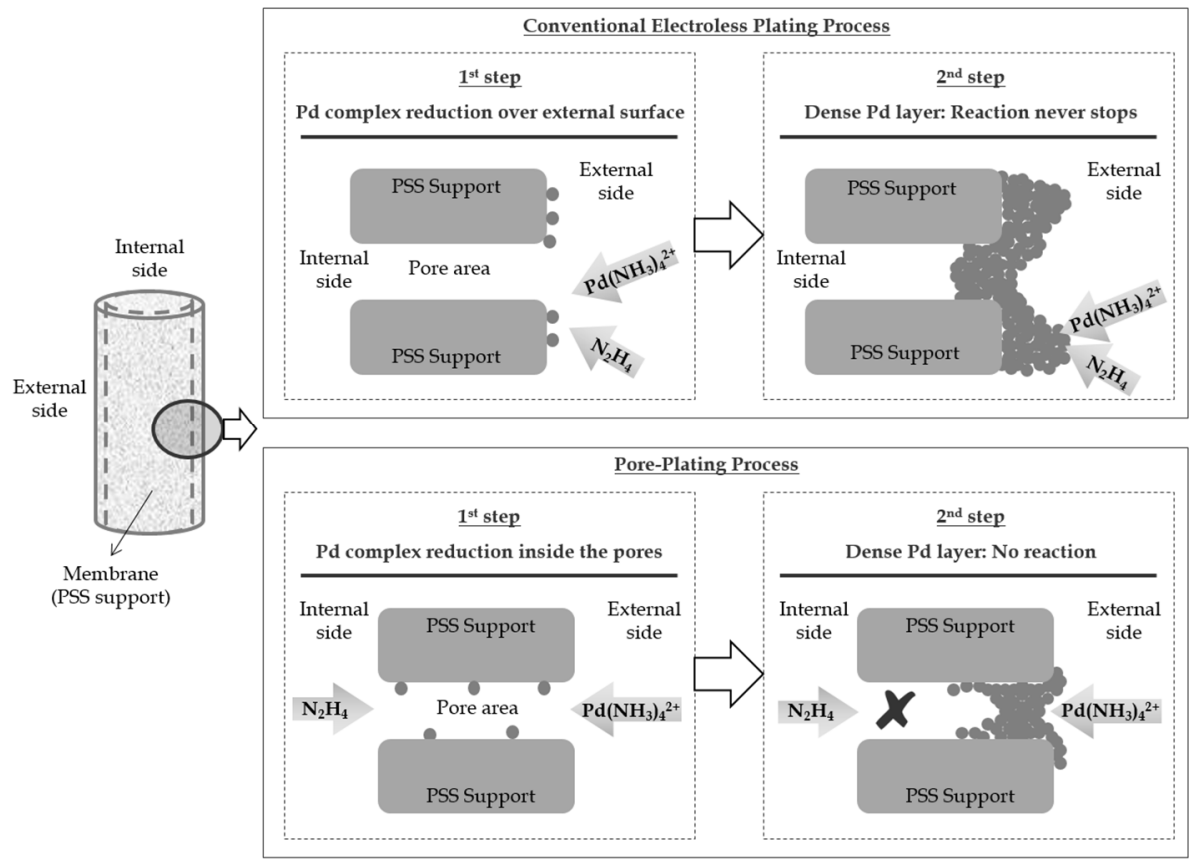

Figure 7. Pd incorporation around pores in both conventional electroless plating (ELP) and pore-plating (ELP-PP) alternatives [185], with permission from @ Elsevier.

Finally, some researchers propose the improvement of membranes properties, mainly the increase of permeation rate and thermal stability simultaneously to the presence of defects is decreased, by using a further thermal treatment step $\left(>640^{\circ} \mathrm{C}\right)$ after the palladium plating [42]. Although this alternative is not strictly an improvement of the metal deposition process, it can be used to enhance the previously prepared membrane. In fact, a heat treatment of as-prepared membranes improved the Pd layer microstructure, achieving a densification of the metal film, as it can be seen in Figure 8.
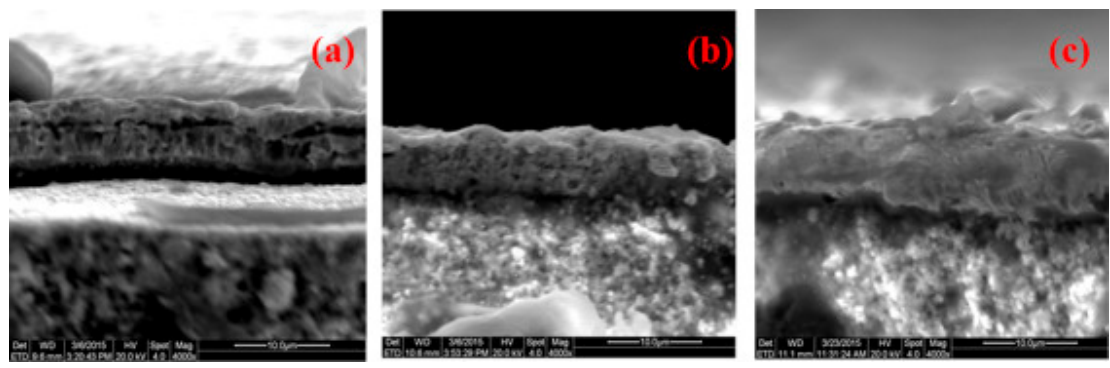

Figure 8. Microstructural modification on Pd films prepared by ELP after different thermal treatments: (a) as prepared; (b) $168 \mathrm{~h}$ at $550{ }^{\circ} \mathrm{C}$; and (c) $72 \mathrm{~h}$ at $700{ }^{\circ} \mathrm{C}$ [42], with permission from (C) Elsevier.

Like previous information about main alternatives for modification of commercial supports, here we summarize the most relevant advances for Pd incorporation by electroless plating in Table 3. Key improvements and experimental details are summarized beside information about support material, support modifications, thickness of selective layer and permeation properties. 
Table 3. Recent improvements on electroless plating to prepare supported Pd-based membranes.

\begin{tabular}{|c|c|c|c|c|c|c|c|c|c|}
\hline \multirow[t]{2}{*}{ ELP Improvement } & \multirow{2}{*}{ Particular Details } & \multirow[t]{2}{*}{ Support } & \multirow{2}{*}{$\begin{array}{c}\text { Support } \\
\text { Modification }\end{array}$} & \multirow{2}{*}{$\begin{array}{l}\text { Tselective } \\
\text { Layer (m) }\end{array}$} & \multicolumn{2}{|c|}{$\begin{array}{l}\text { Permeation } \\
\text { Conditions }\end{array}$} & \multirow[t]{2}{*}{ Permeation Capacity } & \multirow{2}{*}{$\begin{array}{c}\mathbf{H}_{2} \\
\text { Separation } \\
\text { Factor }\end{array}$} & \multirow{2}{*}{ Ref. } \\
\hline & & & & & $\mathrm{T}\left({ }^{\circ} \mathrm{C}\right)$ & $\mathbf{P}(\mathbf{k P a})$ & & & \\
\hline Deposition around pores & Vacuum asisted-deposition & $\mathrm{Al}_{2} \mathrm{O}_{3}$ & - & 6.0 & 500 & n.a. & $8.78 \times 10^{-4(a)}$ & 3000 & {$[176]$} \\
\hline Deposition around pores & Vacuum asisted-deposition & $\mathrm{Al}_{2} \mathrm{O}_{3}$ & $\begin{array}{l}\text { Pd(II)-modified } \\
\text { bohamite sol }\end{array}$ & 1.0 & 450 & n.a. & $2.23 \times 10^{-2}-1.07^{(b)}$ & $20-130$ & [152] \\
\hline Deposition around pores & Osmotic effect with aqueous sucrose solution & Vycor glass & - & 1.6 & n.a. & n.a. & n.a. & n.a. & [177] \\
\hline Deposition around pores & Osmotic effect with aqueous sucrose solution & Vycor glass & - & 2.5 & n.a. & n.a. & n.a. & n.a. & [178] \\
\hline Protecting selective layer & $\begin{array}{l}\text { Pore- filled, vacuum asissted-deposition } \\
\text { between two } \mathrm{ZrO}_{2} \text { layers }\end{array}$ & $\mathrm{Al}_{2} \mathrm{O}_{3}$ & YSZ particles & 5.0 & $150-500$ & $150-400$ & $0.10-0.60^{(b)}$ & n.a. & [50] \\
\hline Reduction of carbon deposits & Free-EDTA baths & $\mathrm{Al}_{2} \mathrm{O}_{3}$ & $\mathrm{ZrO}_{2}$ & 1.3 & 365 & 138 & $394.61^{(a)}$ & n.a. & [181] \\
\hline Reduction of carbon deposits & Free-EDTA baths & PSS & $\mathrm{Al}_{2} \mathrm{O}_{3}$ & 5.0 & 400 & 100 & $3.05 \cdot \times 10^{-3(a)}$ & 500 & [182] \\
\hline Increase film homogeneity & Support rotation & $\mathrm{Al}_{2} \mathrm{O}_{3}$ & $\mathrm{ZrO}_{2}$ & 5.0 & $350-450$ & $100-400$ & $3.00 \cdot \times 10^{-3(a)}$ & $>400$ & [183] \\
\hline Membrane repairing & $\begin{array}{l}\text { Osmotic effect to close defects without } \\
\text { thickness increase }\end{array}$ & PSS & - & 10.0 & $425-475$ & $68-136$ & $2.00 \cdot 10^{-4(b)}$ & $400-1600$ & [179] \\
\hline Membrane repairing & $\begin{array}{l}\text { Point plating to close defects without } \\
\text { thickness increase }\end{array}$ & $\alpha-\mathrm{Al}_{2} \mathrm{O}_{3}$ & $\gamma-\mathrm{Al}_{2} \mathrm{O}_{3}$ & n.a. & 500 & 100 & $7.20 \times 10^{-1}-8.50 \times 10^{-1(b)}$ & n.a. & [184] \\
\hline Reducing rejected membranes & $\begin{array}{l}\text { ELP-PP. Pd-source and reducing agent from } \\
\text { opposite sides of support }\end{array}$ & PSS & $\mathrm{Fe}_{2} \mathrm{O}_{3}-\mathrm{Cr}_{2} \mathrm{O}_{3}$ & $11.0-20.0$ & $350-450$ & $100-250$ & $1.00 \times 10^{-4}-6.00 \times 10^{-4(\mathrm{a})}$ & $\infty$ & [51] \\
\hline Pd microstructure & Heat treatment at $\mathrm{T}>640^{\circ} \mathrm{C}$ & PSS & YSZ & 4.9 & 600 & 82 & $2.40 \times 10^{-3(a)}$ & 200-2000 & [42] \\
\hline
\end{tabular}

Permeation capacity: (a) Permeance $\left(\mathrm{mol} \mathrm{m}^{-2} \cdot \mathrm{s}^{-1} \cdot \mathrm{Pa}^{-0.5}\right)$ or ${ }^{(\mathrm{b})}$ Permeation flux $\left(\mathrm{mol} \cdot \mathrm{m}^{-2} \cdot \mathrm{s}^{-1}\right)$. n.a.: non availabl. 


\section{Pd-Alloy Membranes}

Independently of using conventional or improved electroless plating processes, many researchers endorse the preparation of alloys in which palladium is combined with some amounts of other metals in order to improve the permeation behaviour, the thermal and mechanical stability and the poison tolerance of the membrane [56,186-188]. Thus, in this section we present an overview of most frequent Pd-based alloys, detailing the preparation procedures and main reported benefits, as well as recent trends and future perspectives for new formulations with improving properties.

Pure Pd usually suffers the so-called hydrogen embrittlement phenomenon due to the lattice expansion provoked by the $\alpha$ to $\beta$ phase transition that occurs when the metal is exposed to hydrogen atmosphere at temperatures and pressures below $298^{\circ} \mathrm{C}$ and $2 \mathrm{MPa}$, respectively. This phase transition generates tensile stress, especially in case of tubular geometries, which often leads to cracking the $\mathrm{Pd}$ layer and thus, a subsequent loos of hydrogen selectivity of the membrane. This drawback can be avoided by working at operating conditions above the mentioned critical point when membrane is exposed to hydrogen or modifying the Pd phase diagram [189]. The last option can be realized by alloying pure Pd with other metals, i.e., silver [52,106,190-192], copper [99,102], ruthenium [187,193] or gold [194,195]. It is demonstrated that Pd-based alloys with specific concentrations of these metals modify the metal-hydride phase diagram avoiding the mentioned embrittlement phenomena [28].

Other problem that negatively affects to the permeability of dense Pd-based membranes is the irreversible poisoning by chemical contaminants, such as carbon monoxide or sulphur. These molecules are chemisorbed over the metallic layer, being also possible a chemical reaction with hydrogen to form species that block the active sites on the surface and hinder the hydrogen permeation. Some alloys help to avoid this poisoning effect while maintaining an ideal complete hydrogen separation factor [90], even in presence of sulphur compounds that traditionally causes irreversibly poisoning in pure $\mathrm{Pd}$ films $[28,102,186,196]$.

\subsection{Alloy Preparation}

The preparation of efficient Pd-based alloys by electroless plating with an accurate composition is currently one of the most important milestones for industrial membranes implementation. Physical vapour deposition provides multiple possibilities for incorporating different metals to the membrane with a really good control of the alloy composition [61,197-199]. However, this technique has some difficulty to generate defect-free layers on rough surfaces and high investments costs [60]. Thus, at the present date, the metal incorporation by electroless plating is widely adopted [182].

In general, the incorporation of metals by electroless plating for preparation of alloys can be carried out in different ways after a previous activation of the support, as illustrated in Figure 9. First, a unique plating bath containing all alloy constituents, i.e., materials $\mathrm{A}$ and $\mathrm{B}$, can be used to deposit simultaneously all of them, being denoted as co-deposition (Figure 9a). In this case, the alloy constituents are randomly distributed in the selective layer with similar composition in both longitudinal and transversal directions. Thus, the following thermal treatment to form the alloy is favoured. However, this option is only possible in case of using metals with analogous properties that can be reduced in similar conditions, i.e., palladium and silver with comparable bath compositions and identical reducing agents. However, kinetics of the reduction process can be different for each component and, consequently, it is not easy to define the bath conditions to achieve a desired alloy composition [28,74,200,201].

Other possibility to prepare Pd-alloy membranes is based on sequential depositions of each constituent, incorporating all required amount of material B onto a previous layer formed by the material A (Figure 9b) or vice versa (Figure 9c), denoting both alternatives as consecutive methods. The alternation of different layers formed by each constituent until achieving the desired composition and layer thickness is also viable (Figure $9 \mathrm{~d}$,e, alternate methods). In these cases, it is possible to incorporate metals from different plating baths by using the same or different reducing agents on the condition that galvanic displacement does not occur. The kinetics of deposition processes can be 
easily controlled and the final alloy composition is determined by recurrences of each constituent plating. The most relevant drawback of sequential depositions is the difficulty to achieve a good alloy homogeneity through the whole layer thickness [202].

\section{Co-deposition}

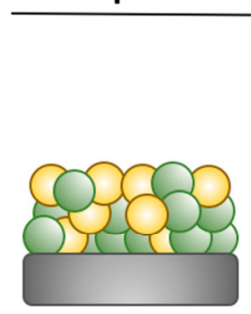

(a)

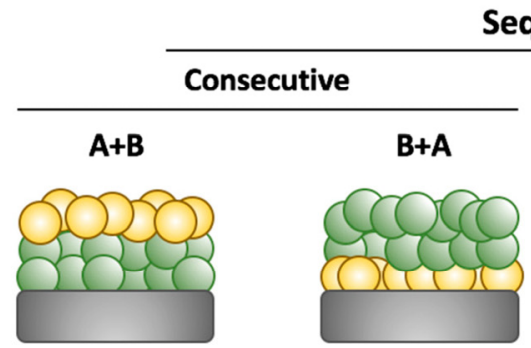

(b)

(c)

Sequential

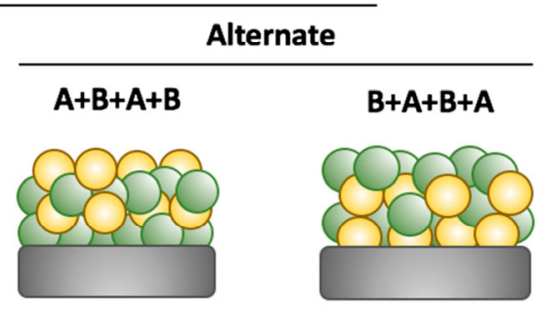

(d)

(e)

Alloy constituent A ; Alloy constituent B

Figure 9. Different possibilities to prepare binary alloys by electroless plating: (a) co-deposition; $(\mathbf{b}, \mathbf{c})$ sequential deposition; (d,e) alternative deposition.

Anyway, a further thermal treatment is always required to achieve the diffusion of atoms within the solid material to form the alloy, independently of using sequential or co-deposited alternatives for the incorporation of metals. This process, also known as annealing, can be carried out under inert atmosphere (usually by using $\mathrm{Ar}$, He or $\mathrm{N}_{2}$ as inert gas) $[99,146,203]$ or in presence of hydrogen $[52,94,187,200,204]$. Traditional annealing processes for Pd-based membranes use inert environment at ambient pressure and require quite long times [53]. However, recent developments prefer faster processes in pressurized hydrogen atmosphere. In this case, it is proposed that dissolved hydrogen forms vacancies in the crystal lattice of palladium favouring the mobility of other alloy constituents and, consequently, reducing the time required to obtain the alloy [195]. As previously mentioned, layers prepared by co-deposition need softer thermal treatments (shorter times or lower temperatures) for annealing as compared with layers generated by sequential deposition (either consecutive or alternative) $[95,202]$. Taking into account that preparation of alloys with accurate control is a decisive challenge for the large-scale application of Pd-based membranes [205], following sections summarize the most relevant advances in this field, distinguishing the preparation of binary and ternary alloys.

\subsection{Binary Alloys}

Among the large number of feasible alloys from different metal pairs, the Pd-based binary alloys are the most frequently studied and used for hydrogen production. As mentioned before, alloying palladium with other component can avoid the hydrogen embrittlement as well as improve mechanical and chemical properties. In some specific cases, the hydrogen permeability may be even increased, depending on the alloy composition (Figure 10). Some alloys can improve the hydrogen permeability of the membrane only in a narrow composition window, while others also work in a wide range of compositions. Deviations from these target compositions or differences in composition inside the bulk metal may deteriorate noticeably the permeation behaviour respect pure palladium. For instance, this occurs when exceeding $36 \mathrm{wt} \%$ or $21 \mathrm{wt} \%$ in case of alloying with silver or gold, respectively. For palladium-copper alloys, small deviations from a target $\mathrm{Pd}_{60} \mathrm{Cu}_{40}$ value reach to a drastic decrease in hydrogen permeability. 


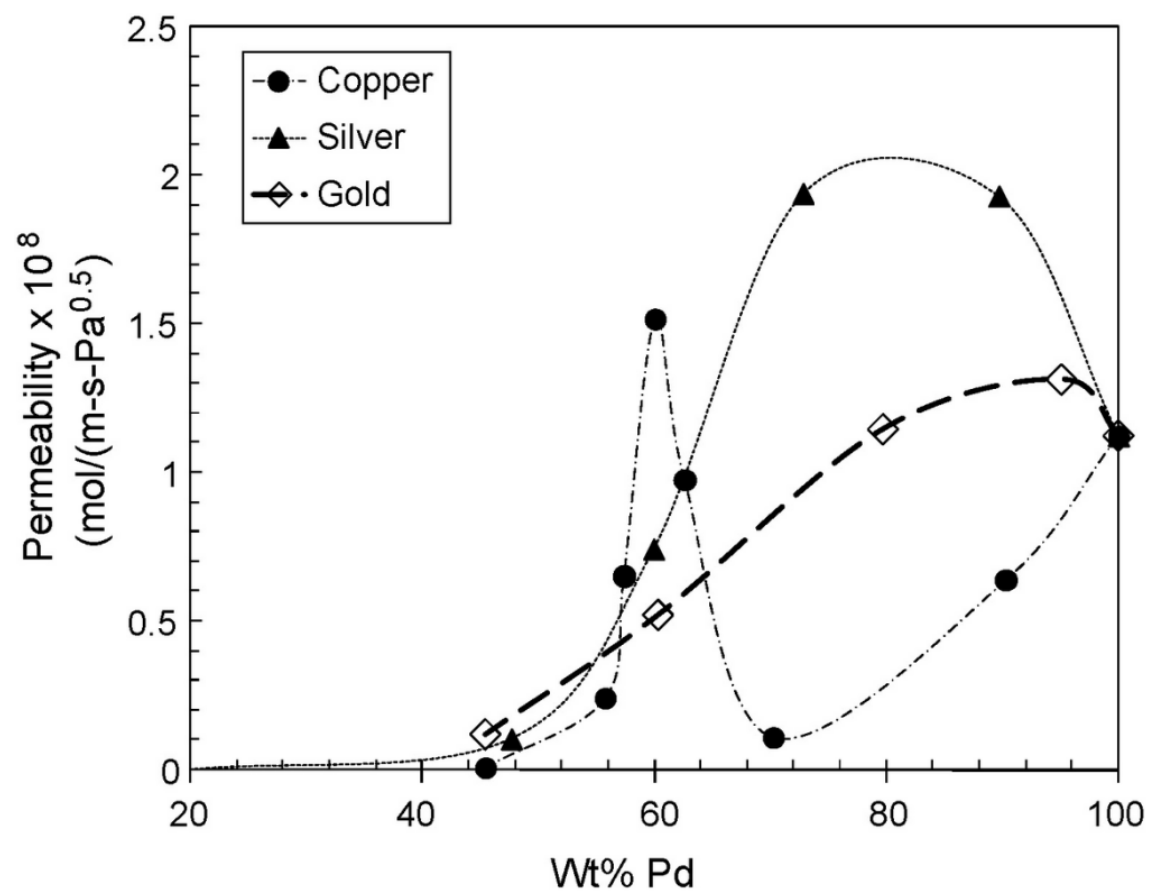

Figure 10. $\mathrm{H}_{2}$ permeability at $350{ }^{\circ} \mathrm{C}$ for different Pd-based alloys containing $\mathrm{Ag}, \mathrm{Cu}$ and $\mathrm{Au}$ [206], with permission from $(C)$ Elsevier.

\subsubsection{PdAg Membranes}

One of the first alternatives to prepare binary Pd-based alloys is based on the addition of silver, used since the eighties for separation of hydrogen isotopes $[207,208]$. It is widely reported that mechanical strength against hydrogen embrittlement is significantly improved after silver incorporation on a palladium layer [201], as well as original hydrogen permeability can be also increased for some particular conditions [209]. As previously shown in Figure 10, the addition of silver on bulk palladium to prepare a binary PdAg alloy increases the membrane permeability in a wide range of compositions, from very low Ag percentages up to around $36 \mathrm{wt} \%$ [206]. Particularly, it is proved that using a $\mathrm{Pd}_{75} \mathrm{Ag}_{25}$ composition the hydrogen permeation reached a maximum and, thus, many researchers around the world have adopted this composition as main target for membrane preparation. Concerning the preparation procedure to obtain this alloy by electroless plating, both co-deposition [95] and sequential deposition [202] alternatives can be widely found in literature.

The research group headed by Yi Hua Ma has reported some studies on the binary PdAg alloy $[83,210]$. For example, one of the most interesting ones, published by Rajkumar et al. [211], presents the results obtained for incorporating Ag by both electroless and electro-plating techniques, after a first $\mathrm{Pd}$ incorporation by electroless plating. These PdAg supported membranes were prepared directly onto a commercial porous Inconel supports of $0.1 \mu \mathrm{m}$ media grade, obtaining $\mathrm{H}_{2}$ selective layers under $10 \mu \mathrm{m}$ thick with complete He retention up to a transmembrane pressure difference of $10^{5} \mathrm{~Pa}$. All membranes were annealed during $24 \mathrm{~h}$ at $550{ }^{\circ} \mathrm{C}$ in $\mathrm{H}_{2}$ atmosphere. They observed that electro-plated Ag exhibited an optimal penetration in the pores of the support, although a non-uniform growth with dendritic morphology was achieved. In contrast, the use of electroless plating for silver incorporation provides a uniform growth without dendritic morphology and a lower penetration into the pores.

The contributions of the research group headed by Laura Cornaglia, based on the use of PdAg membranes prepared by electroless plating, are also widely reported in the literature [201,209,212-214]. One example is the work published by Bosko et al. [202], in which PdAg supported membranes were prepared by sequential electroless plating on tubular stainless-steel supports with thickness ranged from 20 to $26 \mu \mathrm{m}$. The supports were previously modified with both $\alpha-\mathrm{AI}_{2} \mathrm{O}_{3}$ and $\gamma-\mathrm{AI}_{2} \mathrm{O}_{3}$ 
particles by a vacuum assisted-coating method. All membranes were annealed at $500{ }^{\circ} \mathrm{C}$, exhibiting a hydrogen permeability of $3.1 \times 10^{-4} \mathrm{~mol} \cdot \mathrm{m}^{-2} \cdot \mathrm{s}^{-1} \cdot \mathrm{Pa}^{-0.5}$ at $450{ }^{\circ} \mathrm{C}$ and $100 \mathrm{kPa}$ and a $\mathrm{H}_{2} / \mathrm{N}_{2}$ ideal selectivity of around 954 at same conditions. They observed that annealing the membranes at higher temperatures created defects which deteriorated the selective layer, obtaining lower selectivity and higher permeability.

Others works based on electroless-plated PdAg membranes to be highlighted are those of Andreas Goldbach and co-workers. Recently, Zeng et al. [53] reported the use of sequential electroless plating to prepare $\mathrm{H}_{2}$ selective $\mathrm{PdAg}$ membranes on $\mathrm{Al}_{2} \mathrm{O}_{3}$ tubular porous asymmetric supports. They incorporated the palladium prior to the required amount of silver to achieve a final composition of $\mathrm{Pd}_{77} \mathrm{Ag}_{23}$, after a thermal treatment at $500{ }^{\circ} \mathrm{C}$ in the presence of $\mathrm{H}_{2}$ between each deposition. Additionally, intermediate surface activations with $\mathrm{Pd}$ seeds were also carried out. In this way, membranes with a final thickness in the range 2.3-2.5 $\mu \mathrm{m}$ were achieved. Despite the limited thickness of these membranes, authors indicated the need to extend the annealing treatment up to $800 \mathrm{~h}$ maintaining a temperature of $500{ }^{\circ} \mathrm{C}$ under atmospheric $\mathrm{H}_{2}$ pressure. The progress of annealing between palladium and silver was monitored by XRD during the entire process as it is shown in Figure 11, to assess the formation of a homogeneous PdAg alloy. These membranes exhibited a $\mathrm{H}_{2} / \mathrm{N}_{2}$ selectivity between 3770 and 5600, with permeance values ranged from 5.77 to $3.86 \times 10^{-8} \mathrm{~mol} \cdot \mathrm{m}^{-1} \cdot \mathrm{s}^{-1} \cdot \mathrm{Pa}^{-0.5}$, respectively. Similar to other researchers, they also reported the frequent membrane failure during the fabrication process due to the fragility of ceramic supports [89,95].
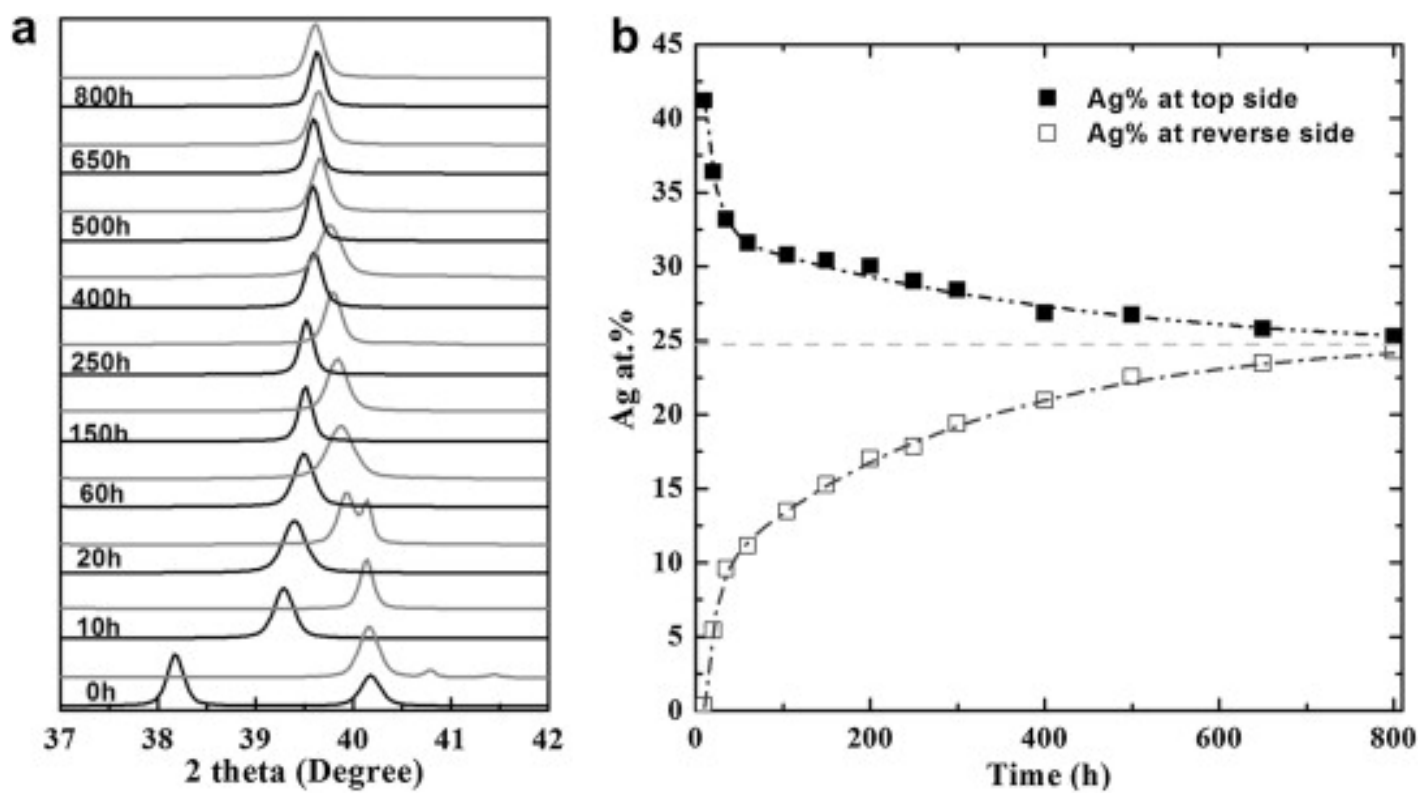

Figure 11. (a) $111 \mathrm{XRD}$ reflections from the top (black) and reverse surface (grey) of a PdAg membrane during alloying at $550{ }^{\circ} \mathrm{C}$ and (b) convergence of the corresponding alloy lattice parameters [53], with permission from (C) Elsevier.

PdAg membranes prepared by Tecnalia innovation centre are also relevant. For instance, Ekain et al. [95] have recently reported a procedure to prepare thin PdAg membranes (thickness of around $3.2 \mu \mathrm{m}$ ) on tubular ceramic supports by using Pd and Ag simultaneous electroless plating during 210-240 min. The final alloy was achieved after annealing at $550{ }^{\circ} \mathrm{C}$ for $2 \mathrm{~h}$, using $\mathrm{N}_{2}$ carrier gas for both heating and cooling rates but a mixture $10 \mathrm{H}_{2}-90 \mathrm{~N}_{2}$ when the annealing temperature has been reached. These membranes exhibit a $\mathrm{H}_{2}$ permeance of $3.10 \times 10^{-6} \mathrm{~mol} \cdot \mathrm{m}^{-2} \cdot \mathrm{s}^{-1} \cdot \mathrm{Pa}$ and ideal selectivity in the range 8000-10,000, calculated for a $\mathrm{H}_{2}$ partial pressure of 1 bar and $400{ }^{\circ} \mathrm{C}$. As other studies, these authors indicate that the use of ceramic supports generates fragile membranes, despite the good quality of 
the Pd-based selective layer. In this case, authors specifically recommended to avoid exceeding a maximum torque value when coupling the membranes into the reactor, usually made in stainless-steel.

\subsubsection{PdCu Membranes}

The use of copper as alloying element of Pd-based membranes not only improves mechanical strength against hydrogen embrittlement, also increases slightly the permeation rate as compared with palladium pure membranes while retaining the permeation capacity in gas mixtures containing sulphur compounds [205]. Moreover, copper is quite cheaper than palladium and thus, the percentage reduction of the last one in the selective layer (optimal composition around $\mathrm{Pd}_{60} \mathrm{Cu}_{40}$ ) reduces its cost. The preparation of $\mathrm{PdCu}$ membranes by electroless plating is usually carried out by sequential incorporation of palladium in first place and the copper, followed by an annealing treatment at high temperature. In this case, stable co-deposition is really difficult due to the different nature of each metal and the order of incorporation is also determined by the galvanic displacement of copper by palladium due to the lower reduction potential of the first one [215].

However, the use of $\mathrm{PdCu}$ alloys with face-centred-cubic metal structure (Figure 12) is restricted to a range of composition due to the drastic fall in $\mathrm{H}_{2}$ permeate when small variations in the $40 \%$ content of $\mathrm{Cu}$ are produced.

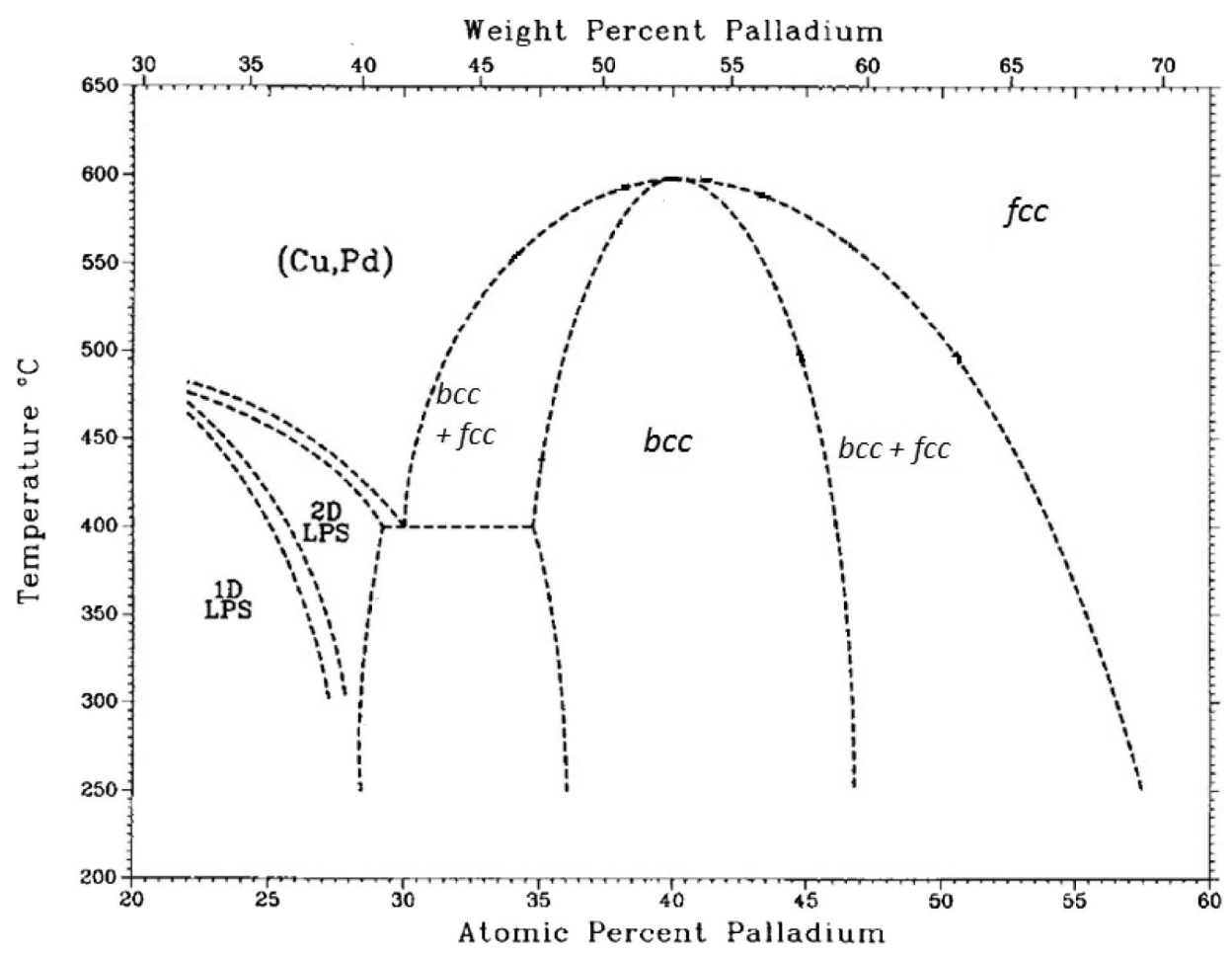

Figure 12. Pd-cu phase diagram [205], with permission from (c Elsevier.

Moreover, sulphur inhibition depended strongly on temperature. Zhao et al. [54] developed PdCu membranes on ceramic supports by using sequential deposition of metals via electroless plating and performed tests to analyse the influence of $\mathrm{H}_{2} \mathrm{~S}$. They revealed that single gas $\mathrm{H}_{2}$ permeation rates were significantly reduced after tests performed with $35 \mathrm{ppm}_{2} \mathrm{~S}$ at $400{ }^{\circ} \mathrm{C}$, although they fully restored the original operation capacity of the membrane after flowing $\mathrm{H}_{2}$ at $500{ }^{\circ} \mathrm{C}$. However, the precedent flow rate obtained for $\mathrm{N}_{2}$ leaks increase noticeably (thus, decreasing $\alpha_{\mathrm{H} 2 / \mathrm{N} 2}$ up to 1194), presumably due to sulphide formation in defect sites at lower temperatures.

The research group headed by Douglas J. Way maintains a wide activity on the study of $\mathrm{PdCu}$ systems for years $[102,181,216,217]$. Among all of them, it can be pointed out the preparation of 
PdCu alloys on tubular porous supports of symmetric $\alpha$-alumina published by Roa et al. [84]. In this work, the incorporation of the $\mathrm{H}_{2}$ selective layer was carried out by sequential electroless plating of both metals, palladium and copper, followed by an annealing treatment at high temperature in flowing $\mathrm{H}_{2}$. Thus, a PdCu membrane with $11 \mu \mathrm{m}$ thick was obtained, exhibiting a $\mathrm{H}_{2}$ permeate flux of $0.8 \mathrm{~mol} \cdot \mathrm{m}^{-2} \cdot \mathrm{s}^{-1}$ at $\mathrm{T}=450{ }^{\circ} \mathrm{C}$ and $\Delta \mathrm{P}=345 \mathrm{kPa}$ with a $\mathrm{H}_{2} / \mathrm{N}_{2}$ ideal separation factor of 1150 .

Similar supported membranes based on electroless deposition of a $\mathrm{Pd}_{60} \mathrm{Cu}_{40}$ alloy layer were prepared by Qiao et al. [123] but using porous stainless-steel modified by the incorporation of a $\mathrm{CeO}_{2}$ as intermediate layer. In this work, copper was incorporated at room temperature on a first Pd layer prepared at $\mathrm{T}=55^{\circ} \mathrm{C}$ and a further annealing treatment at $480{ }^{\circ} \mathrm{C}$ under hydrogen atmosphere. The alloy layer thickness was around $8 \mu \mathrm{m}$, that yielded a hydrogen permeability of $5.92 \times 10^{12} \mathrm{~mol} \cdot \mathrm{m}^{-2} \cdot \mathrm{s}^{-1}$ at $\mathrm{T}=450{ }^{\circ} \mathrm{C}$ (pressure was maintained at $10^{5} \mathrm{~Pa}$ ). No nitrogen permeate was detected at $\Delta \mathrm{P}=10^{5} \mathrm{~Pa}$ and room temperature.

\subsubsection{PdAu Membranes}

The addition of gold in a palladium layer brings out similar benefits to that of copper in Pd-based alloys, mainly attending to sulphur tolerance [91], although the cost of the resulting membranes is higher due to the higher cost of gold respect to that of copper and the need of a higher content in palladium for these types of alloys, usually upper than $80 \%$ [206]. However, the range of compositions in the PdAu that exhibits FCC structure without phase segregation, which ensures greater permeability than pure Pd membranes with diverse alloy formulation, is wider [205]. This fact is very beneficial in the membrane preparation since it is possible to achieve the alloy varying the gold content up to $21 \%$, while maintaining improved permeation and sulphur tolerance. Among these possibilities, a composition target of $\mathrm{Pd}_{90} \mathrm{Au}_{10}$ seems to offer the best properties in the resulting membrane [206].

Attending to the preparation of these membranes, the combination of Pd electroless plating with a consecutive $\mathrm{Au}$ incorporation by galvanic displacement is the procedure widely described in most published works. Thus, Yi Hua Ma and co-workers prepared PdAu membranes that ensure good resistance to sulphur presence in a mixture $54.8 \mathrm{ppm} \mathrm{H}_{2} \mathrm{~S} / \mathrm{H}_{2}$ at temperatures ranged from 350 to $500{ }^{\circ} \mathrm{C}$ [94]. These membranes, prepared on a PSS support, have a gold content around 8-11 wt \% with a total thickness below $15 \mu \mathrm{m}$. PdAu membrane experienced a decline in $\mathrm{H}_{2}$ permeance by $\sim 85 \%$ after the $\mathrm{H}_{2} \mathrm{~S}$ exposure. Despite this, a value of $\sim 65 \%$ of the original permeance could be recovered in pure $\mathrm{H}_{2}$ at the poisoning temperature of $400{ }^{\circ} \mathrm{C}$.

Similar PdAu alloys were also prepared by Tarditi et al. [93], in a $\mathrm{ZrO}_{2}$-modified porous stainless-steel support. Both metals, palladium and gold, were incorporated by sequential electroless deposition: palladium was first deposited at $50{ }^{\circ} \mathrm{C}$ in two steps, while a unique step at $60^{\circ} \mathrm{C}$ was used for incorporating the gold. This process was repeated several times up to obtain a $\mathrm{N}_{2}$ non-permeable membrane at room temperature and $\Delta \mathrm{P}=10^{5} \mathrm{kPa}$ at, obtaining a total thickness of around $10 \mu \mathrm{m}$. Finally, the membranes were annealed at $500{ }^{\circ} \mathrm{C}$ in $\mathrm{H}_{2}$ atmosphere to promote the alloy formation. $\mathrm{A} \mathrm{H}_{2}$ permeation flux of $0.14 \mathrm{~mol} \cdot \mathrm{s}^{-1} \cdot \mathrm{m}^{-2}$ was obtained at $\mathrm{T}=400{ }^{\circ} \mathrm{C}$ and $\Delta \mathrm{P}=100 \mathrm{kPa}$, showing a $\mathrm{H}_{2} / \mathrm{N}_{2}$ ideal selectivity upper than 10,000 . It was also possible to recover $\sim 65 \% \mathrm{H}_{2}$ flux, in a $\mathrm{Pd}_{91} \mathrm{Au}_{9}$ membrane with an initial permeability of $1.1 \times 10^{-8} \mathrm{~mol} \cdot \mathrm{m}^{-1} \cdot \mathrm{s}^{-1} \cdot \mathrm{Pa}^{-0.5}$ at $400{ }^{\circ} \mathrm{C}$ after $24 \mathrm{~h}$ exposure of $54.8 \mathrm{ppm}_{2} \mathrm{~S}$ in $\mathrm{H}_{2}$ [201].

\subsubsection{Others Binary Alloys}

The previously mentioned binary alloys based on palladium, silver, copper and gold are the most common alternatives used by researchers for $\mathrm{H}_{2}$ selective separation. However, it is also possible to find the combination of palladium with other metals to achieve additional advantages in cost-reduction or permeation behaviour. In this context, the principal limitation to explore new alloys it is the chance to incorporate the metals by electroless plating, being preferred to use the magnetron sputtering [61,199]. However, as we previously detailed, the use of electroless plating for $\mathrm{H}_{2}$ selective membranes preparation is recommended in terms of cost efficiency [33]. In this context, the use of nickel $[148,218]$ 
or platinum $[85,187]$ to prepare Pd-based alloys by electroless plating has been explored. Pd-Ni alloy supported membranes show long-term thermal stability at $300^{\circ} \mathrm{C}$ under hydrogen permeation. An example of this alloy can be found in the work published $\mathrm{Lu}$ et al. in which $\mathrm{Pd}$ and $\mathrm{Ni}$ were consecutively incorporated by ELP on a capillary $\alpha-\mathrm{Al}_{2} \mathrm{O}_{3}$ substrate [218]. The PdNi selective layer thickness is $\sim 7 \mu \mathrm{m}$ and shows a hydrogen permeance of $2.74 \times 10^{-3} \mathrm{~mol} \cdot \mathrm{s}^{-1} \cdot \mathrm{m}^{-2} \cdot \mathrm{Pa}^{-0.5}$, close to that obtained for a similar supported membrane of pure palladium. However, the manuscript does not mention the particular alloy composition achieved. In contrast to PdNi alloy, PdRu and PdPt [187] alloys showed long-term thermal stability at high temperatures. Membranes based on a PdRu thin film are prepared by co-deposition with really low contents on ruthenium $(<2 \mathrm{wt} \%)$ [193], while the $\mathrm{PdPt}$ membranes are formed by alternating layers of $\mathrm{Pd}$ and $\mathrm{Pt}$ [85] with a final platinum load of around $25 \mathrm{wt} \%$. El Hawa et al. prepared these types of alloys on modified porous stainless-steel with yttria-stabilized zirconia [187], reaching an average thickness of $6 \mu \mathrm{m}$. The $\mathrm{H}_{2}$ permeance achieved at $550{ }^{\circ} \mathrm{C}$ for membranes based on PdRu and PdPt alloys were $2.1 \times 10^{-3} \mathrm{~mol} \cdot \mathrm{s}^{-1} \cdot \mathrm{m}^{-2} \cdot \mathrm{Pa}^{-0.5}$ and $1.39 \times 10^{-3} \mathrm{~mol} \cdot \mathrm{s}^{-1} \mathrm{~m}^{-2} \cdot \mathrm{Pa}^{-0.5}$, respectively.

\subsection{Ternary Alloys}

The formulation of ternary alloys has been also considered to combine simultaneously the improvements of each constituent [74]. However, published researches about preparation of multicomponent alloys by electroless plating is still scarce, being initiated only some years ago. First works suggest that particular compositions seems to reach an additional improvement on the membrane properties as compared to binary alloys, in terms of increasing hydrogen permeability and/or chemical resistance [56]. Alloying Pd simultaneously with two or more other metals (i.e., $\mathrm{Ag}$, $\mathrm{Cu}$, or $\mathrm{Au}$ ) it is possible to improve not only the membrane permeability but also the mechanical and chemical resistances to sulphur poisons at the same time [41,201]. Additionally, the use of cheaper materials (i.e., Ag or $\mathrm{Cu}$ ) in these formulations reduces the membrane cost [219-222]. On the other hand, copper and gold present higher melting points than silver, although lightly lower permeability of their binary alloys with palladium. Hence adding these metals on PdAg alloys to conform a ternary alloy could increase the thermal stability of the membrane $[41,56,223]$.

Generally, the procedure to prepare these ternary alloys is similar to the previously described for obtaining binary alloys, including co-deposition or sequential electroless plating following by an annealing process at high temperature to finally obtain free-defects, homogeneous and continuous layers [74]. For instance, Tarditi et al. [224] presented the fabrication procedure of a PdAgCu ternary alloy on stainless-steel supports by consecutive deposition of palladium, silver and copper, in this order. They evidenced a hydrogen permeation flux of the ternary alloy about $70 \%$ higher than in case of considering a binary PdCu alloyed membrane with similar copper loading and average thickness of the selective layer. The annealing process for these membranes consists of a thermal treatment at $500{ }^{\circ} \mathrm{C}$ for $162 \mathrm{~h}$, to obtain the FCC phase of the ternary alloy by XRD after the treatment. Figure 13 shows the evolution of the alloy during the annealing process.

In this work, no uniform distribution of metals was achieved, increasing silver content as going towards top surface in radial direction. Authors explain this effect by the lower surface tension of silver compared with this value in both palladium and copper, obtaining a surface segregation of silver after the annealing treatment [55].

Other researchers add gold to a previously prepared $\mathrm{PdAg}$ membrane to increase the resistance against $\mathrm{H}_{2} \mathrm{~S}$ poison, in a similar way as using $\mathrm{PdCu}$ or PdAu binary alloys but with higher permeabilities derived from the presence of silver. For instance, Melendez et al. has lately published the preparation and testing of ternary $\mathrm{PdAgAu}$ alloys by incorporation of gold over a previously electroless plated $\mathrm{PdAg}$ membrane (using co-deposition of metals) on an asymmetric tubular $\mathrm{Al}_{2} \mathrm{O}_{3}$ support, with a thickness of $2.71 \mu \mathrm{m}$ and final composition near to $\mathrm{Pd}_{91.7} \mathrm{Ag}_{4.8} \mathrm{Au}_{3.5}$ [41]. Prior to gold incorporation, the Pd-Ag layer was annealed at $550^{\circ} \mathrm{C}$ for $4 \mathrm{~h}$ and the process was repeated again after incorporating gold. This membrane exhibited a $\mathrm{H}_{2}$ permeance of $4.71 \times 10^{-3} \mathrm{~mol} \cdot \mathrm{s}^{-1} \cdot \mathrm{m}^{-2} \cdot \mathrm{Pa}^{-0.5}$ at 
$600{ }^{\circ} \mathrm{C}$. The authors affirm that the $\mathrm{H}_{2} / \mathrm{N}_{2}$ ideal separation factor achieved with the ternary $\mathrm{PdAgAu}$ membrane was maintained relatively high after $\mathrm{H}_{2} \mathrm{~S}$ exposure, in comparison with other binary $\mathrm{PdAg}$ membranes taken as reference. In fact, a $\mathrm{Pd}_{96.1} \mathrm{Ag}_{3.9}$ membrane suffered a decrease in hydrogen selectivity from 1308 to 18 after exposure to $9 \mathrm{ppm} \mathrm{H}_{2} \mathrm{~S}$ for $15.25 \mathrm{~h}$. However, the selectivity of a ternary alloy composition with composition like that of previously described, $\mathrm{Pd}_{91.5} \mathrm{Ag}_{4.7} \mathrm{Au}_{3.8}$, experienced a lower decrease in hydrogen selectivity, from 4115 to 800 after $9 \mathrm{ppm}$ of $\mathrm{H}_{2} \mathrm{~S}$ for $12.5 \mathrm{~h}$. Moreover, ternary alloy membranes recovered original permeation rates in an $85 \%$ after sulphur exposure, whereas the hydrogen flux of PdAg membranes maintained below detectable values.
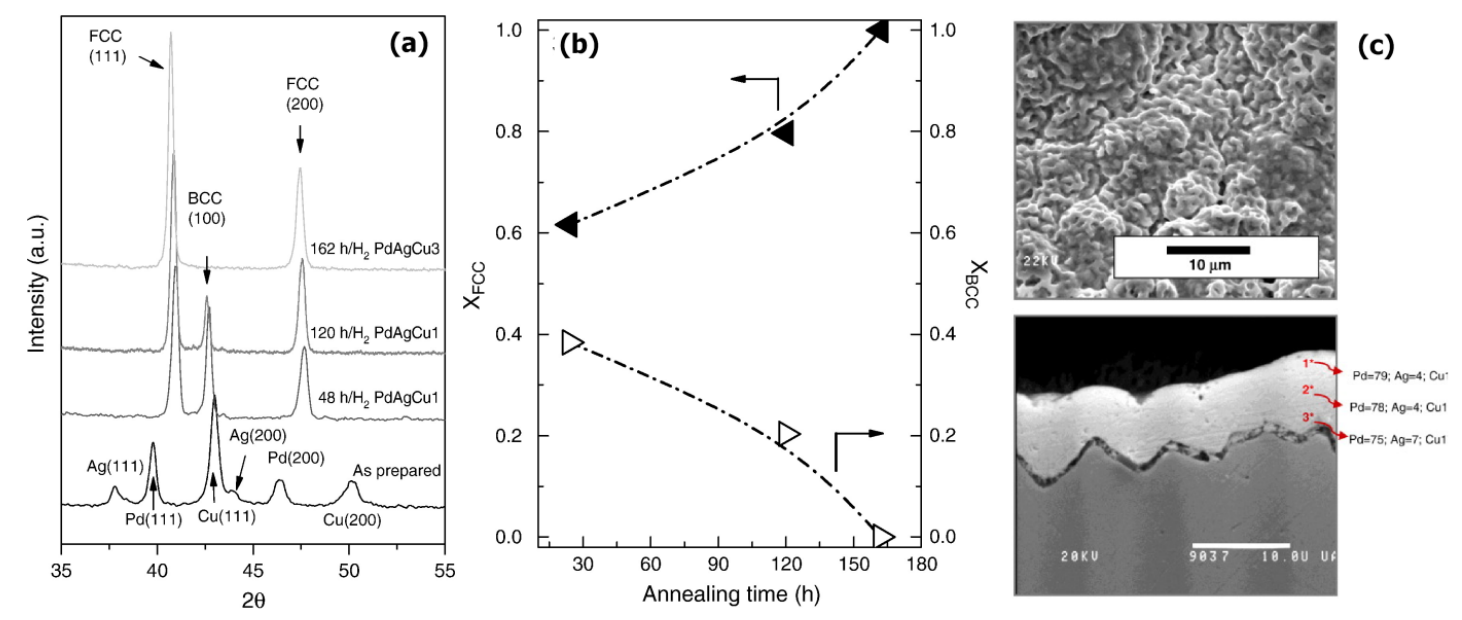

Figure 13. Ternary PdAgCu alloy formation: (a) XRD patterns after annealing up to $500{ }^{\circ} \mathrm{C}_{\text {in }} \mathrm{H}_{2}$ at different times, (b) Microstructure evolution with annealing time and (c) SEM images after annealing of both top surface and cross-section [224], with permission from (C) Elsevier.

Membranes formed by the alloy PdAuCu were also prepared by Tarditi et al. onto PSS disks with sequential electroless deposition of each metal [200]. First, the supports were cleaned and oxidized before incorporating a $\mathrm{ZrO}_{2}$ intermediate layer by using a vacuum-assisted dip-coating method. Palladium was deposited onto this modified support in two steps of $60 \mathrm{~min}$, following by the incorporation of gold. Later, the membrane was rinsed and dried at $120^{\circ} \mathrm{C}$ for $12 \mathrm{~h}$ prior to be activated again by conventional sensitization-activation process with $\mathrm{SnCl}_{2}-\mathrm{PdCl}_{2}$ solutions to allow for copper deposition on the top layer. Finally, in order to achieve an alloy with homogeneous composition, the membrane was annealed at $500{ }^{\circ} \mathrm{C}$ in $\mathrm{H}_{2}$ atmospheric pressure. After using this synthesis procedure, the best membrane was reached with $14 \mu \mathrm{m}$ in thickness of the alloy composition $\mathrm{Pd}_{69} \mathrm{Au}_{17} \mathrm{Cu}_{14}$, obtaining a hydrogen permeance of $8.7 \times 10^{-9} \mathrm{~mol} \cdot \mathrm{s}^{-1} \cdot \mathrm{m}^{-1} \cdot \mathrm{Pa}^{-0.5}$ at $400{ }^{\circ} \mathrm{C}$ and $50 \mathrm{kPa}$. The permeability value taken as reference in clean conditions were reduced around $55 \%$ after exposure to $100 \mathrm{ppm} \mathrm{H}_{2} \mathrm{~S} / \mathrm{H}_{2}$ at $400{ }^{\circ} \mathrm{C}$ for $24 \mathrm{~h}$. However, authors affirmed that it was possible to recover around the $80 \%$ of the original permeation capacity of the membrane after testing with pure $\mathrm{H}_{2}$ at $400{ }^{\circ} \mathrm{C}$.

Table 4 summarizes the most relevant information about Pd-alloy membranes detailed in this section, including information about metal incorporation, final thickness, alloy composition and annealing conditions, as well as used support and main permeation properties. 
Table 4. Recent advances on preparation of Pd-based alloys.

\begin{tabular}{|c|c|c|c|c|c|c|c|c|c|c|c|c|}
\hline \multirow{2}{*}{ Alloy Type } & \multirow{2}{*}{$\begin{array}{c}\text { Alloy } \\
\text { Composition }\end{array}$} & \multirow{2}{*}{$\begin{array}{l}\text { ELP Metal } \\
\text { Incorporation }\end{array}$} & \multirow{2}{*}{ Support } & \multirow{2}{*}{$\begin{array}{c}\text { Support } \\
\text { Modification }\end{array}$} & \multirow{2}{*}{$\begin{array}{l}\text { Tselective } \\
\text { Layer (m) }\end{array}$} & \multirow{2}{*}{ Annealing } & \multicolumn{2}{|c|}{$\begin{array}{l}\text { Permeation } \\
\text { Conditions }\end{array}$} & \multirow{2}{*}{$\begin{array}{c}\text { Permeation } \\
\text { Capacity }\end{array}$} & \multirow{2}{*}{$\begin{array}{l}\mathrm{H}_{2} \text { Separation } \\
\text { Factor }\end{array}$} & \multirow{2}{*}{$\begin{array}{c}\text { Sulfur } \\
\text { Tolerance }\end{array}$} & \multirow{2}{*}{ Ref } \\
\hline & & & & & & & $\mathrm{T}\left({ }^{\circ} \mathrm{C}\right)$ & $\mathrm{P}(\mathrm{kPa})$ & & & & \\
\hline Binary & $\mathrm{Pd}_{75} \mathrm{Ag}_{25}$ & Sequential & Inconel & 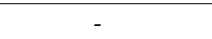 & 10.0 & $500^{\circ} \mathrm{C}, 24 \mathrm{~h}$ & $250-500$ & 100 & & $60-436$ & - & [211] \\
\hline Binary & $\mathrm{Pd}_{75} \mathrm{Ag}_{25}$ & Sequential & PSS & $\alpha-\mathrm{Al}_{2} \mathrm{O}_{3} / \gamma-\mathrm{Al}_{2} \mathrm{O}_{4}$ & $20.0-26.0$ & $500^{\circ} \mathrm{C}$ & 450 & 100 & $3.10 \times 10^{-4(a)}$ & 954 & - & [202] \\
\hline Binary & $\mathrm{Pd}_{77} \mathrm{Ag}_{23}$ & Sequential & $\alpha-\mathrm{Al}_{2} \mathrm{O}_{3} / \gamma-\mathrm{Al}_{2} \mathrm{O}_{3}$ & - & $2.3-2.5$ & $500^{\circ} \mathrm{C}, 800 \mathrm{~h}$ in $\mathrm{H}_{2}$ & 500 & 100 & $1.61-1.57 \times 10^{-2(a)}$ & $3770-5600$ & - & [53] \\
\hline Binary & $\mathrm{Pd}_{77} \mathrm{Ag}_{23}$ & Co-deposition & $\mathrm{Al}_{2} \mathrm{O}_{3}$ & - & 3.2 & $500^{\circ} \mathrm{C}, 2 \mathrm{~h}$ in $\mathrm{N}_{2}$ & 400 & 100 & $3.10 \times 10^{-6(\mathrm{a})}$ & $8000-10,000$ & - & [95] \\
\hline Binary & PdAg & Co-deposition & Hast X & $\mathrm{YSZ}-\mathrm{Al}_{2} \mathrm{O}_{3}$ & $4.0-5.0$ & n.a. & $4-600$ & 100 & $100.00 \times 10^{-8(b)}$ & $>200,000$ & - & [192] \\
\hline Binary & $\mathrm{Pd}_{81} \mathrm{Cu}_{19}$ & Sequential & $\mathrm{Al}_{2} \mathrm{O}_{3}$ & - & 5.0 & $500^{\circ} \mathrm{C}, 48 \mathrm{~h}$ in $\mathrm{N}_{2}$ & 400 & 100 & $1.20 \times 10^{-3(\mathrm{a})}$ & 1194 & Yes (35 ppm) & [54] \\
\hline Binary & $\mathrm{Pd}_{60} \mathrm{Cu}_{40}$ & Sequential & $\alpha-\mathrm{Al}_{2} \mathrm{O}_{3} / \gamma-\mathrm{Al}_{2} \mathrm{O}_{3}$ & - & 11.0 & $\mathrm{H}_{2}$ atmosphere & 450 & 345 & $0.80^{(b)}$ & 1150 & Yes & [84] \\
\hline Binary & $\mathrm{Pd}_{62} \mathrm{Cu}_{38}$ & Sequential & PSS & $\mathrm{CeO}_{2}$ & 8.0 & $480^{\circ} \mathrm{C}, 6 \mathrm{~h}$ in $\mathrm{H}_{2}$ & 450 & 100 & $74.00^{\text {(a) }}$ & 2369 & Yes & [123] \\
\hline Binary & $\mathrm{Pd}_{90} \mathrm{Au}_{10}$ & $\begin{array}{c}\text { Sequential, } \\
\text { galvanic } \\
\text { displacement }\end{array}$ & PSS & $\begin{array}{l}\text { Oxidation in air } \\
\left(700^{\circ} \mathrm{C}, 12 \mathrm{~h}\right)\end{array}$ & $<15.0$ & $500^{\circ} \mathrm{C}, 48 \mathrm{~h}$ in $\mathrm{H}_{2}$ & $3-500$ & 100 & $9.35 \times 10^{-4(a)}$ & $\infty$ & Yes (54.8 ppm) & [94] \\
\hline Binary & $\mathrm{Pd}_{91} \mathrm{Au}_{9}$ & $\begin{array}{l}\text { Sequential, } \\
\text { galvanic } \\
\text { displacement }\end{array}$ & PSS & $\mathrm{ZrO}_{2}$ & 10.0 & $500{ }^{\circ} \mathrm{C}$ in $\mathrm{H}_{2}$ & 400 & 100 & $1.10 \times 10^{-3(a)}$ & $>10,000$ & Yes (54.8 ppm) & [93] \\
\hline Binary & $\mathrm{Pd}_{x} \mathrm{Ni}_{\mathrm{y}}$ & Sequential & $\alpha-\mathrm{Al}_{2} \mathrm{O}_{3}$ & - & 7.0 & n.a. & 500 & $20-120$ & $2.74 \times 10^{-3 \text { (a) }}$ & 640 & - & [218] \\
\hline Binary & $\mathrm{Pd}_{98} \mathrm{Ru}_{2}$ & Co-deposition & PSS & YSZ & 6.0 & n.a. & 550 & n.a. & $2.10 \times 10^{-3(\mathrm{a})}$ & 1860 & - & [187] \\
\hline Binary & $\mathrm{P}_{75} \mathrm{Pt}_{25}$ & Co-deposition & PSS & YSZ & 6.0 & n.a. & 550 & n.a. & $1.39 \times 10^{-4(a)}$ & 1590 & - & [187] \\
\hline Ternary & $\mathrm{Pd}_{x} \mathrm{Ag}_{\mathrm{y}} \mathrm{Cu}_{\mathrm{z}}$ & Sequential & PSS & $\begin{array}{l}\text { Oxidation in air } \\
\left(500^{\circ} \mathrm{C}, 12 \mathrm{~h}\right)\end{array}$ & $24.0-27.0$ & $500^{\circ} \mathrm{C}, 162 \mathrm{~h}$ & $3-450$ & $10-100$ & $1.70-2.10 \times 10^{-4(a)}$ & $300-10,000$ & n.a. & [224] \\
\hline Ternary & $\mathrm{Pd}_{91.7} \mathrm{Ag}_{4.8} \mathrm{Au}_{3.5}$ & $\begin{array}{l}\text { Co-deposition/ } \\
\text { Sequential }\end{array}$ & $\alpha-\mathrm{Al}_{2} \mathrm{O}_{3} / \gamma-\mathrm{Al}_{2} \mathrm{O}_{3}$ & - & 2.7 & $550^{\circ} \mathrm{C}, 8 \mathrm{~h}$ & 600 & n.a. & $4.71 \times 10^{-3(a)}$ & n.a. & Yes (9 ppm) & [41] \\
\hline Ternary & $\mathrm{Pd}_{91.5} \mathrm{Ag}_{4.7} \mathrm{Au}_{3.8}$ & $\begin{array}{l}\text { Co-deposition/ } \\
\text { Sequential }\end{array}$ & $\alpha-\mathrm{Al}_{2} \mathrm{O}_{3} / \gamma-\mathrm{Al}_{2} \mathrm{O}_{4}$ & - & 2.7 & $550^{\circ} \mathrm{C}, 8 \mathrm{~h}$ & 600 & n.a. & $2.32 \times 10^{-3}(\mathrm{a})$ & $4115-793$ & Yes (9 ppm) & [41] \\
\hline Ternary & $\mathrm{Pd}_{69} \mathrm{Au}_{17} \mathrm{Cu}_{14}$ & Sequential & PSS & $\mathrm{ZrO}_{2}$ & 14.0 & $500^{\circ} \mathrm{C}$ in $\mathrm{H}_{2}$ & 400 & 50 & $6.20 \times 10^{-4(a)}$ & n.a. & Yes (100 ppm) & [200] \\
\hline
\end{tabular}

Permeation capacity: (a) Permeance $\left(\mathrm{mol} \cdot \mathrm{m}^{-2} \cdot \mathrm{s}^{-1} \cdot \mathrm{Pa}^{-0.5}\right)$ or ${ }^{(b)}$ Permeation flux $\left(\mathrm{mol} \cdot \mathrm{m}^{-2} \cdot \mathrm{s}^{-1}\right)$. n.a.: non available. 


\section{Concluding Remarks and Future Perspectives}

This concluding section offers a perspective on current research in Pd-based membranes for $\mathrm{H}_{2}$ production processes, focused on dense supported membranes prepared by electroless plating, as well as future challenges need to be addressed for the real implementation of this technology in the industry. Supported membranes are preferred to reduce the thickness of the hydrogen selective layer and, consequently, the cost of the process. Moreover, the hydrogen permeation values, as well as thermal and mechanical resistances of the supported membranes, are increased comparing to unsupported membranes. Among the wide variety of materials that can be used as support, porous ceramic and 316L stainless-steel are the prevalent ones in recent researches. Particularly, it is expected that metal supports will prevail for industrial applications, above all at high temperatures, in which most devices are made in stainless-steel. Up to now, suitable ceramic-steel fitting for long operation times is not guaranteed. In this context, considering the wide pore size distribution and the high roughness of the metallic stainless-steel supports, it is usually required to modify its external surface with the aim to facilitate the incorporation of a thin selective palladium layer. One of the best alternatives is the incorporation of an intermediate layer, which simultaneously reduces the average pore size and roughness of the support top surface and avoids inter-diffusion problems. The main features to be considered to select the most suitable material used as interlayer are thermal compatibility between each component (support, barrier and selective layer) and membrane cost. Many of these intermediate layers are formed by metal oxides (i.e., $\mathrm{CeO}_{2}, \mathrm{ZrO}_{2}$ or $\mathrm{SiO}_{2}$ based materials) incorporated by dip-coating techniques. However, nowadays it has not been reached any prevalent solution and additional research in this issue is still required. Future directions are aimed to explore new materials or the combination of some of the already studied to achieve improved properties for the intermediate layer.

Attending to the selective layer deposition, three main objectives are being followed: (i) reduction of the selective layer thickness (target: permeability increase and membrane cost reduction while ensuring complete absence of defects), (ii) reduction in the number of rejected membranes (target: to control the overall cost of the fabrication process) and (iii) preparation of Pd-based alloys (target: to improve permeation properties in real operation conditions, i.e., thermal cycles or presence of sulphur). To reach these objectives and to make easier the metal incorporation around the pores, several modifications of the conventional electroless plating method have been proposed in the last years, including the use of osmotic effect, vacuum or feeding both metal source and reducing agent from opposite sides of the support (ELP-PP). Finally, the use of binary Pd-based alloys to avoid hydrogen embrittlement of pure palladium or sulphur poisoning is also frequent, mainly adding specific amounts of silver, copper or gold. In the last years, an increasing number of alloy constituents is observed, trying to obtain membranes that gather particular benefits of different metals saving costs, i.e., hydrogen perm-selectivity of bulk palladium, increase of permeation rate provided by silver or sulphur resistance given by copper and gold. Here, it is very important to indicate the current limitation of possible metal constituents that can be incorporated by electroless plating and reproducibility between published results in terms of alloy composition, annealing conditions and hydrogen permeability. Thus, future trends go towards the combination of the most promising modifications for electroless plating with additional exploration of new Pd-based alloys with better properties in real industrial operation conditions (i.e., thermal cycling, presence of sulphur compounds, low hydrogen concentrations, etc.).

Acknowledgments: First, authors want to acknowledge the invitation to prepare the present review focused on the current state of the art in Pd membranes preparation by electroless plating. The financial support achieved through competitive projects ENE-2007-66959 and CTQ2010-21102-C02-01 during last years has been very important to become expertise in this field. We also thank the European Commission for the contract of David Martinez-Diaz through the Young Employment Initiative program. Lastly, we also acknowledge to the publishers of referenced figures for allowing the reproduction here.

Conflicts of Interest: The authors declare no conflict of interest. 


\section{References}

1. Grunewald, N.; Klasen, S.; Martínez-Zarzoso, I.; Muris, C. The Trade-off between Income Inequality and Carbon Dioxide Emissions. Ecol. Econ. 2017, 142, 249-256. [CrossRef]

2. Henriques, I.; Sadorsky, P. Investor implications of divesting from fossil fuels. Glob. Financ. J. 2017. [CrossRef]

3. Furlan, C.; Mortarino, C. Forecasting the impact of renewable energies in competition with non-renewable sources. Renew. Sustain. Energy Rev. 2018, 81, 1879-1886. [CrossRef]

4. Hanley, E.S.; Deane, J.P.; Gallachóir, B.P.Ó. The role of hydrogen in low carbon energy futures-A review of existing perspectives. Renew. Sustain. Energy Rev. 2017. [CrossRef]

5. Muradov, N. Low to near-zero $\mathrm{CO}_{2}$ production of hydrogen from fossil fuels: Status and perspectives. Int. J. Hydrog. Energy 2017, 42, 14058-14088. [CrossRef]

6. Abbasi, T.; Abbasi, S.A. "Renewable" hydrogen: Prospects and challenges. Renew. Sustain. Energy Rev. 2011, 15, 3034-3040. [CrossRef]

7. Vivas, F.J.; de las Heras, A.; Segura, F.; Andújar, J.M. A review of energy management strategies for renewable hybrid energy systems with hydrogen backup. Renew. Sustain. Energy Rev. 2018, 82, 126-155. [CrossRef]

8. Valente, A.; Iribarren, D.; Dufour, J. Harmonised life-cycle global warming impact of renewable hydrogen. J. Clean. Prod. 2017, 149, 762-772. [CrossRef]

9. Li, R. Latest progress in hydrogen production from solar water splitting via photocatalysis, photoelectrochemical and photovoltaic-photoelectrochemical solutions. Chin. J. Catal. 2017, 38, 5-12. [CrossRef]

10. Moniruddin, M.; Ilyassov, B.; Zhao, X.; Smith, E.; Serikov, T.; Ibrayev, N.; Asmatulu, R.; Nuraje, N. Recent progress on perovskite materials in photovoltaic and water splitting applications. Mater. Today Energy 2017. [CrossRef]

11. Rau, F.; Herrmann, A.; Krause, H.; Fino, D.; Trimis, D. Production of hydrogen by autothermal reforming of biogas. Energy Procedia 2017, 120, 294-301. [CrossRef]

12. Sengodan, S.; Lan, R.; Humphreys, J.; Du, D.; Xu, W.; Wang, H.; Tao, S. Advances in reforming and partial oxidation of hydrocarbons for hydrogen production and fuel cell applications. Renew. Sustain. Energy Rev. 2018, 82, 761-780. [CrossRef]

13. Li, X.; Li, A.; Lim, C.J.; Grace, J.R. Hydrogen permeation through Pd-based composite membranes: Effects of porous substrate, diffusion barrier and sweep gas. J. Membr. Sci. 2016, 499, 143-155. [CrossRef]

14. Coutanceau, C.; Baranton, S.; Audichon, T. Chapter 2-Hydrogen Production from Thermal Reforming BT-Hydrogen Electrochemical Production. In Hydrogen Energy Fuel Cells Primary; Academic Press: Cambridge, MA, USA, 2018; pp. 7-15.

15. Hossain, M.A.; Jewaratnam, J.; Ganesan, P. Prospect of hydrogen production from oil palm biomass by thermochemical process-A review. Int. J. Hydrog. Energy 2016, 41, 16637-16655. [CrossRef]

16. Devasahayam, S.; Strezov, V. Thermal Decomposition of Magnesium Carbonate with Biomass and Plastic Wastes for Simultaneous Production of Hydrogen and Carbon Avoidance. J. Clean. Prod. 2018, 174, 1089-1095. [CrossRef]

17. Tosti, S.; Cavezza, C.; Fabbricino, M.; Pontoni, L.; Palma, V.; Ruocco, C. Production of hydrogen in a Pd-membrane reactor via catalytic reforming of olive mill wastewater. Chem. Eng. J. 2015, 275, 366-373. [CrossRef]

18. Tian, T.; Li, Q.; He, R.; Tan, Z.; Zhang, Y. Effects of biochemical composition on hydrogen production by biomass gasification. Int. J. Hydrog. Energy 2017, 42, 19723-19732. [CrossRef]

19. Zahedi, S.; Solera, R.; García-Morales, J.L.; Sales, D. Effect of the addition of glycerol on hydrogen production from industrial municipal solid waste. Fuel 2016, 180, 343-347. [CrossRef]

20. Murugan, A.; Brown, A.S. Review of purity analysis methods for performing quality assurance of fuel cell hydrogen. Int. J. Hydrog. Energy 2015, 40, 4219-4233. [CrossRef]

21. Pinacci, P.; Basile, A. 3-Palladium-based composite membranes for hydrogen separation in membrane reactors. In Handbook of Membrane Reactors; Elsevier: Amsterdam, The Netherlands, 2013; pp. 149-182.

22. Di Marcoberardino, G.; Binotti, M.; Manzolini, G.; Viviente, J.L.; Arratibel, A.; Roses, L.; Gallucci, F. Achievements of European projects on membrane reactor for hydrogen production. J. Clean. Prod. 2017, 161, 1442-1450. [CrossRef]

23. Yin, H.; Yip, A.C.K. A Review on the Production and Purification of Biomass-Derived Hydrogen Using Emerging Membrane Technologies. Catalysts 2017, 7, 297. [CrossRef] 
24. Dittmeyer, R.; Boeltken, T.; Piermartini, P.; Selinsek, M.; Loewert, M.; Dallmann, F.; Kreuder, H.; Cholewa, M.; Wunsch, A.; Belimov, M.; et al. Micro and micro membrane reactors for advanced applications in chemical energy conversion. Curr. Opin. Chem. Eng. 2017, 17, 108-125. [CrossRef]

25. Al-Mufachi, N.A.; Rees, N.V.; Steinberger-Wilkens, R. Hydrogen selective membranes: A review of palladium-based dense metal membranes. Renew. Sustain. Energy Rev. 2015, 47, 540-551. [CrossRef]

26. Deveau, N.D.; Ma, Y.H.; Datta, R. Beyond Sieverts' law: A comprehensive microkinetic model of hydrogen permeation in dense metal membranes. J. Membr. Sci. 2013, 437, 298-311. [CrossRef]

27. Adhikari, S.; Fernando, S. Hydrogen Membrane Separation Techniques. Ind. Eng. Chem. Res. 2006, 45, 875-881. [CrossRef]

28. Rahimpour, M.R.; Samimi, F.; Babapoor, A.; Tohidian, T.; Mohebi, S. Palladium membranes applications in reaction systems for hydrogen separation and purification: A review. Chem. Eng. Process. Process Intensif. 2017, 121, 24-49. [CrossRef]

29. Deville, H.; Troost, L. Sur la permeabilitè du fer a haute temperature. Comptes Rendus 1863, 57, $965-967$.

30. Deville, H. Note sur le passage des gaz au travers des corps solides homogènes. Comptes Rendus 1864, 59, 102.

31. Thomas, G. On the absorption and dialytic separation of gases by colloid septa. Philos. Trans. R. Soc. A 1866, 156, 399-439.

32. Dunbar, Z.W.; Lee, I.C. Effects of elevated temperatures and contaminated hydrogen gas mixtures on novel ultrathin palladium composite membranes. Int. J. Hydrog. Energy 2017, 42, 29310-29319. [CrossRef]

33. Yun, S.; Oyama, S.T. Correlations in palladium membranes for hydrogen separation: A review. J. Membr. Sci. 2011, 375, 28-45. [CrossRef]

34. Helmi, A.; Gallucci, F.; van Sint Annaland, M. Resource scarcity in palladium membrane applications for carbon capture in integrated gasification combined cycle units. Int. J. Hydrog. Energy 2014, 39, 10498-10506. [CrossRef]

35. Jayaraman, V.; Lin, Y.S. Synthesis and hydrogen permeation properties of ultrathin palladium-silver alloy membranes. J. Membr. Sci. 1995, 104, 251-262. [CrossRef]

36. Yun, S.; Ko, J.H.; Oyama, S.T. Ultrathin palladium membranes prepared by a novel electric field assisted activation. J. Membr. Sci. 2011, 369, 482-489. [CrossRef]

37. Maneerung, T.; Hidajat, K.; Kawi, S. Ultra-thin $(<1 \mu \mathrm{m})$ internally-coated Pd-Ag alloy hollow fiber membrane with superior thermal stability and durability for high temperature $\mathrm{H}_{2}$ separation. J. Membr. Sci. 2014, 452, 127-142. [CrossRef]

38. Melendez, J.; Fernandez, E.; Gallucci, F.; van Annaland, M.; Arias, P.L.; Tanaka, D.A.P. Preparation and characterization of ceramic supported ultra-thin $(\sim 1 \mu \mathrm{m})$ Pd-Ag membranes. J. Membr. Sci. 2017, 528, $12-23$. [CrossRef]

39. Feitosa, J.L.C.S.; da Cruz, A.G.B.; Souza, A.C.; Duda, F.P. Stress effects on hydrogen permeation through tubular multilayer membranes: Modeling and simulation. Int. J. Hydrog. Energy 2015, 40, 17031-17037. [CrossRef]

40. Dittmar, B.; Behrens, A.; Schödel, N.; Rüttinger, M.; Franco, T.; Straczewski, G.; Dittmeyer, R. Methane steam reforming operation and thermal stability of new porous metal supported tubular palladium composite membranes. Int. J. Hydrog. Energy 2013, 38, 8759-8771. [CrossRef]

41. Melendez, J.; de Nooijer, N.; Coenen, K.; Fernandez, E.; Viviente, J.L.; van Sint Annaland, M.; Arias, P.L.; Tanaka, D.A.P.; Gallucci, F. Effect of Au addition on hydrogen permeation and the resistance to $\mathrm{H}_{2} \mathrm{~S}$ on Pd-Ag alloy membranes. J. Membr. Sci. 2017, 542, 329-341. [CrossRef]

42. El Hawa, H.W.A.; Lundin, S.-T.B.; Paglieri, S.N.; Harale, A.; Way, J.D. The influence of heat treatment on the thermal stability of Pd composite membranes. J. Membr. Sci. 2015, 494, 113-120. [CrossRef]

43. Lundin, S.-T.B.; Patki, N.S.; Fuerst, T.F.; Wolden, C.A.; Way, J.D. Inhibition of hydrogen flux in palladium membranes by pressure-induced restructuring of the membrane surface. J. Membr. Sci. 2017, 535, 70-78. [CrossRef]

44. Livshits, A.I. The hydrogen transport through the metal alloy membranes with a spatial variation of the alloy composition: Potential diffusion and enhanced permeation. Int. J. Hydrog. Energy 2017, 42, 13111-13119. [CrossRef] 
45. Fernandez, E.; Helmi, A.; Medrano, J.A.; Coenen, K.; Arratibel, A.; Melendez, J.; de Nooijer, N.C.A.; Spallina, V.; Viviente, J.L.; Zuñiga, J.; et al. Palladium based membranes and membrane reactors for hydrogen production and purification: An overview of research activities at Tecnalia and TU/e. Int. J. Hydrog. Energy 2017, 42, 13763-13776. [CrossRef]

46. Guo, Y.; Wu, H.; Fan, X.; Zhou, L.; Chen, Q. Palladium composite membrane fabricated on rough porous alumina tube without intermediate layer for hydrogen separation. Int. J. Hydrog. Energy 2017, 42, 9958-9965. [CrossRef]

47. Nayebossadri, S.; Fletcher, S.; Speight, J.D.; Book, D. Hydrogen permeation through porous stainless steel for palladium-based composite porous membranes. J. Membr. Sci. 2016, 515, 22-28. [CrossRef]

48. Itoh, N.; Suga, E.; Sato, T. Composite palladium membrane prepared by introducing metallic glue and its high durability below the critical temperature. Sep. Purif. Technol. 2014, 121, 46-53. [CrossRef]

49. Calles, J.A.; Sanz, R.; Alique, D.; Furones, L.; Marín, P.; Ordoñez, S. Influence of the selective layer morphology on the permeation properties for Pd-PSS composite membranes prepared by electroless pore-plating: Experimental and modeling study. Sep. Purif. Technol. 2018, 194, 10-18. [CrossRef]

50. Tanaka, D.A.P.; Tanco, M.A.L.; Okazaki, J.; Wakui, Y.; Mizukami, F.; Suzuki, T.M. Preparation of "pore-fill” type $\mathrm{Pd}-\mathrm{YSZ}-\gamma-\mathrm{Al}_{2} \mathrm{O}_{3}$ composite membrane supported on $\alpha-\mathrm{Al}_{2} \mathrm{O}_{3}$ tube for hydrogen separation. J. Membr. Sci. 2008, 320, 436-441. [CrossRef]

51. Sanz, R.; Calles, J.A.; Alique, D.; Furones, L. New synthesis method of Pd membranes over tubular \{PSS\} supports via "pore-plating" for hydrogen separation processes. Int. J. Hydrog. Energy 2012, 37, 18476-18485. [CrossRef]

52. Pacheco, D.A.; Llosa, M.A.; Niwa, S.; Wakui, Y.; Mizukami, F.; Namba, T.; Suzuki, T.M. Preparation of palladium and silver alloy membrane on a porous $\alpha$-alumina tube via simultaneous electroless plating. J. Membr. Sci. 2005, 247, 21-27. [CrossRef]

53. Zeng, G.; Goldbach, A.; Shi, L.; Xu, H. On alloying and low-temperature stability of thin, supported PdAg membranes. Int. J. Hydrog. Energy 2012, 37, 6012-6019. [CrossRef]

54. Zhao, L.; Goldbach, A.; Bao, C.; Xu, H. Sulfur inhibition of PdCu membranes in the presence of external mass flow resistance. J. Membr. Sci. 2015, 496, 301-309. [CrossRef]

55. Tarditi, A.M.; Braun, F.; Cornaglia, L.M. Novel PdAgCu ternary alloy: Hydrogen permeation and surface properties. Appl. Surf. Sci. 2011, 257, 6626-6635. [CrossRef]

56. Jia, H.; Wu, P.; Zeng, G.; Salas-Colera, E.; Serrano, A.; Castro, G.R.; Xu, H.; Sun, C.; Goldbach, A. High-temperature stability of Pd alloy membranes containing $\mathrm{Cu}$ and Au. J. Membr. Sci. 2017, 544, 151-160. [CrossRef]

57. Tosti, S. Supported and laminated Pd-based metallic membranes. Int. J. Hydrog. Energy 2003, 28, 1445-1454. [CrossRef]

58. Zhang, K.; Gade, S.K.; Hatlevik, Ø.; Way, J.D. A sorption rate hypothesis for the increase in $\mathrm{H}_{2}$ permeability of palladium-silver (Pd-Ag) membranes caused by air oxidation. Int. J. Hydrog. Energy 2012, 37, 583-593. [CrossRef]

59. Tosti, S.; Bettinali, L.; Violante, V. Rolled thin Pd and Pd-Ag membranes for hydrogen separation and production. Int. J. Hydrog. Energy 2000, 25, 319-325. [CrossRef]

60. Tosti, S.; Bettinali, L.; Castelli, S.; Sarto, F.; Scaglione, S.; Violante, V. Sputtered, electroless and rolled palladium-ceramic membranes. J. Membr. Sci. 2002, 196, 241-249. [CrossRef]

61. Peters, T.A.; Kaleta, T.; Stange, M.; Bredesen, R. Development of thin binary and ternary Pd-based alloy membranes for use in hydrogen production. J. Membr. Sci. 2011, 383, 124-134. [CrossRef]

62. Calles, J.A.; Sanz, R.; Alique, D. Influence of the type of siliceous material used as intermediate layer in the preparation of hydrogen selective palladium composite membranes over a porous stainless steel support. Int. J. Hydrog. Energy 2012, 37, 6030-6042. [CrossRef]

63. Peters, T.A.; Stange, M.; Bredesen, R. 2-Fabrication of palladium-based membranes by magnetron sputtering. In Palladium Membrane Technology Hydrogen Production, Carbon Capture and Other Application; Doukelis, A., Panopoulos, K., Koumanakos, A., Kakaras, E., Eds.; Woodhead Publishing: Sawston, UK, 2015; pp. $25-41$.

64. Huang, L.; Chen, C.S.; He, Z.D.; Peng, D.K.; Meng, G.Y. Palladium membranes supported on porous ceramics prepared by chemical vapor deposition. Thin Solid Films 1997, 302, 98-101. [CrossRef]

65. Jun, C.-S.; Lee, K.-H. Palladium and palladium alloy composite membranes prepared by metal-organic chemical vapor deposition method (cold-wall). J. Membr. Sci. 2000, 176, 121-130. [CrossRef] 
66. Lee, S.M.; Xu, N.; Kim, S.S.; Li, A.; Grace, J.R.; Lim, C.J.; Boyd, T.; Ryi, S.-K.; Susdorf, A.; Schaadt, A. Palladium/ruthenium composite membrane for hydrogen separation from the off-gas of solar cell production via chemical vapor deposition. J. Membr. Sci. 2017, 541, 1-8. [CrossRef]

67. Chen, S.C.; Tu, G.C.; Hung, C.C.Y.; Huang, C.A.; Rei, M.H. Preparation of palladium membrane by electroplating on AISI 316L porous stainless steel supports and its use for methanol steam reformer. J. Membr. Sci. 2008, 314, 5-14. [CrossRef]

68. Chen, C.-H.; Huang, Y.-R.; Liu, C.-W.; Wang, K.-W. Preparation and modification of PdAg membranes by electroless and electroplating process for hydrogen separation. Thin Solid Films 2016, 618, 189-194. [CrossRef]

69. Yoshii, K.; Oshino, Y.; Tachikawa, N.; Toshima, K.; Katayama, Y. Electrodeposition of palladium from palladium(II) acetylacetonate in an amide-type ionic liquid. Electrochem. Commun. 2015, 52, 21-24. [CrossRef]

70. Sanz, R.; Calles, J.A.; Alique, D.; Furones, L.; Ordóñez, S.; Marín, P.; Corengia, P.; Fernandez, E. Preparation, testing and modelling of a hydrogen selective Pd/YSZ/SS composite membrane. Int. J. Hydrog. Energy 2011, 36, 15783-15793. [CrossRef]

71. Alique, D.; Imperatore, M.; Sanz, R.; Calles, J.A.; Baschetti, M.G. Hydrogen permeation in composite Pd-membranes prepared by conventional electroless plating and electroless pore-plating alternatives over ceramic and metallic supports. Int. J. Hydrog. Energy 2016, 41, 19430-19438. [CrossRef]

72. Ryi, S.-K.; Lee, S.-W.; Oh, D.-K.; Seo, B.-S.; Park, J.-W.; Park, J.-S.; Lee, D.-W.; Kim, S.S. Electroless plating of Pd after shielding the bottom of planar porous stainless steel for a highly stable hydrogen selective membrane. J. Membr. Sci. 2014, 467, 93-99. [CrossRef]

73. Sari, R.; Yaakob, Z.; Ismail, M.; Daud, W.R.W.; Hakim, L. Palladium-alumina composite membrane for hydrogen separator fabricated by combined sol-gel and electroless plating technique. Ceram. Int. 2013, 39, 3211-3219. [CrossRef]

74. Tarditi, A.M.; Bosko, M.L.; Cornaglia, L.M. Electroless Plating of Pd Binary and Ternary Alloys and Surface Characteristics for Application in Hydrogen Separation A2-Hashmi, MSJ BT. In Comprehensive Materials Finishing; Elsevier: Oxford, UK, 2017; pp. 1-24.

75. Zhang, B. Chapter 1-History-From the Discovery of Electroless Plating to the Present BT. In Amorphous and Nano Alloys Electroless Depositions; Elsevier: Oxford, UK, 2016; pp. 3-48.

76. Tosti, S.; Fabbricino, M.; Pontoni, L.; Palma, V.; Ruocco, C. Catalytic reforming of olive mill wastewater and methane in a Pd-membrane reactor. Int. J. Hydrog. Energy 2016, 41, 5465-5474. [CrossRef]

77. Tosti, S.; Adrover, A.; Basile, A.; Camilli, V.; Chiappetta, G.; Violante, V. Characterization of thin wall Pd-Ag rolled membranes. Int. J. Hydrog. Energy 2003, 28, 105-112. [CrossRef]

78. Calles, J.A.; Sanz, R.; Alique, D.; Furones, L. Thermal stability and effect of typical water gas shift reactant composition on $\mathrm{H}_{2}$ permeability through a Pd-YSZ-PSS composite membrane. Int. J. Hydrog. Energy 2014, 39, 1398-1409. [CrossRef]

79. Sanz, R.; Calles, J.A.; Alique, D.; Furones, L. $\mathrm{H}_{2}$ production via water gas shift in a composite Pd membrane reactor prepared by the pore-plating method. Int. J. Hydrog. Energy 2014, 39, 4739-4748. [CrossRef]

80. Sanz, R.; Calles, J.A.; Alique, D.; Furones, L.; Ordóñez, S.; Marín, P. Hydrogen production in a Pore-Plated Pd-membrane reactor: Experimental analysis and model validation for the Water Gas Shift reaction. Int. J. Hydrog. Energy 2015, 40, 3472-3484. [CrossRef]

81. Masuda, H.; Nishio, K.; Baba, N. Preparation of microporous metal membrane using two-step replication of interconnected structure of porous glass. J. Mater. Sci. Lett. 1994, 13, 338-340. [CrossRef]

82. Cheng, Y.S.; Yeung, K.L. Palladium-silver composite membranes by electroless plating technique. J. Membr. Sci. 1999, 158, 127-141. [CrossRef]

83. Augustine, A.S.; Mardilovich, I.P.; Kazantzis, N.K.; Ma, Y.H. Durability of PSS-supported Pd-membranes under mixed gas and water-gas shift conditions. J. Membr. Sci. 2012, 415-416, 213-220. [CrossRef]

84. Roa, F.; Way, J.D.; McCormick, R.L.; Paglieri, S.N. Preparation and characterization of Pd-Cu composite membranes for hydrogen separation. Chem. Eng. J. 2003, 93, 11-22. [CrossRef]

85. Lewis, A.E.; Kershner, D.C.; Paglieri, S.N.; Slepicka, M.J.; Way, J.D. Pd-Pt/YSZ composite membranes for hydrogen separation from synthetic water-gas shift streams. J. Membr. Sci. 2013, 437, 257-264. [CrossRef]

86. Kong, S.Y.; Kim, D.H.; Henkensmeier, D.; Kim, H.J.; Ham, H.C.; Han, J.; Yoon, S.P.; Yoon, C.W.; Choi, S.H. Ultrathin layered Pd/PBI-HFA composite membranes for hydrogen separation. Sep. Purif. Technol. 2017, 179, 486-493. [CrossRef] 
87. Kim, D.H.; Kong, S.Y.; Lee, G.; Yoon, C.W.; Ham, H.C.; Han, J.; Song, K.H.; Henkensmeier, D.; Choi, S.H. Effect of PBI-HFA surface treatments on Pd/PBI-HFA composite gas separation membranes. Int. J. Hydrog. Energy 2017, 42, 22915-22924. [CrossRef]

88. Kumar, R.; Kamakshi; Kumar, M.; Awasthi, K. Selective deposition of Pd nanoparticles in porous PET membrane for hydrogen separation. Int. J. Hydrog. Energy 2017, 42, 15203-15210. [CrossRef]

89. Alique, D. Processing and Characterization of Coating and Thin Film Materials. In Advanced Ceramic and Metallic Coating and Thin Film Materials Energy and Environmental Applications; Zhang, J., Jung, Y., Eds.; Springer: Cham, Switzerland, 2018.

90. Plazaola, A.A.; Tanaka, D.P.; Van Sint Annaland, M.; Gallucci, F. Recent Advances in Pd-Based Membranes for Membrane Reactors. Molecules 2017, 22, 51. [CrossRef] [PubMed]

91. Li, H.; Caravella, A.; Xu, H.Y. Recent progress in Pd-based composite membranes. J. Mater. Chem. A 2016, 4 , 14069-14094. [CrossRef]

92. Mardilovich, I.P.; Engwall, E.; Ma, Y.H. Dependence of hydrogen flux on the pore size and plating surface topology of asymmetric Pd-porous stainless steel membranes. Desalination 2002, 144, 85-89. [CrossRef]

93. Tarditi, A.; Gerboni, C.; Cornaglia, L. PdAu membranes supported on top of vacuum-assisted $\mathrm{ZrO}_{2}$-modified porous stainless steel substrates. J. Membr. Sci. 2013, 428, 1-10. [CrossRef]

94. Chen, C.; Ma, Y.H. The effect of $\mathrm{H}_{2} \mathrm{~S}$ on the performance of $\mathrm{Pd}$ and $\mathrm{Pd} / \mathrm{Au}$ composite membrane. J. Membr. Sci. 2010, 362, 535-544. [CrossRef]

95. Fernandez, E.; Helmi, A.; Coenen, K.; Melendez, J.; Luis, J.; Alfredo, D.; Tanaka, P.; van Sint, M.; Gallucci, F. Development of thin Pd-Ag supported membranes for fluidized bed membrane reactors including WGS related gases. Int. J. Hydrog. Energy 2014, 40, 3506-3519. [CrossRef]

96. Shackelford, J.F.; William, A. Materials Science Engineering Hand Book, 3rd ed.; CRC Press: Boca Raton, FL, USA, 2001.

97. Ryi, S.K.; Xu, N.; Li, A.; Lim, C.J.; Grace, J.R. Electroless Pd membrane deposition on alumina modified porous Hastelloy substrate with EDTA-free bath. Int. J. Hydrog. Energy 2010, 35, 2328-2335. [CrossRef]

98. Fernandez, E.; Medrano, J.A.; Melendez, J.; Parco, M.; Viviente, J.L.; van Sint Annaland, M.; Gallucci, F.; Tanaka, D.A.P. Preparation and characterization of metallic supported thin Pd-Ag membranes for hydrogen separation. Chem. Eng. J. 2016, 305, 182-190. [CrossRef]

99. Ryi, S.K.; Ahn, H.S.; Park, J.S.; Kim, D.W. Pd-Cu alloy membrane deposited on $\mathrm{CeO}_{2}$ modified porous nickel support for hydrogen separation. Int. J. Hydrog. Energy 2014, 39, 4698-4703. [CrossRef]

100. Zhang, D.; Zhou, S.; Fan, Y.; Xu, N.; He, Y. Preparation of dense Pd composite membranes on porous Ti-Al alloy supports by electroless plating. J. Membr. Sci. 2012, 387-388, 24-29. [CrossRef]

101. Kim, S.S.; Xu, N.; Li, A.; Grace, J.R.; Lim, C.J.; Ryi, S.K. Development of a new porous metal support based on nickel and its application for Pd based composite membranes. Int. J. Hydrog. Energy 2015, 40, 3520-3527. [CrossRef]

102. Kulprathipanja, A.; Alptekin, G.O.; Falconer, J.L.; Way, J.D. Pd and Pd-Cu membranes: Inhibition of $\mathrm{H}_{2}$ permeation by $\mathrm{H}_{2}$ S. J. Membr. Sci. 2005, 254, 49-62. [CrossRef]

103. Okazaki, J.; Tanaka, D.A.P.; Tanco, M.A.L.; Wakui, Y.; Ikeda, T.; Mizukami, F.; Suzuki, T.M. Preparation and Hydrogen Permeation Properties of Thin Pd-Au Alloy Membranes Supported on Porous $\alpha$-Alumina Tube. Mater. Trans. 2008, 49, 449-452. [CrossRef]

104. Wang, W.P.; Thomas, S.; Zhang, X.L.; Pan, X.L.; Yang, W.S.; Xiong, G.X. $\mathrm{H}_{2} / \mathrm{N}_{2}$ gaseous mixture separation in dense $\mathrm{Pd} / \alpha-\mathrm{Al}_{2} \mathrm{O}_{3}$ hollow fiber membranes: Experimental and simulation studies. Sep. Purif. Technol. 2006, 52, 177-185. [CrossRef]

105. Nair, B.K.R.; Choi, J.; Harold, M.P. Electroless plating and permeation features of Pd and Pd/Ag hollow fiber composite membranes. J. Membr. Sci. 2007, 288, 67-84. [CrossRef]

106. Incelli, M.; Santucci, A.; Tosti, S.; Sansovini, M.; Carlini, M. Heavy water decontamination tests through a Pd-Ag membrane reactor: Water Gas Shift and Isotopic Swamping performances. Fusion Eng. Des. 2016, 124, 692-695. [CrossRef]

107. Yu, C.; Xu, H. An efficient palladium membrane reactor to increase the yield of styrene in ethylbenzene dehydrogenation. Sep. Purif. Technol. 2011, 78, 249-252. [CrossRef]

108. Brunetti, A.; Caravella, A.; Fernandez, E.; Tanaka, D.A.P.; Gallucci, F.; Drioli, E.; Curcio, E.; Viviente, J.L.; Barbieri, G. Syngas upgrading in a membrane reactor with thin Pd-alloy supported membrane. Int. J. Hydrog. Energy 2015, 40, 10883-10893. [CrossRef] 
109. Rahman, M.A.; García-García, F.R.; Li, K. Development of a catalytic hollow fibre membrane microreactor as a microreformer unit for automotive application. J. Membr. Sci. 2012, 390-391, 68-75. [CrossRef]

110. Mardilovich, P.P.; She, Y.; Ma, Y.H.; Rei, M.-H. Defect-free palladium membranes on porous stainless-steel support. AIChE J. 1998, 44, 310-322. [CrossRef]

111. Li, A.; Grace, J.R.; Lim, C.J. Preparation of thin Pd-based composite membrane on planar metallic substrate: Part II. Preparation of membranes by electroless plating and characterization. J. Membr. Sci. 2007, 306, 159-165. [CrossRef]

112. Jayaraman, V.; Lin, Y.S.; Pakala, M.; Lin, R.Y. Fabrication of ultrathin metallic membranes on ceramic supports by sputter deposition. J. Membr. Sci. 1995, 99, 89-100. [CrossRef]

113. Ryi, S.-K.; Park, J.-S.; Kim, S.-H.; Kim, D.-W.; Cho, K.-I. Formation of a defect-free Pd-Cu-Ni ternary alloy membrane on a polished porous nickel support (PNS). J. Membr. Sci. 2008, 318, 346-354. [CrossRef]

114. Pinacci, P.; Drago, F. Influence of the support on permeation of palladium composite membranes in presence of sweep gas. Catal. Today 2012, 193, 186-193. [CrossRef]

115. Ryi, S.-K.; Park, J.-S.; Hwang, K.-R.; Lee, C.-B.; Lee, S.-W. Repair of Pd-based composite membrane by polishing treatment. Int. J. Hydrog. Energy 2011, 36, 13776-13780. [CrossRef]

116. Jemaa, N.; Shu, J.; Kaliaguine, S.; Grandjean, B.P.A. Thin Palladium Film Formation on Shot Peening Modified Porous Stainless Steel Substrates. Ind. Eng. Chem. Res. 1996, 35, 973-977. [CrossRef]

117. Huang, Y.; Dittmeyer, R. Preparation of thin palladium membranes on a porous support with rough surface. J. Membr. Sci. 2007, 302, 160-170. [CrossRef]

118. Huang, Y.; Li, X.; Fan, Y.; Xu, N. Palladium-based composite membranes: Principle, preparation and characterization. Prog. Chem. 2006, 18, 230-238.

119. Collins, J.P.; Way, J.D. Catalytic decomposition of ammonia in a membrane reactor. J. Membr. Sci. 1994, 96, 259-274. [CrossRef]

120. Huang, Y.; Shu, S.; Lu, Z.; Fan, Y. Characterization of the adhesion of thin palladium membranes supported on tubular porous ceramics. Thin Solid Films 2007, 515, 5233-5240. [CrossRef]

121. Coronas, J.; Santamaría, J. Catalytic reactors based on porous ceramic membranes. Catal. Today 1999, 51, 377-389. [CrossRef]

122. Tong, J.; Matsumura, Y.; Suda, H.; Haraya, K. Thin and dense $\mathrm{Pd} / \mathrm{CeO}_{2} / \mathrm{MPSS}$ composite membrane for hydrogen separation and steam reforming of methane. Sep. Purif. Technol. 2005, 46, 1-10. [CrossRef]

123. Qiao, A.; Zhang, K.; Tian, Y.; Xie, L.; Luo, H.; Lin, Y.S.; Li, Y. Hydrogen separation through palladium-copper membranes on porous stainless steel with sol-gel derived ceria as diffusion barrier. Fuel 2010, 89, 1274-1279. [CrossRef]

124. Wang, D.; Tong, J.; Xu, H.; Matsumura, Y. Preparation of palladium membrane over porous stainless steel tube modified with zirconium oxide. Catal. Today 2004, 93-95, 689-693. [CrossRef]

125. Gao, H.; Lin, J.Y.S.; Li, Y.; Zhang, B. Electroless plating synthesis, characterization and permeation properties of Pd-Cu membranes supported on $\mathrm{ZrO}_{2}$ modified porous stainless steel. J. Membr. Sci. 2005, 265, 142-152. [CrossRef]

126. Lee, C.-B.; Lee, S.-W.; Park, J.-S.; Ryi, S.-K.; Lee, D.-W.; Hwang, K.-R.; Kim, S.-H. Ceramics used as intermetallic diffusion barriers in Pd-based composite membranes sputtered on porous nickel supports. J. Alloys Compd. 2013, 578, 425-430. [CrossRef]

127. Zhang, K.; Gao, H.; Rui, Z.; Liu, P.; Li, Y.; Lin, Y.S. High-Temperature Stability of Palladium Membranes on Porous Metal Supports with Different Intermediate Layers. Ind. Eng. Chem. Res. 2009, 48, 1880-1886. [CrossRef]

128. Yepes, D.; Cornaglia, L.M.; Irusta, S.; Lombardo, E.A. Different oxides used as diffusion barriers in composite hydrogen permeable membranes. J. Membr. Sci. 2006, 274, 92-101. [CrossRef]

129. Li, A.; Grace, J.R.; Lim, C.J. Preparation of thin Pd-based composite membrane on planar metallic substrate: Part I: Pre-treatment of porous stainless steel substrate. J. Membr. Sci. 2007, 298, 175-181. [CrossRef]

130. Broglia, M.; Pinacci, P.; Radaelli, M.; Bottino, A.; Capannelli, G.; Comite, A.; Vanacore, G.; Zani, M. Synthesis and characterization of Pd membranes on alumina-modified porous stainless steel supports. Desalination 2009, 245, 508-515. [CrossRef]

131. Chi, Y.-H.; Yen, P.-S.; Jeng, M.-S.; Ko, S.-T.; Lee, T.-C. Preparation of thin Pd membrane on porous stainless steel tubes modified by a two-step method. Int. J. Hydrog. Energy 2010, 35, 6303-6310. [CrossRef] 
132. Nam, S.-E.; Lee, K.-H. Hydrogen separation by Pd alloy composite membranes: Introduction of diffusion barrier. J. Membr. Sci. 2001, 192, 177-185. [CrossRef]

133. Van Gestel, T.; Hauler, F.; Bram, M.; Meulenberg, W.A.; Buchkremer, H.P.; van Gestel, T.; Hauler, F.; Bram, M.; Meulenberg, W.A.; Buchkremer, H.P. Synthesis and characterization of hydrogen-selective sol-gel $\mathrm{SiO}_{2}$ membranes supported on ceramic and stainless steel supports. Sep. Purif. Technol. 2014, 121, 20-29. [CrossRef]

134. Kanezashi, M.; Fuchigami, D.; Yoshioka, T.; Tsuru, T. Control of Pd dispersion in sol-gel-derived amorphous silica membranes for hydrogen separation at high temperatures. J. Membr. Sci. 2013, 439, 78-86. [CrossRef]

135. Zheng, L.; Li, H.; Xu, T.; Bao, F.; Xu, H. Defect size analysis approach combined with silicate gel/ceramic particles for defect repair of Pd composite membranes. Int. J. Hydrog. Energy 2016, 41, 18522-18532. [CrossRef]

136. Bosko, M.L.; Ojeda, F.; Lombardo, E.A.; Cornaglia, L.M. NaA zeolite as an effective diffusion barrier in composite Pd/PSS membranes. J. Membr. Sci. 2009, 331, 57-65. [CrossRef]

137. Mobarake, M.D.; Jafari, P.; Irani, M. Preparation of Pd-based membranes on $\mathrm{Pd} / \mathrm{TiO}_{2}$ modified NaX/PSS substrate for hydrogen separation: Design and optimization. Microporous Mesoporous Mater. 2016, 226, 369-377. [CrossRef]

138. Yu, J.; Qi, C.; Zhang, J.; Bao, C.; Xu, H. Synthesis of a zeolite membrane as a protective layer on a metallic Pd composite membrane for hydrogen purification. J. Mater. Chem. A 2015, 3, 5000-5006. [CrossRef]

139. Sato, K.; Natsui, M.; Hasegawa, Y. Preparation of Double Layer Membrane Combined with Palladium Metal and FAU Zeolite for Catalytic Membrane Reactor. Mater. Trans. 2015, 56, 473-478. [CrossRef]

140. Wang, X.; Tan, X.; Meng, B.; Zhang, X.; Liang, Q.; Pan, H.; Liu, S. TS-1 zeolite as an effective diffusion barrier for highly stable Pd membrane supported on macroporous $\alpha-\mathrm{Al}_{2} \mathrm{O}_{3}$ tube. RSC Adv. 2013, 3, 4821-4834. [CrossRef]

141. Abate, S.; Díaz, U.; Prieto, A.; Gentiluomo, S.; Palomino, M.; Perathoner, S.; Corma, A.; Centi, G. Influence of Zeolite Protective Overlayer on the Performances of Pd Thin Film Membrane on Tubular Asymmetric Alumina Supports. Ind. Eng. Chem. Res. 2016, 55, 4948-4959. [CrossRef]

142. Ma, Y.H.; Mardilovich, P.P.; She, Y. Hydrogen Gas-Extraction Module and Method of Fabrication. U.S. Patent 6152987 A, 28 November 2000.

143. Guazzone, F.; Engwall, E.E.; Ma, Y.H. Effects of surface activity, defects and mass transfer on hydrogen permeance and n-value in composite palladium-porous stainless steel membranes. Catal. Today 2006, 118, 24-31. [CrossRef]

144. Mateos-Pedrero, C.; Soria, M.A.; Rodríguez-Ramos, I.; Guerrero-Ruiz, A. Modifications of porous stainless steel previous to the synthesis of Pd membranes. Stud. Surf. Sci. Catal. 2010, 175, 779-783. [CrossRef]

145. Nam, S.-E.; Lee, K.-H. Preparation and Characterization of Palladium Alloy Composite Membranes with a Diffusion Barrier for Hydrogen Separation. Ind. Eng. Chem. Res. 2005, 44, 100-105. [CrossRef]

146. Ayturk, M.E.; Mardilovich, I.P.; Engwall, E.E.; Ma, Y.H. Synthesis of composite Pd-porous stainless steel (PSS) membranes with a Pd/Ag intermetallic diffusion barrier. J. Membr. Sci. 2006, 285, 385-394. [CrossRef]

147. Lee, J.-H.; Han, J.-Y.; Kim, K.-M.; Ryi, S.-K.; Kim, D.-W. Development of homogeneous Pd-Ag alloy membrane formed on porous stainless steel by multi-layered films and Ag-upfilling heat treatment. J. Membr. Sci. 2015, 492, 242-248. [CrossRef]

148. Pujari, M.; Agarwal, A.; Uppaluri, R.; Verma, A. Role of electroless nickel diffusion barrier on the combinatorial plating characteristics of dense Pd/Ni/PSS composite membranes. Appl. Surf. Sci. 2014, 305, 658-664. [CrossRef]

149. Tong, J.; Suda, H.; Haraya, K.; Matsumura, Y. A novel method for the preparation of thin dense Pd membrane on macroporous stainless steel tube filter. J. Memb. Sci. 2005, 260, 10-18. [CrossRef]

150. Tong, J.; Su, L.; Haraya, K.; Suda, H. Thin Pd membrane on $\alpha-\mathrm{Al}_{2} \mathrm{O}_{3}$ hollow fiber substrate without any interlayer by electroless plating combined with embedding Pd catalyst in polymer template. J. Membr. Sci. 2008, 310, 93-101. [CrossRef]

151. Hu, X.; Chen, W.; Huang, Y. Fabrication of Pd/ceramic membranes for hydrogen separation based on low-cost macroporous ceramics with pencil coating. Int. J. Hydrog. Energy 2010, 35, 7803-7808. [CrossRef]

152. Zhao, H.-B.; Pflanz, K.; Gu, J.-H.; Li, A.-W.; Stroh, N.; Brunner, H.; Xiong, G.-X. Preparation of palladium composite membranes by modified electroless plating procedure. J. Membr. Sci. 1998, 142, 147-157. [CrossRef]

153. Bottino, A.; Broglia, M.; Capannelli, G.; Comite, A.; Pinacci, P.; Scrignari, M.; Azzurri, F. Sol-gel synthesis of thin alumina layers on porous stainless steel supports for high temperature palladium membranes. Int. J. Hydrog. Energy 2014, 39, 4717-4724. [CrossRef] 
154. Brenner, A.; Riddell, G.E. Nickel plating on steel by chemical reduction. J. Res. Natl. Bur. Stand. 1946, 37, 31-34. [CrossRef]

155. Zornoza, B.; Casado, C.; Navajas, A. Chapter 11-Advances in Hydrogen Separation and Purification with Membrane Technology. In Renewable Hydrogen Technologies; Gandía, L.M., Arzamendi, G., Diéguez, P.M., Eds.; Elsevier: Amsterdam, The Netherlands, 2013; pp. 245-268.

156. De Falco, M.; Iaquaniello, G.; Palo, E.; Cucchiella, B.; Palma, V.; Ciambelli, P. 11—Palladium-based membranes for hydrogen separation: Preparation, economic analysis and coupling with a water gas shift reactor. In Handbook of Membrane Reactors; Basile, A., Ed.; Woodhead Publishing: Sawston, UK, 2013; pp. 456-486.

157. Den Exter, M.J. 3-The use of electroless plating as a deposition technology in the fabrication of palladium-based membranes. In Palladium Membrane Technology Hydrogen Production, Carbon Capture and Other Application; Doukelis, A., Panopoulos, K., Koumanakos, A., Kakaras, E., Eds.; Woodhead Publishing: Sawston, UK, 2015; pp. 43-67.

158. Basile, A.; Tong, J.; Millet, P. 2-Inorganic membrane reactors for hydrogen production: An overview with particular emphasis on dense metallic membrane materials. In Handbook of Membrane Reactors; Basile, A., Ed.; Woodhead Publishing: Sawston, UK, 2013; pp. 42-148.

159. Cheng, Y.S.; Yeung, K.L. Effects of electroless plating chemistry on the synthesis of palladium membranes. J. Membr. Sci. 2001, 182, 195-203. [CrossRef]

160. Dogan, M.; Kilicarslan, S. Effects of process parameters on the synthesis of palladium membranes. Nucl. Instrum. Methods Phys. Res. Sect. B 2008, 266, 3458-3466. [CrossRef]

161. Yeung, K.L.; Christiansen, S.C.; Varma, A. Palladium composite membranes by electroless plating technique: Relationships between plating kinetics, film microstructure and membrane performance. J. Membr. Sci. 1999, 159, 107-122. [CrossRef]

162. Djokić, S.S. Fundamentals of Electroless Deposition BT. In Reference Module in Chemistry, Molecular Sciences and Chemical Engineering; Elsevier: Oxford, UK, 2016.

163. Mallory, G.O.; Hajdu, J.B. Electroless Plating: Fundamentals and Applications; American Electroplaters and Surface Finishers Society: Orlando, FL, USA, 1990.

164. Shu, J.; Grandjean, B.P.A.; Ghali, E.; Kaliaguine, S. Simultaneous deposition of Pd and Ag on porous stainless steel by electroless plating. J. Membr. Sci. 1993, 77, 181-195. [CrossRef]

165. Rothenberger, K.S.; Cugini, A.V.; Howard, B.H.; Killmeyer, R.P.; Ciocco, M.V.; Morreale, B.D.; Enick, R.M.; Bustamante, F.; Mardilovich, I.P.; Ma, Y.H. High pressure hydrogen permeance of porous stainless steel coated with a thin palladium film via electroless plating. J. Membr. Sci. 2004, 244, 55-68. [CrossRef]

166. Paglieri, S.N.; Way, J.D. Innovations in palladium membrane research. Sep. Purif. Methods 2002, 31, 1-169. [CrossRef]

167. Wei, L.; Yu, J.; Hu, X.; Wang, R.; Huang, Y. Effects of Sn residue on the high temperature stability of the $\mathrm{H}_{2}$-permeable palladium membranes prepared by electroless plating on $\mathrm{Al}_{2} \mathrm{O}_{3}$ substrate after $\mathrm{SnCl}_{2}-\mathrm{PdCl}_{2}$ process: A case study. Chin. J. Chem. Eng. 2016, 24, 1154-1160. [CrossRef]

168. Chi, Y.-H.; Uan, J.-Y.; Lin, M.-C.; Lin, Y.-L.; Huang, J.-H. Preparation of a novel Pd/layered double hydroxide composite membrane for hydrogen filtration and characterization by thermal cycling. Int. J. Hydrog. Energy 2013, 38, 13734-13741. [CrossRef]

169. Guo, Y.; Jin, Y.; Wu, H.; Zhou, L.; Chen, Q.; Zhang, X.; Li, X. Preparation of palladium membrane on $\mathrm{Pd}$ /silicalite-1 zeolite particles modified macroporous alumina substrate for hydrogen separation. Int. J. Hydrog. Energy 2014, 39, 21044-21052. [CrossRef]

170. Seshimo, M.; Ozawa, M.; Sone, M.; Sakurai, M.; Kameyama, H. Fabrication of a novel Pd/ $\gamma$-alumina graded membrane by electroless plating on nanoporous $\gamma$-alumina. J. Membr. Sci. 2008, 324, 181-187. [CrossRef]

171. Touyeras, F.; Hihn, J.Y.; Delalande, S.; Viennet, R.; Doche, M.L. Ultrasound influence on the activation step before electroless coating. Ultrason. Sonochem. 2003, 10, 363-368. [CrossRef]

172. Paglieri, S.N.; Foo, K.Y.; Way, J.D.; Collins, J.P.; Harper-Nixon, D.L. A New Preparation Technique for Pd/Alumina Membranes with Enhanced High-Temperature Stability. Ind. Eng. Chem. Res. 1999, 38, 1925-1936. [CrossRef]

173. Zhu, B.; Tang, C.H.; Xu, H.Y.; Su, D.S.; Zhang, J.; Li, H. Surface activation inspires high performance of ultra-thin Pd membrane for hydrogen separation. J. Membr. Sci. 2017, 526, 138-146. [CrossRef] 
174. Uemiya, S.; Sato, N.; Ando, H.; Kikuchi, E. The water gas shift reaction assisted by a palladium membrane reactor. Ind. Eng. Chem. Res. 1991, 30, 585-589. [CrossRef]

175. Shi, Z.; Wu, S.; Szpunar, J.A.; Roshd, M. An observation of palladium membrane formation on a porous stainless steel substrate by electroless deposition. J. Membr. Sci. 2006, 280, 705-711. [CrossRef]

176. Zhang, X.; Xiong, G.; Yang, W. A modified electroless plating technique for thin dense palladium composite membranes with enhanced stability. J. Membr. Sci. 2008, 314, 226-237. [CrossRef]

177. Yeung, K.L.; Sebastian, J.M.; Varma, A. Novel preparation of Pd/Vycor composite membranes. Catal. Today 1995, 25, 231-236. [CrossRef]

178. Souleimanova, R.S.; Mukasyan, A.S.; Varma, A. Effects of osmosis on microstructure of Pd-composite membranes synthesized by electroless plating technique. J. Membr. Sci. 2000, 166, 249-257. [CrossRef]

179. Li, A.; Liang, W.; Hughes, R. Characterisation and permeation of palladium/stainless steel composite membranes. J. Membr. Sci. 1998, 149, 259-268. [CrossRef]

180. Tanaka, D.A.P.; Tanco, M.A.L.; Nagase, T.; Okazaki, J.; Wakui, Y.; Mizukami, F.; Suzuki, T.M. Fabrication of hydrogen-permeable composite membranes packed with palladium nanoparticles. Adv. Mater. 2006, 18, 630-632. [CrossRef]

181. Thoen, P.M.; Roa, F.; Way, J.D. High flux palladium-copper composite membranes for hydrogen separations. Desalination 2006, 193, 224-229. [CrossRef]

182. Gade, S.K.; Thoen, P.M.; Way, J.D. Unsupported palladium alloy foil membranes fabricated by electroless plating. J. Membr. Sci. 2008, 316, 112-118. [CrossRef]

183. Chi, Y.-H.; Lin, J.-J.; Lin, Y.-L.; Yang, C.-C.; Huang, J.-H. Influence of the rotation rate of porous stainless steel tubes on electroless palladium deposition. J. Membr. Sci. 2015, 475, 259-265. [CrossRef]

184. Zeng, G.; Goldbach, A.; Xu, H. Defect sealing in Pd membranes via point plating. J. Membr. Sci. 2009, 328, 6-10. [CrossRef]

185. Sanz, R.; Calles, J.A.; Ordóñez, S.; Marín, P.; Alique, D.; Furones, L. Modelling and simulation of permeation behaviour on Pd/PSS composite membranes prepared by "pore-plating" method. J. Membr. Sci. 2013, 446, 410-421. [CrossRef]

186. Hatlevik, Ø.; Gade, S.K.; Keeling, M.K.; Thoen, P.M.; Davidson, A.P.; Way, J.D. Palladium and palladium alloy membranes for hydrogen separation and production: History, fabrication strategies and current performance. Sep. Purif. Technol. 2010, 73, 59-64. [CrossRef]

187. Abu El Hawa, H.W.; Paglieri, S.N.; Morris, C.C.; Harale, A.; Way, J.D. Identification of thermally stable Pd-alloy composite membranes for high temperature applications. J. Membr. Sci. 2014, 466, 151-160. [CrossRef]

188. Conde, J.J.; Maroño, M.; Sánchez-Hervás, J.M. Pd-Based Membranes for Hydrogen Separation: Review of Alloying Elements and Their Influence on Membrane Properties. Sep. Purif. Rev. 2017, 46, 152-177. [CrossRef]

189. Shu, J.; Grandjean, B.P.A.; van Neste, A. Catalytic Palladium-Based Membrane Reactors: A Review. Can. J. Chem. Eng. 1991. [CrossRef]

190. Lin, W.H.; Chang, H.F. Characterizations of Pd-Ag membrane prepared by sequential electroless deposition. Surf. Coat. Technol. 2005, 194, 157-166. [CrossRef]

191. Santucci, A.; Borgognoni, F.; Vadrucci, M.; Tosti, S. Testing of dense Pd-Ag tubes: Effect of pressure and membrane thickness on the hydrogen permeability. J. Membr. Sci. 2013, 444, 378-383. [CrossRef]

192. Medrano, J.A.; Fernandez, E.; Melendez, J.; Parco, M.; Tanaka, D.A.P.; van Sint Annaland, M.; Gallucci, F. Pd-based metallic supported membranes: High-temperature stability and fluidized bed reactor testing. Int. J. Hydrog. Energy 2016, 41, 8706-8718. [CrossRef]

193. Abu El Hawa, H.W.; Paglieri, S.N.; Morris, C.C.; Harale, A.; Way, J.D. Application of a Pd-Ru composite membrane to hydrogen production in a high temperature membrane reactor. Sep. Purif. Technol. 2015, 147, 388-397. [CrossRef]

194. Abu El Hawa, H.W.; Lundin, S.-T.B.; Patki, N.S.; Way, J.D. Steam methane reforming in a PdAu membrane reactor: Long-term assessment. Int. J. Hydrog. Energy 2016, 41, 10193-10201. [CrossRef]

195. Patki, N.S.; Lundin, S.T.; Way, J.D. Rapid annealing of sequentially plated Pd-Au composite membranes using high pressure hydrogen. J. Membr. Sci. 2016, 513, 197-205. [CrossRef]

196. Morreale, B.D.; Ciocco, M.V.; Howard, B.H.; Killmeyer, R.P.; Cugini, A.V.; Enick, R.M. Effect of hydrogen-sulfide on the hydrogen permeance of palladium-copper alloys at elevated temperatures. J. Membr. Sci. 2004, 241, 219-224. [CrossRef] 
197. Kurokawa, H.; Yakabe, H.; Yasuda, I.; Peters, T.; Bredesen, R. Inhibition effect of CO on hydrogen permeability of Pd-Ag membrane applied in a microchannel module conFiguration. Int. J. Hydrog. Energy 2014, 39, 17201-17209. [CrossRef]

198. Peters, T.A.; Liron, O.; Tschentscher, R.; Sheintuch, M.; Bredesen, R. Investigation of Pd-based membranes in propane dehydrogenation (PDH) processes. Chem. Eng. J. 2016, 305, 191-200. [CrossRef]

199. Peters, T.A.; Kaleta, T.; Stange, M.; Bredesen, R. Hydrogen transport through a selection of thin Pd-alloy membranes: Membrane stability, $\mathrm{H}_{2} \mathrm{~S}$ inhibition and flux recovery in hydrogen and simulated WGS mixtures. Catal. Today 2012, 193, 8-19. [CrossRef]

200. Tarditi, A.M.; Imhoff, C.; Braun, F.; Miller, J.B.; Gellman, A.J.; Cornaglia, L. PdCuAu ternary alloy membranes: Hydrogen permeation properties in the presence of $\mathrm{H}_{2}$ S. J. Membr. Sci. 2015, 479, 246-255. [CrossRef]

201. Braun, F.; Tarditi, A.M.; Miller, J.B.; Cornaglia, L.M. Pd-based binary and ternary alloy membranes: Morphological and perm-selective characterization in the presence of $\mathrm{H}_{2}$ S. J. Membr. Sci. 2014, 450, $299-307$. [CrossRef]

202. Bosko, M.L.; Miller, J.B.; Lombardo, E.A.; Gellman, A.J.; Cornaglia, L.M. Surface characterization of Pd-Ag composite membranes after annealing at various temperatures. J. Membr. Sci. 2011, 369, 267-276. [CrossRef]

203. Gao, H.; Lin, Y.S.; Li, Y.; Zhang, B. Chemical Stability and Its Improvement of Palladium-Based Metallic Membranes. Ind. Eng. Chem. Res. 2004, 43, 6920-6930. [CrossRef]

204. Okazaki, J.; Ikeda, T.; Tanaka, D.A.P.; Sato, K.; Suzuki, T.M.; Mizukami, F. An investigation of thermal stability of thin palladium-silver alloy membranes for high temperature hydrogen separation. J. Membr. Sci. 2011, 366, 212-219. [CrossRef]

205. Zhang, K.; Way, J.D. Palladium-copper membranes for hydrogen separation. Sep. Purif. Technol. 2017, 186, 39-44. [CrossRef]

206. Gade, S.K.; Payzant, E.A.; Park, H.J.; Thoen, P.M.; Way, J.D. The effects of fabrication and annealing on the structure and hydrogen permeation of Pd-Au binary alloy membranes. J. Membr. Sci. 2009, 340, 227-233. [CrossRef]

207. Bond, R.A.; Evans, J.; Harris, I.R.; Ross, D.K. Hydrogen isotope separation using palladium alloy membranes. In Proceedings of the 12th Symposium on Fusion Technology, Juelich, Germany, 13-17 September 1982; Elsevier: Amsterdam, The Netherlands, 1983; pp. 537-542.

208. Evans, J.; Harris, I.R.; Ross, D.K. A proposed method of hydrogen isotope separation using palladium alloy membranes. J. Less Common Met. 1983, 89, 407-414. [CrossRef]

209. Pérez, P.; Cornaglia, C.A.; Mendes, A.; Madeira, L.M.; Tosti, S. Surface effects and $\mathrm{CO} / \mathrm{CO}_{2}$ influence in the $\mathrm{H}_{2}$ permeation through a Pd-Ag membrane: A comprehensive model. Int. J. Hydrog. Energy 2015, 40, 6566-6572. [CrossRef]

210. Augustine, A.S.; Ma, Y.H.; Kazantzis, N.K. High pressure palladium membrane reactor for the high temperature water-gas shift reaction. Int. J. Hydrog. Energy 2011, 36, 5350-5360. [CrossRef]

211. Bhandari, R.; Ma, Y.H. Pd-Ag membrane synthesis: The electroless and electro-plating conditions and their effect on the deposits morphology. J. Membr. Sci. 2009, 334, 50-63. [CrossRef]

212. Bosko, M.L.; Yepes, D.; Irusta, S.; Eloy, P.; Ruiz, P.; Lombardo, E.A.; Cornaglia, L.M. Characterization of Pd-Ag membranes after exposure to hydrogen flux at high temperatures. J. Membr. Sci. 2007, 306, 56-65. [CrossRef]

213. Bosko, M.L.; Múnera, J.F.; Lombardo, E.A.; Cornaglia, L.M. Dry reforming of methane in membrane reactors using Pd and Pd-Ag composite membranes on a NaA zeolite modified porous stainless steel support. J. Membr. Sci. 2010, 364, 17-26. [CrossRef]

214. Bosko, M.L.; Lombardo, E.A.; Cornaglia, L.M. The effect of electroless plating time on the morphology, alloy formation and $\mathrm{H}_{2}$ transport properties of Pd-Ag composite membranes. Int. J. Hydrog. Energy 2011, 36, 4068-4078. [CrossRef]

215. Huerta, E.O. Corrosión y degradación de materiales, n.d. Comput. Fraud Secur. 2013, 2000, 3.

216. Roa, F.; Block, M.J.; Way, J.D. The influence of alloy composition on the $\mathrm{H}_{2}$ flux of composite $\mathrm{Pd}-\mathrm{Cu}$ membranes. Desalination 2002, 147, 411-416. [CrossRef]

217. Roa, F.; Way, J.D. The effect of air exposure on palladium-copper composite membranes. Appl. Surf. Sci. 2005, 240, 85-104. [CrossRef] 
218. Lu, H.; Zhu, L.; Wang, W.; Yang, W.; Tong, J. Pd and Pd-Ni alloy composite membranes fabricated by electroless plating method on capillary $\alpha-\mathrm{Al}_{2} \mathrm{O}_{3}$ substrates. Int. J. Hydrog. Energy 2015, 40, 3548-3556. [CrossRef]

219. Reboredo, J.C.; Ugolini, A. Quantile causality between gold commodity and gold stock prices. Resour. Policy 2017, 53, 56-63. [CrossRef]

220. Zhu, H.; Peng, C.; You, W. Quantile behaviour of cointegration between silver and gold prices. Financ. Res. Lett. 2016, 19, 119-125. [CrossRef]

221. Liu, C.; Hu, Z.; Li, Y.; Liu, S. Forecasting copper prices by decision tree learning. Resour. Policy 2017, 52, 427-434. [CrossRef]

222. Balcilar, M.; Hammoudeh, S.; Asaba, N.-A.F. A regime-dependent assessment of the information transmission dynamics between oil prices, precious metal prices and exchange rates. Int. Rev. Econ. Financ. 2015, 40, 72-89. [CrossRef]

223. Sumrunronnasak, S.; Tantayanon, S.; Kiatgamolchai, S. Influence of layer compositions and annealing conditions on complete formation of ternary $\mathrm{PdAgCu}$ alloys prepared by sequential electroless and electroplating methods. Mater. Chem. Phys. 2017, 185, 98-103. [CrossRef]

224. Tarditi, A.M.; Cornaglia, L.M. Novel PdAgCu ternary alloy as promising materials for hydrogen separation membranes: Synthesis and characterization. Surf. Sci. 2011, 605, 62-71. [CrossRef]

(c) 2018 by the authors. Licensee MDPI, Basel, Switzerland. This article is an open access article distributed under the terms and conditions of the Creative Commons Attribution (CC BY) license (http://creativecommons.org/licenses/by/4.0/). 